University of New Mexico UNM Digital Repository

Nanoscience and Microsystems ETDs

Engineering ETDs

Summer 7-6-2017

\title{
STUDY OF POLYSULFIDE SPECIATION IN LITHIUM SULFUR BATTERIES USING IN SITU CONFOCAL RAMAN MICROSCOPY
}

Josefine McBrayer

Follow this and additional works at: https://digitalrepository.unm.edu/nsms_etds

Part of the Nanoscience and Nanotechnology Commons

\section{Recommended Citation}

McBrayer, Josefine. "STUDY OF POLYSULFIDE SPECIATION IN LITHIUM SULFUR BATTERIES USING IN SITU CONFOCAL RAMAN MICROSCOPY." (2017). https://digitalrepository.unm.edu/nsms_etds/39

This Thesis is brought to you for free and open access by the Engineering ETDs at UNM Digital Repository. It has been accepted for inclusion in Nanoscience and Microsystems ETDs by an authorized administrator of UNM Digital Repository. For more information, please contact disc@unm.edu. 
Josefine Desiree McBrayer

Candidate

Nanoscience and Microsystems Engineering

Department

This thesis is approved, and it is acceptable in quality and form for publication:

Approved by the Thesis Committee:

Fernando Garzón, Chairperson

Christopher Apblett

Andrew Shreve 
STUDY OF POLYSULFIDE SPECIATION IN LITHIUM SULFUR BATTERIES USING IN SITU CONFOCAL RAMAN MICROSCOPY

\author{
BY \\ JOSEFINE DESIREE MCBRAYER \\ B.S., Chemical Engineering, University of New Mexico, 2016
}

\title{
THESIS
}

Submitted in Partial Fulfillment of the

Requirements for the Degree of

Master of Science

Nanoscience and Microsystems Engineering

The University of New Mexico

Albuquerque, New Mexico

July, 2017 


\section{DEDICATION}

I dedicate this work to my family for their endless and unconditional support and belief in my abilities. I would not be where I am today without them. 


\section{ACKNOWLEDGMENTS}

I would like to acknowledge all of my group members at Sandia and UNM for their useful discussion and help with this work.

I thank Dr. Chelsea Snyder for initial training on the Raman microscope and Lance Miller for his help with mass spectroscopy. For help with the design of the in situ cell I thank John Plakio, Jonathan Leonard, and Harry Pratt. For help with materials, I thank Dr. Nathan Hahn and Dr. Tylan Watkins.

A big thank you also to Dr. Andy Shreve and Dr. Thomas Beechem for all the time you dedicated to teaching me how to analyze Raman spectra correctly and for answering any and all of my questions despite how busy you are.

Thank you to Dr. Brian Perdue for his detailed discussions on lithium sulfur batteries, mentorship, and for giving me his fancy mouse.

I would like to give a special thank you to Hannah Height for both her technical support in deciding next steps and for her friendship. Thank you for celebrating with me in the best of times and listening to me complain in the worst of times, I look forward to a lifetime of friendship with you.

To Dr. Kyle Fenton and Dr. Mani Nagasubramanian, thank you for showing up at 8 am to help me practice presentations and for your support on a daily basis.

To my manager, Dr. Chris Orendorff, and the whole Power Sources and Technology Group, thank you for all of the opportunities you've given me over the past two years and for making my time in 2546 a truly amazing and positive experience. I could not ask for a better place to work. 
Thank you to my family for the support and love they have always given me. Thank you for staying up late to help me practice my ECS talk and for all the emotional support you've shown me throughout my master's and my entire academic career. Thank you to my dad for forcing me to take breaks and calm down. To my mother for talking through life with me and the changes it inevitably brings. To my brother for his humor and wit and making me laugh when I feel like crying. To my sister for the reminder that life is more than work and research. And lastly to my dog and birds for the love and companionship they have given me.

Thank you to my advisors, Dr. Fernando Garzón and Dr. Christopher Apblett for all the knowledge I have gained over the last year and the opportunities you have given me.

To Chris, thank you for showing me the kind of person I want to be and instilling in me a passion for both research and for life. I cannot thank you enough for the doors you have opened for me and the kindness you have shown me. I hope to show you in the coming years that your investment was worthwhile and that your efforts will be extended to the future as I try my best to pay what you have taught and given me forward.

Lastly, I would like to acknowledge and thank my funding sources for this work including the Department of Defense and the Joint Center for Energy Storage Research.

Sandia National Laboratories is a multi-mission laboratory managed and operated by National Technology \& Engineering Solutions of Sandia, LLC, a wholly owned subsidiary of Honeywell International, Inc., for the U.S. Department of Energy's National Nuclear Security Administration under contract DE-NA0003525.

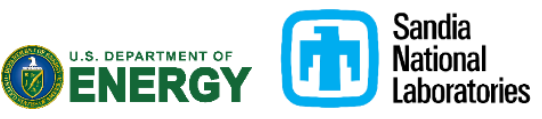




\title{
STUDY OF POLYSULFIDE SPECIATION IN LITHIUM SULFUR BATTERIES USING IN SITU CONFOCAL RAMAN MICROSCOPY
}

by

\section{Josefine Desiree McBrayer}

B.S., Chemical Engineering, University of New Mexico, 2016

M.S., Nanoscience and Microsystems Engineering, University of New Mexico, 2017

\begin{abstract}
Secondary lithium sulfur (Li-S) batteries have been heavily studied in the battery community since the start of the $21^{\text {st }}$ century due to their high theoretical capacity and specific energy density. The ground-breaking lithium ion battery has revolutionized society and its ability to store energy, however the lithium ion battery is reaching its limit with a theoretical capacity almost five times lower than that of lithium sulfur. With the improvement and commercialization of Li-S batteries, electric vehicles and personal electronics will have extended performance on a single charge. The viability of this promising chemistry relies on overcoming several key difficulties, one of the most imperative being high solubility, mobility, and reactivity of polysulfide reaction intermediates in liquid electrolytes. In situ Raman microscopy is used to study polysulfide speciation in the bulk electrolyte (1:1 1,2-dimethoxyethane (DME): 1,3-dioxolane (DOL) with $1 \mathrm{M}$ lithium bis(trifluoromethane)sulfonimide (LiTFSI) and $0.25 \mathrm{M} \mathrm{LiNO}_{3}$ ) during
\end{abstract}


the discharge and charge of a Li-S T-cell to better understand the complex interplay between chemical and electrochemical reactions in solution. Long chain polysulfides and the $\mathrm{S}_{3}{ }^{-}$radical appear in the electrolyte at $2.4 \mathrm{~V}$ indicating a rapid equilibrium of the dissociation reaction to form $\mathrm{S}_{3}$. Interestingly, an increase in the concentration of all polysulfides was observed during charge indicating the importance of the E/S ratio and potentially a loss in the useful sulfur inventory from the cathode to the electrolyte. For peak comparisons, nominal $\mathrm{Li}_{2} \mathrm{~S}_{8}, \mathrm{Li}_{2} \mathrm{~S}_{6}$, and $\mathrm{Li}_{2} \mathrm{~S}_{4}$ standards were chemically synthesized under argon and analyzed for stability, using Raman, for one week. All three standards equilibrated to contain the same polysulfide species, however the relative distributions of the species distinguished the standards from one another. Not all peaks observed in the in situ cell were seen in the standards, indicating that the electrochemical and chemical equilibria do not yield the same speciation. 


\section{TABLE OF CONTENTS}

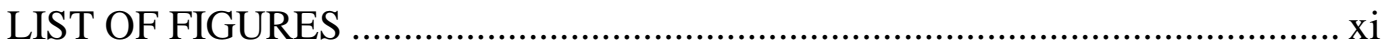

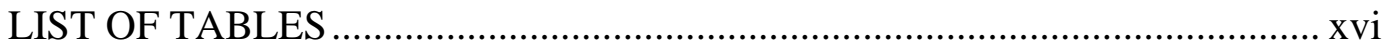

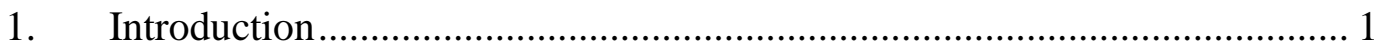

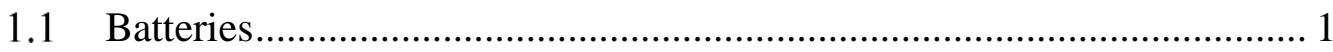

1.2 Lithium Sulfur Batteries ................................................................... 4

1.2.1 Attributes of Lithium Sulfur Batteries ............................................. 4

1.2.2 Obstacles to Lithium Sulfur Batteries ............................................. 7

1.2.3 Mitigating the Polysulfide Shuttle and Other Difficulties ................ 8

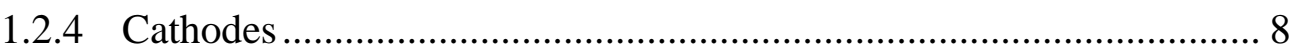

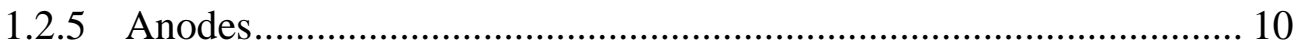

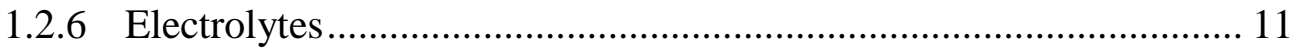

1.2.7 Conclusions .......................................................................... 20

1.3 Characterization of Lithium Polysulfides ........................................ 20

1.3.1 Characterization Techniques ........................................................ 20

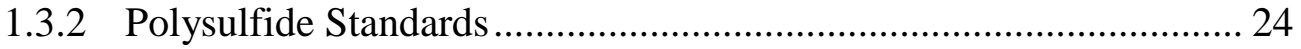

1.4 Confocal Raman Microscopy.......................................................... 25

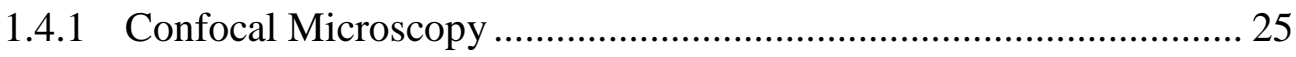

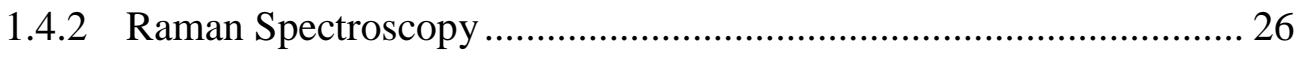


1.4.3 Raman to Analyze Lithium Sulfur Batteries

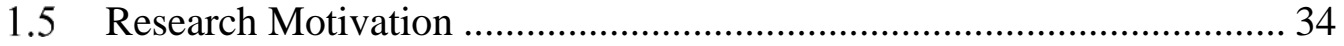

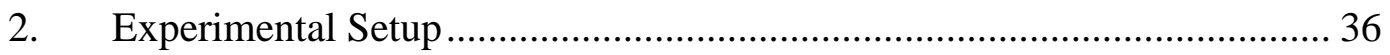

2.1 Raman System and Raman Data Acquisition .................................... 36

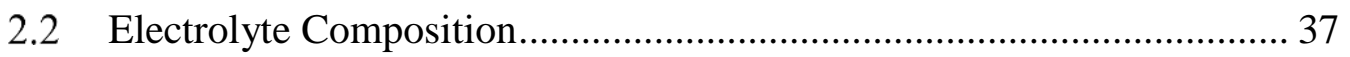

2.3 Raman Polysulfide Standards ..................................................... 38

2.4 ESI Mass Spectroscopy Polysulfide Standards ................................. 40

2.5 In Situ Raman Cell Design ............................................................. 41

2.5.1 Generation 1 ............................................................................ 41

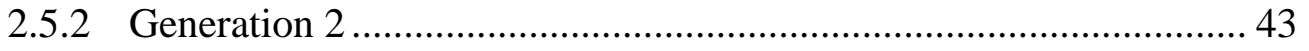

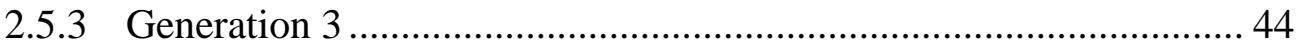

2.6 In Situ Raman Cell Preparation....................................................... 46

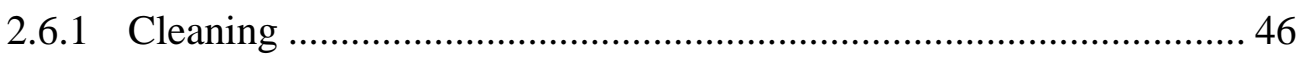

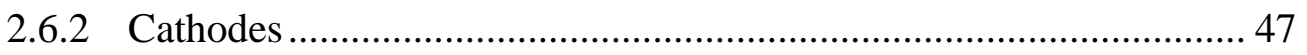

2.7 Electrochemical Testing .......................................................... 48

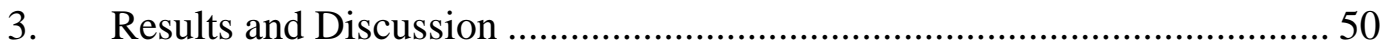

3.1 Analysis of Cell Components using Raman.................................... 50

3.2 ESI Mass Spectroscopy Results ................................................. 55

3.3 Raman of Lithium Polysulfide Standards ....................................... 57

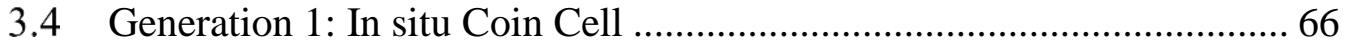




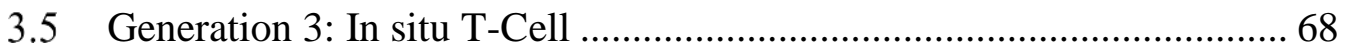

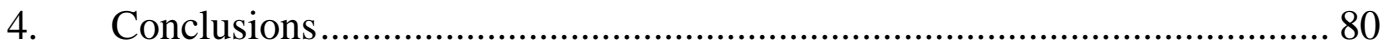

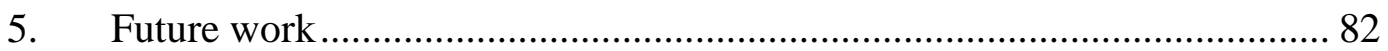

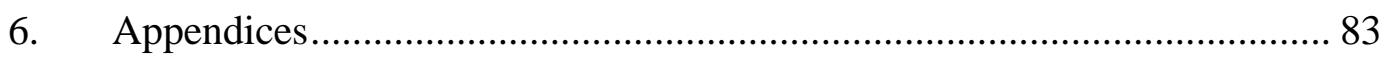

6.1 Appendix A: Mass Spectra for all Polysulfide Standards ..................... 83

6.2 Appendix B: Spectral Processing ............................................... 84

6.3 Appendix C: Voltage Steps and Current Decay, T-Cell Replicates........ 87

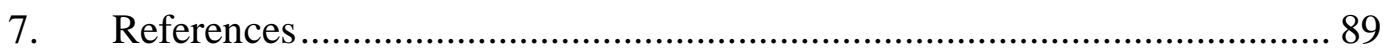




\section{LIST OF FIGURES}

Figure 1: Electrochemical cell during discharge ${ }^{6,8}$............................................ 2

Figure 2: Typical first discharge and charge curves of a Li-S battery showing the believed

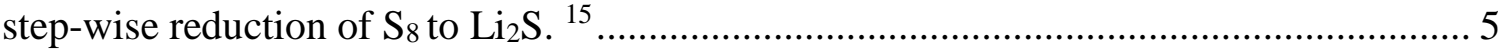

Figure 3: Diagram of the polysulfide shuttle mechanism during the charge cycle. Figure adapted from Ref. ${ }^{2,6}$ 7

Figure 4: Percentage of research focused on various electrolyte solvents for Li-S batteries. Figure from Hagen et al. ${ }^{39}$ 11

Figure 5: Discharge and charge profiles of various ether and carbonate solvents used in electrolytes. $^{46}$ 14

Figure 6: Lithium salts used in Li-S battery electrolytes. ${ }^{48}$. 15

Figure 7: ESI/MS results from Zheng et al. ${ }^{58}$ 22

Figure 8: Jablonski diagram showing Rayleigh, Stokes, and Anti-Stokes scattering. ${ }^{75}$.. 26 Figure 9: Figure from Suo et al. ${ }^{66}$ showing the effect of LiTFSI concentration variation in 1:1 DME:DOL electrolyte on Raman spectrum. 30

Figure 10: Raman spectra during the discharge and charge of a lithium sulfur in situ cell. Figure from Hagen et al. ${ }^{39}$ 31

Figure 11: Figure from $\mathrm{Wu}$ et al. depicting a cyclic voltammogram of a $\mathrm{Li}-\mathrm{S}$ cell and changes in polysulfide peak intensities during discharge. ${ }^{67}$ 33

Figure 12: WiTec Alpha300M Raman schematic. 36

Figure 13: Example Raman calibration curve. 37

Figure 14: Polysulfide standards at reaction initiation and just prior to removal from hot plate. 38 
Figure 15: EIS mass spectroscopy polysulfide standards prior to dilution.................... 40

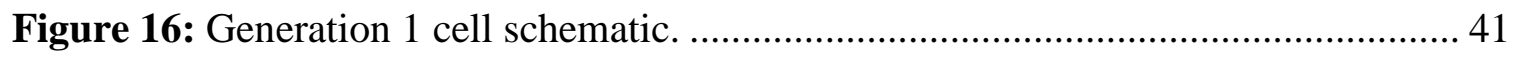

Figure 17: Generation 2 cell schematic of a commercial in situ cell from MTI

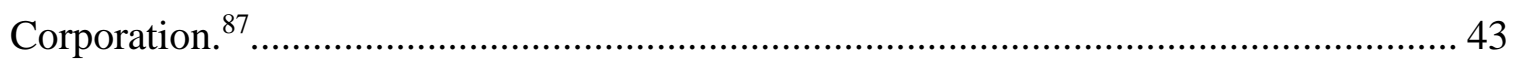

Figure 18: Cathode and tabs used to attach the cathode to the stainless steel rod leads.. 44

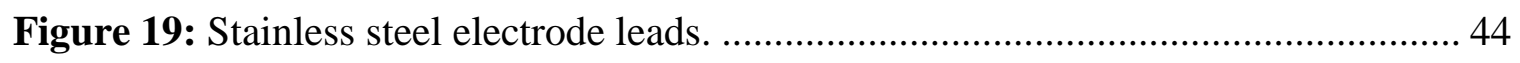

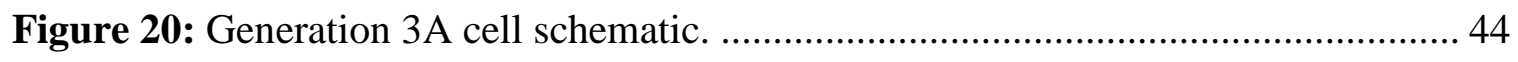

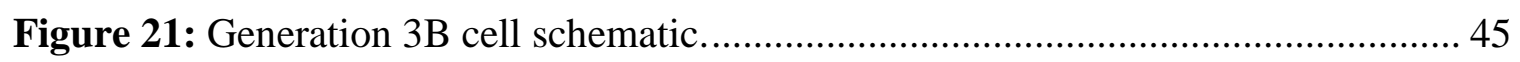

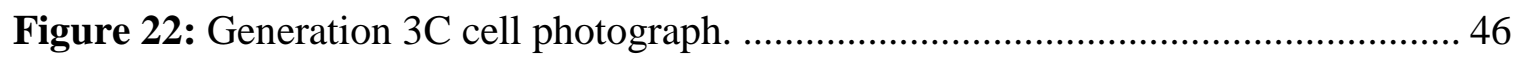

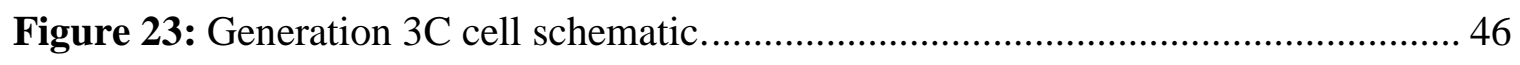

Figure 24: The normal discharge curve of a 2032 coin cell with a 60:30:10 sulfur: Super P: SBR/LI133 cathode and lithium on copper anode (black) and example of voltage steps

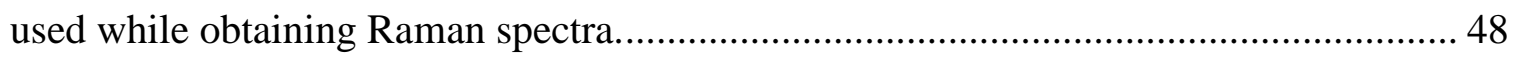

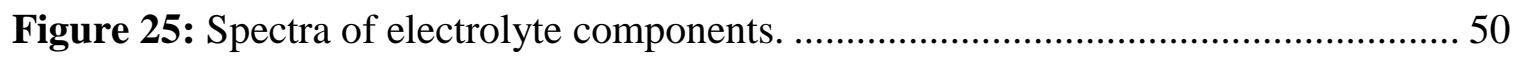

Figure 26: Difference in fluorescence background when electrolyte was under argon vs.

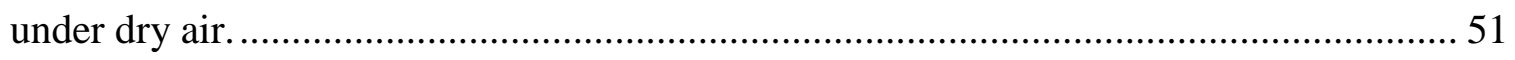

Figure 27: Raman spectra of the electrolyte using a laser power of $8 \mathrm{~mW}$ with 30 seconds integration time and 10 accumulations and a laser power of $0.5 \mathrm{~mW}$ with 240 seconds

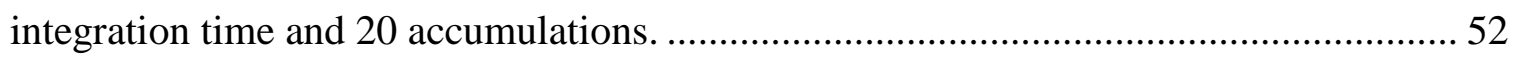

Figure 28: LiTFSI in air using a laser power of $8 \mathrm{~mW}$ with 30 seconds integration time and 10 accumulations and a laser power of $0.5 \mathrm{~mW}$ with 240 seconds integration time and 20 accumulations. 53 
Figure 29: LiTFSI time study in air and argon from 2 seconds illumination time to 60 seconds illumination time showing the effect of photo-bleaching at a power of $8 \mathrm{~mW} .53$ Figure 30: Raman spectra for $\mathrm{S}_{8}$ in air and $\mathrm{Li}_{2} \mathrm{~S}$ under argon using a laser power of $8 \mathrm{~mW}$, 30 seconds integration time, and 10 accumulations 54

Figure 31: Raman spectra of 3501 Celgard separator and 60:30:10 sulfur: Super P: LI133/SBR 8 mil WFT cathode. 55

Figure 32: ESI mass spectra of $50 \mathrm{mM}^{~ " ~} \mathrm{Li}_{2} \mathrm{~S}_{8}$ " in 1:1 DME: DOL and $0.2 \mathrm{mmol} \mathrm{Na}_{2} \mathrm{~S}$ and $0.075 \mathrm{mmol} \mathrm{S}_{8}$ in DME. 56

Figure 33: Polysulfides exposed to air 1 and 2 days after being synthesized. 57

Figure 34: Example of color change of polysulfide standards after exposure to air..... 57

Figure 35: Polysulfides under argon 1 and 2 days after being synthesized 58

Figure 36: Nominal $\mathrm{Li}_{2} \mathrm{~S}_{8}, \mathrm{Li}_{2} \mathrm{~S}_{6}$, and $\mathrm{Li}_{2} \mathrm{~S}_{4}$ standards under argon at 17 hours from reaction initiation with peak positions from the literature 59

Figure 37: Solid identified as $\mathrm{Li}_{2} \mathrm{~S}$ in the $\mathrm{Li}_{2} \mathrm{~S}_{4}$ standards.. 59

Figure 38: Difference in coloration of the $\mathrm{Li}_{2} \mathrm{~S}_{8}, \mathrm{Li}_{2} \mathrm{~S}_{6}$, and $\mathrm{Li}_{2} \mathrm{~S}_{4}$ standards in argon ... 60 Figure 39: Examples of Lorentzian fits for peaks located approximately at 390, 450, 510, and $533 \mathrm{~cm}^{-1}$ at 17 hours from reaction initiation for $\mathrm{Li}_{2} \mathrm{~S}_{4}, \mathrm{Li}_{2} \mathrm{~S}_{6}$, and $\mathrm{Li}_{2} \mathrm{~S}_{8}$.

Figure 40: Peak position in the $510 \mathrm{~cm}^{-1}$ range for the $\mathrm{Li}_{2} \mathrm{~S}_{8}, \mathrm{Li}_{2} \mathrm{~S}_{6}$, and $\mathrm{Li}_{2} \mathrm{~S}_{4}$ standards over a week period.

Figure 41: Stability study of polysulfide standards under argon.... 64 Figure 42: First discharge curves with current interrupts for a normal coin cell, and two replicates of coin cells sealed from the outside using Double/Bubble® extra fast setting epoxy 66 
Figure 43: Image of coin cells sealed from the outside with Double/Bubble® extra fast setting epoxy before and after cycling.

Figure 44: Result of soaking lithium metal and Double/Bubble ${ }^{\circledR}$ extra fast setting epoxy in electrolyte for one day. 67

Figure 45: Example of current decay reaching equilibrium just prior to the acquisition of

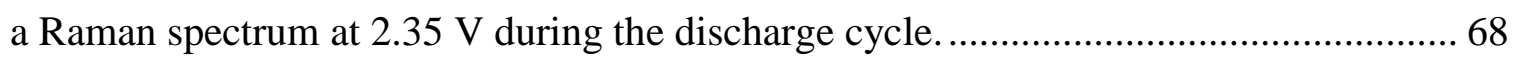

Figure 46: Voltage steps and current decays for T-cell replicate number one. .............. 69

Figure 47: T-cell window before and after 1 discharge and charge cycle..................... 69

Figure 48: Raman spectra of replicate \#1 for in situ discharge and charge at each voltage step.. 70

Figure 49: $365 \mathrm{~cm}^{-1}$ peak intensities during the discharge and charge of the in situ Li-S Tcell 72

Figure 50: $365 \mathrm{~cm}^{-1}$ peak intensities as a function of depth of discharge. 73 Figure 51: Representative raw data and fits of the peaks located at approximately 365 and $390 \mathrm{~cm}^{-1}$ during discharge and charge.. 74

Figure 52: Ratio of 390 to $365 \mathrm{~cm}^{-1}$ peak intensities during the discharge and charge of the in situ Li-S T-cell. 75

Figure 53: $533 \mathrm{~cm}^{-1}$ peak intensities during the discharge and charge of the in situ Li-S Tcell 76

Figure 54: $450 \mathrm{~cm}^{-1}$ peak intensities during the discharge and charge of the in situ Li-S Tcell 77

Figure 55: $1066 \mathrm{~cm}^{-1}$ peak intensities during the discharge and charge of the in situ Li-S T-cell.. 78 
Figure 56: Initial experiment results on the effect of the laser on the current decay and

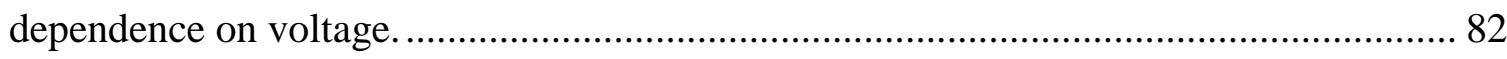

Figure 57: Mass spectra of polysulfide standards................................................ 83

Figure 58: Example of background subtraction for a $\mathrm{Li}_{2} \mathrm{~S}_{8}$ standard before and after

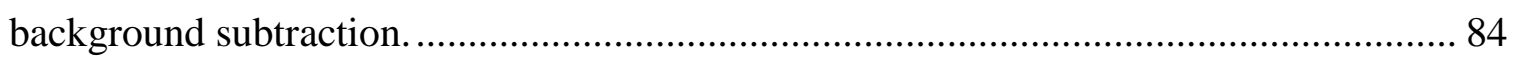

Figure 59: Example of normalization to the $740.7 \mathrm{~cm}^{-1}$ LiTFSI peak and subtraction of

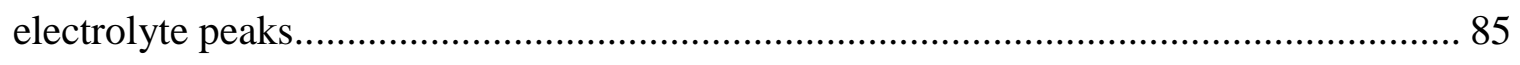

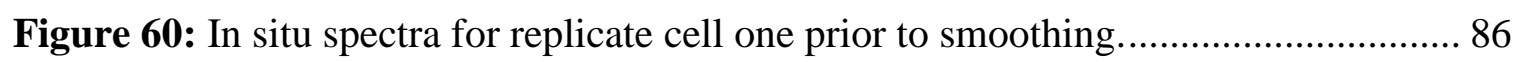

Figure 61: Normal, constant discharge of a T-cell at C/50 .................................... 88

Figure 62: Voltage steps and current decays for replciates two and three .................... 88 


\section{LIST OF TABLES}

Table 1: Theoretical electrochemical properties of a .............................................. 4

Table 2: Summary of some of the major characterization techniques used to study lithium sulfur batteries.

Table 3: Comparison of important parameters for the Wu et al. ${ }^{67}$ and Hagen et al. ${ }^{39}$ papers

Table 4: ESI mass spectroscopy parameters. ........................................................ 40

Table 5: List of adhesives tested for compatibility with the Li-S system and with the DME:

DOL electrolyte.

Table 6: Peaks observed in current work and their assignments based on literature values. 


\section{Introduction}

A transition to sustainable energy is among society's greatest challenges. ${ }^{1}$ With this change, the development of more efficient, safe, and cost effective batteries is also necessary. ${ }^{2,3}$ Batteries are becoming ever more integral to today's technology rich world. ${ }^{4}$ Phones and other personal electronics are reliant on battery performance. Intermittent power sources, such as wind and solar, require storage devices to deliver a consistent energy supply ${ }^{2,5,6}$ and more ecofriendly electric vehicles have limited travel distances due to low energy density batteries. ${ }^{3}$ Current lithium (Li) ion batteries are already nearing the bounds of their performance capabilities. An encouraging improvement in specific energy is possible with lithium sulfur ( $\mathrm{Li}-\mathrm{S})$ batteries. ${ }^{2,3,7}$

This chapter provides an introduction to battery terminology followed by a description of obstacles in Li-S battery research, the use of Raman spectroscopy and other characterization techniques to better understand the behavior of a Li-S battery, and the motivation behind the current research.

\subsection{Batteries}

A battery is one or more electrochemical cells connected in series or parallel in order to achieve a desired capacity or voltage. Chemical energy is converted to electrical energy through a coupled reduction-oxidation (redox) reaction. ${ }^{8}$ Unlike an engine, a battery does not require a temperature difference to function and is not limited by the Carnot efficiency. 
There are three components to an electrochemical cell: the cathode, the anode, and the electrolyte. A typical electrochemical cell, during the discharge cycle, is depicted in Figure 1. The cathode, also called the positive electrode, is defined as the electrode where

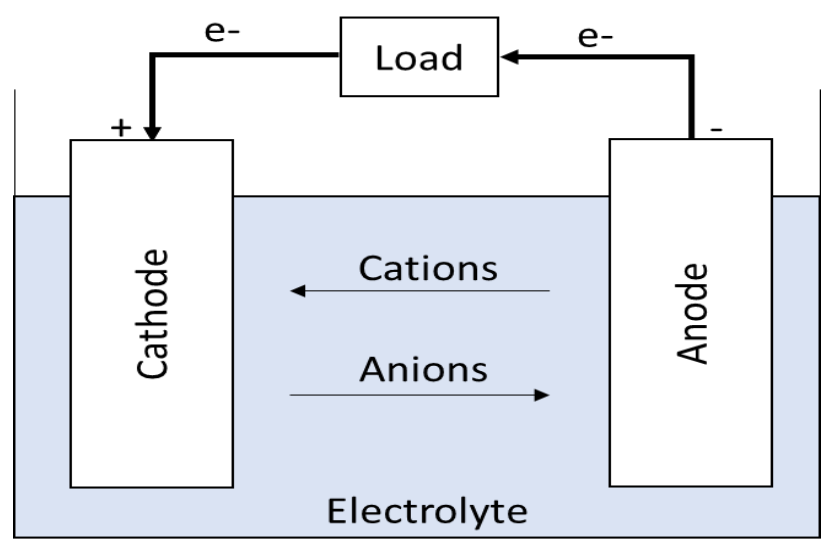

Figure 1: Electrochemical cell during discharge. The cathode accepts electrons from the external circuit while the anode donates electrons to the external circuit. $^{6,8}$ reduction takes place; the cathode accepts electrons from the anode via the external circuit. The anode, the negative electrode, is oxidized as it donates electrons to the cathode through the external circuit. ${ }^{8}$ As electrons flow through the circuit, they perform electrical work. The flow of electrons during cycling is balanced through the movement of ions. The electrolyte provides a pathway for ions as it is ionically, but not electronically conductive.

If a direct, electronic path between anode and cathode is created, the cell will short. An internal short circuit renders the battery useless because there is no longer a potential difference between the two electrodes. It can also pose a safety hazard; if a large current is allowed to pass uncontrolled between electrodes, excessive heating may occur. Direct contact between electrodes is prevented by either separation by physical distance or through the use of an insulating separator. The separator is still permeable to ions, allowing the passage of ions between cathode and anode.

The potential difference between the cathode and anode, when no current is present, is called the open circuit potential. This difference is the driving force for the battery voltage and changes as the materials in the cathode and anode change during the charge and 
discharge cycles. The active materials of a battery are defined as the components that are intended to be involved in the redox reaction.

The amount of electricity available from the redox reaction per gram of active material is called the cell's specific capacity. ${ }^{8}$ The C-rate of a cell is calculated from the maximum, theoretical capacity and is defined as the rate that will discharge the battery in one hour. For example, a rate of $2 \mathrm{C}$ will lead to a discharge time of 0.5 hours while a rate of $0.10 \mathrm{C}$ will lead to a discharge time of 10 hours.

During normal operation, in the forward (exothermic) reaction, cations move through the electrolyte towards the cathode, and anions shift towards the anode. This process is called discharge when referring to batteries. The current and ion flows are reversed during the charge cycle; cations and anions diffuse towards the anode and cathode respectively, while electrons pass through the external circuit from cathode to anode.

Cycling is relevant to secondary (rechargeable) batteries which can be charged and discharged multiple times through the reversal of the redox reaction. Primary batteries are discarded after a single discharge, as their chemical reactions are considered irreversible.

Although batteries allow for greater efficiencies than engines and provide the convenience of stored energy, they also have many limitations. Safety is one of the major limitations of batteries. Volatile, flammable solvents are often used, which can start fires and cause a battery to explode, given an internal short circuit. Additionally, batteries require time to recharge and can have a lasting environmental impact due to the use of hazardous materials. They also cannot yet compete with the mass and volume energy densities of gasoline. These limitations drive current and future research into the 
improvement of state of the art batteries as well as the development of new battery systems to address energy density, safety, environmental impact, and convenience.

\subsection{Lithium Sulfur Batteries}

Li-S batteries are one of several chemistries being researched with the hope of improving energy density and safety. This section discusses the benefits and limitations to lithium sulfur batteries and the research to attempt to overcome a variety of technical challenges.

\subsubsection{Attributes of Lithium Sulfur Batteries}

Due to the high theoretical capacity and specific energy of sulfur, there has been interest in primary Li-S batteries since the mid-1960s. Research into secondary Li-S batteries has increased since the year $2000 .^{2}$

In addition to these benefits, Li-S batteries have relatively nontoxic, inexpensive, and abundant raw materials. Li-S batteries are built charged with an initial voltage of approximately $3 \mathrm{~V}$. The average voltage of the discharge reaction is $2.15 \mathrm{~V}^{2}$ Table 1

Table 1: Theoretical electrochemical properties of a lithium sulfur battery. Capacities and energy densities are based on the complete reduction of $\mathrm{S}_{8}$ to $\mathrm{Li}_{2} \mathrm{~S}$. The conductivity is for a monocrystal of sulfur.

$\begin{array}{lcc}\text { Property } & \text { Value } & \text { Reference } \\ \text { Average discharge voltage (V) } & 2.15 & 2 \\ \text { Capacity (mAh/g S) } & 1675 & 9-11 \\ \text { Specific Energy (Wh/kg S) } & 2567 & 9-11 \\ \text { Energy Density (Wh/L) } & 2199 & 12 \\ \text { Electrical Conductivity (S/m) } & 6.1 \times 10^{-15} & 13\end{array}$

summarizes the theoretical electrochemical properties of sulfur and a Li-S battery. In a lithium sulfur battery, lithium metal serves as the anode and a carbonsulfur composite is typically used as the cathode. Sulfur is

highly insulating, as seen from its low conductivity in Table 1. It requires a conductive 
phase to allow for efficient electron transport. A binder is used to combine the conducting phase and sulfur to ensure consistent electrical contact.

The most common allotrope of sulfur is an eight-membered ring. During discharge, sulfur $\left(\mathrm{S}_{8}\right)$ in the cathode is reduced, forming polysulfide anions. $\mathrm{S}_{8}$ has the ability to transfer sixteen electrons during a redox reaction while most transition metals in intercalation batteries can only transfer one electron. ${ }^{3}$ The full reaction is the reduction of $\mathrm{S}_{8}$ to $\mathrm{Li}_{2} \mathrm{~S}$. The half and overall reactions for the discharge cycle are listed in Equations 1$3 .^{2,14}$

$$
\begin{array}{ll}
16 \mathrm{Li}^{+}+\mathrm{S}_{8}+16 e^{-} \rightarrow 8 \mathrm{Li}_{2} \mathrm{~S} & \text { (cathode) } \\
16 \mathrm{Li} \rightarrow 16 \mathrm{Li}^{+}+16 e^{-} & \text {(anode) } \\
16 \mathrm{Li}+\mathrm{S}_{8} \rightarrow 8 \mathrm{Li}_{2} \mathrm{~S} & \text { (overall) }
\end{array}
$$

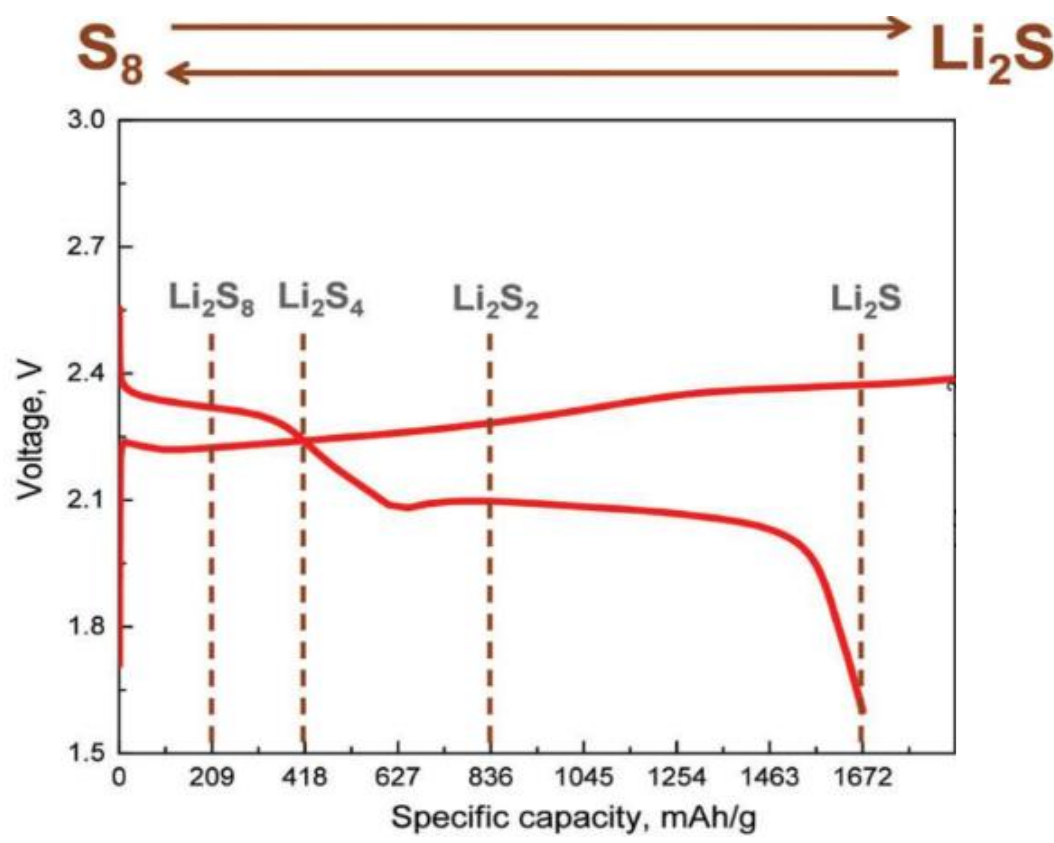

Figure 2: Typical first discharge and charge curves of a Li-S battery showing the believed step-wise reduction of $\mathrm{S}_{8}$ to $\mathrm{Li}_{2} \mathrm{~S}$. ${ }^{15}$

However, $\mathrm{S}_{8}$ is reduced in a step wise process to $\mathrm{Li}_{2} \mathrm{~S}$; first it is believed to be reduced to long chain polysulfides, $\mathrm{Li}_{2} \mathrm{~S}_{\mathrm{x}}(4<x \leq 8)$, and then to short chain polysulfides 
$(2<x \leq 4)$, before being fully reduced to $\mathrm{Li}_{2} \mathrm{~S}$. As shown in Figure $2,{ }^{15}$ there are three regions in a typical Li-S discharge curve when using ether electrolytes. ${ }^{16}$ The first spans from the charged state, open circuit potential of approximately $3 \mathrm{~V}$, to $2 \mathrm{~V}$, and is the reduction of $\mathrm{S}_{8}$ to $\mathrm{Li}_{2} \mathrm{~S}_{4}$. The second region consists of the plateau at $2 \mathrm{~V}$; it is the reduction of $\mathrm{Li}_{2} \mathrm{~S}_{4}$ to $\mathrm{Li}_{2} \mathrm{~S}_{2}$. The final curved region is the reduction of $\mathrm{Li}_{2} \mathrm{~S}_{2}$ to the final product of $\mathrm{Li}_{2} \mathrm{~S} .{ }^{17}$ Long chain polysulfides are highly soluble in organic electrolytes while $\mathrm{S}_{8}, \mathrm{Li}_{2} \mathrm{~S}_{2}$, and $\mathrm{Li}_{2} \mathrm{~S}$ are insoluble. ${ }^{8}$

Due to similar Gibbs energies of formation, the electrolyte contains a mixture of the various polysulfide anions at equilibrium with each other throughout cycling. ${ }^{3,8}$ While a mixture of polysulfide anions is present throughout, certain species are thought to dominate at various states of charge; below $\sim 2.2 \mathrm{~V}$, short chain polysulfides dominate while above, long chain polysulfides dominate. ${ }^{18}$

Further complications arise from the interplay between electrochemical and chemical reactions. The presence of disproportionation reactions also contributes to the mixture of polysulfides. In disproportionation reactions, a single reactant is spontaneously oxidized and reduced without an external electron transfer. Disproportionation reactions are believed to form polysulfide radicals or dianions depending on the solvent used. ${ }^{19,} 20$ The suspected disproportionation reactions in Li-S batteries are shown in Equations $4^{19-21}$ and 5. ${ }^{21}$ Dissociations reactions, shown in Equation 6, ${ }^{20,21}$ also occur.

$$
\begin{aligned}
& S_{8}^{2-} \rightarrow S_{6}^{2-}+(1 / 4) S_{8} \\
& 2 S_{n}^{2-} \rightarrow S_{n+m}^{2-}+S_{n-m}^{2-} \\
& S_{n}^{2-} \leftrightarrow 2 S_{n / 2}^{--}
\end{aligned}
$$




\subsubsection{Obstacles to Lithium Sulfur Batteries}

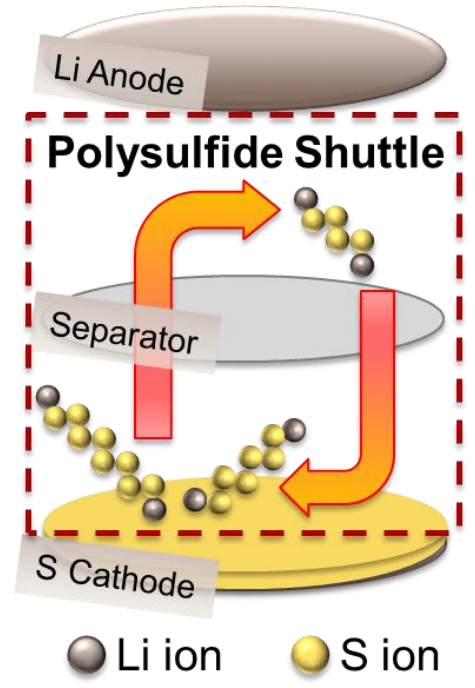

Figure 3: Polysulfide shuttle mechanism during the charge cycle. Long chain polysulfides shuttle to the anode where they are reduced to short chain polysulfides. The short chain polysulfides are then oxidized back to long chain polysulfides at the cathode. Figure adapted from Ref. ${ }^{2,6}$
There are several difficulties with secondary Li-S

batteries that must be overcome in order to make them more commercially viable.

One problem is that sulfur is highly insulating and does not efficiently conduct electrons, as required of a cathode. To address this issue, conductive carbon is often added to increase conductivity. However, so much carbon is currently required that the specific energy of the battery is significantly decreased due to a decrease in active material loading. ${ }^{2}$

Eroglu et al. performed a techno-economic analysis on the use of Li-S batteries in electric vehicles and found that

a sulfur loading of approximately $7 \mathrm{mg} / \mathrm{cm}^{2}$ is necessary for Li-S batteries to be economically feasible for use in electric vehicles. ${ }^{14}$ The loading of sulfur in the cathode must remain high to maintain high specific energy, but must be conductive enough to function as a cathode in a battery.

Another problem arises from the solubility characteristics of the discharge products. The dissolution of polysulfide intermediates allows for the presence of a detrimental process called the polysulfide shuttle mechanism. During the charge cycle of a Li-S battery, long chain polysulfides $\left(\operatorname{Li}_{2} \mathrm{~S}_{\mathrm{x}}, 4<x \leq 8\right)$ diffuse to the anode where they are reduced to short chain polysulfides $\left(\mathrm{Li}_{2} \mathrm{~S}_{\mathrm{x}}, 2<x \leq 4\right)$. The short chain polysulfides then shuttle back to the cathode where a portion of them are partially oxidized to long chain 
polysulfides, rather than completely to $\mathrm{S}_{8}{ }^{2,3,22}$ The polysulfide shuttle leads to poor active material utilization, damage to the anode, inefficient recharging, and rapid capacity fade. In the presence of this shuttling behavior, complete recharging of a Li-S battery is not possible. ${ }^{3}$ The polysulfide shuttling mechanism is shown pictorially in Figure 3.

In addition, $\mathrm{Li}_{2} \mathrm{~S}$ and $\mathrm{Li}_{2} \mathrm{~S}_{2}$ are highly insulating. The repeated precipitation of these insoluble products leads to capacity loss with cycling as an insulating layer forms on the cathode and anode. ${ }^{23} \mathrm{~A}$ volume expansion of approximately $80 \%$ also occurs due to the density difference between $\mathrm{Li}_{2} \mathrm{~S}$ and $\mathrm{S}_{8}{ }^{2},{ }^{15,} 20$ The precipitated solids on the cathode and anode are no longer fully electrochemically available and contribute to low active material utilization and an increased cell resistance. ${ }^{23}$

Thus the obstacles to Li-S batteries can be summarized into four predominant categories, including (1) the insulating nature of sulfur, (2) the solubility and mobility of reaction intermediates in the electrolyte, (3) the volume change of the cathode, and (4) the reactivity of the lithium anode. ${ }^{24}$

\subsubsection{Mitigating the Polysulfide Shuttle and Other Difficulties}

Current Li-S battery research attempts to reduce or eliminate the polysulfide shuttle while maintaining a conductive cathode, high capacity, and high specific energy. Various cathodes, electrolytes, and anode protectants have been developed for this purpose.

\subsubsection{Cathodes}

Before the cathode structure for Li-S batteries was well defined, low discharge efficiencies were obtained when sulfur was in the solid form, due to its insulating nature. As a result, there has been research into a liquid cathode. In 1979, Rauh et al. dissolved lithium polysulfides $\left(\mathrm{Li}_{2} \mathrm{~S}_{\mathrm{n}}, \mathrm{n}=5-8\right)$ in tetrahydrofuran (THF) with a solid electrolyte 
preventing the anode from coming in direct contact with the liquid cathode..$^{25}$ The result was a rechargeable system with approximately $300 \mathrm{Wh} / \mathrm{kg}$ energy density. The precipitation of insoluble $\mathrm{Li}_{2} \mathrm{~S}$ was still a major obstacle for this system.

Since then, many contained cathodes have been produced with the goal of increasing conductivity, retaining the specific energy of sulfur, and keeping sulfur polysulfides from dissolving into the electrolyte. ${ }^{11,26-31}$ Materials such as conductive carbons and polymers have been added to sulfur to form a more electronically conductive composite cathode. In particular, research has focused on conductive carbons due to higher conductivities and capacities.

In 2002, Wang et al. demonstrated the performance of carbon-sulfur cathodes with a reversible capacity of $440 \mathrm{mAh} / \mathrm{g} .{ }^{31}$ Thermal treatment of the sulfur and carbon was seen to further increase the capacity by improving sulfur utilization and cyclability. ${ }^{30}$

Pore size also plays an important role in contact between sulfur and carbon. Zhang et al. concluded that the use of microporous carbon allowed for an increase in active material utilization and battery life. ${ }^{32} \mathrm{Ji}$ et al. studied the ability of mesoporous, CMK-3 carbon to support higher sulfur loadings through a larger carbon pore size. ${ }^{27}$ Cycle life was also improved in a study by Han et al. in which multiwalled carbon nanotubes were used as the conductive phase to help decrease sulfur dissolution. ${ }^{33}$

In 2013, Song et al. developed a sulfur graphene oxide (S-GO) nanocomposite cathode modified with cetyltrimethyl ammonium bromide (CTAB). ${ }^{29}$ The cationic modifier, CTAB, helped retain sulfur in the cathode and improved rate and cycle capabilities. $^{23,29}$ 
$\mathrm{Ji}$ et al. ${ }^{34}$ built cathodes of sulfur immobilized on graphene oxide and saw reversible capacities of $950-1400 \mathrm{mAh} /$ gram sulfur after 50 cycles. Building upon this concept, polysulfide adsorption can be enhanced through the use of functional groups containing oxygen, boron, nitrogen, and sulfur. Nitrogen in particular has shown promise in the work by Qiu et al. ${ }^{35}$ which showed that it more evenly traps sulfur. This cathode in this work yielded a capacity decay rate of only $0.028 \%$ per cycle.

\subsubsection{Anodes}

Lithium metal is the predominant anode for Li-S batteries because it has a high capacity $(\sim 3860 \mathrm{mAh} / \mathrm{g})$ and low voltage. ${ }^{2}$ Issues with lithium metal anodes in Li-S batteries include dendrite formation, low lithium cycling efficiency, and the precipitation of the insoluble polysulfides, $\mathrm{Li}_{2} \mathrm{~S}$ and $\mathrm{Li}_{2} \mathrm{~S}_{2}$, on the lithium surface. Dendrites are known to form on lithium metal anodes; however, the ether solvent and polysulfides in Li-S batteries cause additional parasitic reactions not seen in other systems. ${ }^{2}$ Dendrites are believed to form due to an unstable solid electrolyte interphase (SEI) layer; this is caused by uneven Li dissolution and plating. ${ }^{12}$ Dendrites can pose a safety concern as they can cause the cell to short if they grow into the separator.

Passivation of the lithium anode can help mitigate these detrimental processes. SION Power® added lithium nitrate $\left(\mathrm{LiNO}_{3}\right)$ to ether electrolytes for $\mathrm{Li}-\mathrm{S}$ batteries and found that $\mathrm{LiNO}_{3}$ helps passivate the lithium anode, greatly increasing the capacity and coulombic efficiency. ${ }^{23}$ The passivation layer consists of various $\mathrm{Li}_{\mathrm{x}} \mathrm{NO}_{\mathrm{y}}$ and $\mathrm{Li}_{\mathrm{x}} \mathrm{SO}_{\mathrm{y}}$ species and helps to reduce the polysulfide shuttle mechanism by restricting the precipitation of insoluble polysulfides. ${ }^{36}$ 
Other anodes such as silicon nanowires, lithium tin alloys, and hard carbons have been investigated. ${ }^{2}$ The use of alternative anodes requires the addition of lithium to the system because the anode can no longer act as the source of lithium. Yang et al. developed a Li-S battery with a silicon nanowire anode and added lithium through the use of a $\mathrm{Li}_{2} \mathrm{~S}$ mesoporous carbon cathode. Although this system achieved an initial discharge specific energy of $630 \mathrm{Wh} / \mathrm{kg}$, it showed significant capacity loss with cycling. ${ }^{2,37}$ Another example is the work done by Liu et al. in which prelithiated silicon is used as the anode. This work successfully demonstrated a proof of concept in which the prelithiated silicon anode and a sulfur, mesoporous carbon cathode obtained a first discharge capacity of approximately $800 \mathrm{mAh} / \mathrm{g}$ sulfur. ${ }^{38}$

\subsubsection{Electrolytes}

Electrolyte selection is imperative to the Li-S system because the solubility and speciation of polysulfides can change greatly with varying electrolytes, therefore this section will go into more depth than that of the cathode or anode sections.

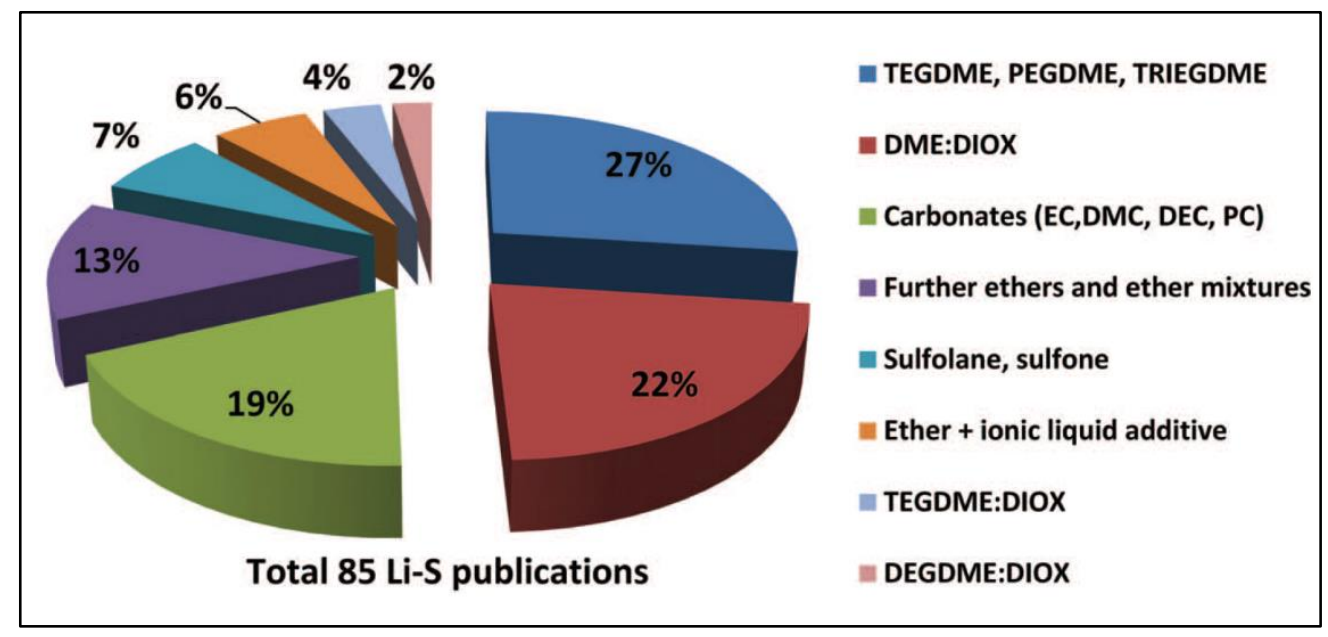

Figure 4: Percentage of research focused on various electrolyte solvents for Li-S batteries. Figure from Hagen et al. ${ }^{39}$ 
Polysulfides are soluble in solvents with high basicity. The degree of solubility can influence active material utilization, achievable discharge current densities, and cyclability of the battery. Several different liquid electrolytes, as well as solid electrolytes have been developed with the hope of shutting down the polysulfide shuttle while maintaining a high capacity. The percentage of research focused on various liquid electrolytes was summarized by Hagen et al. in Figure 4. In addition to changes in speciation, the amount of electrolyte also greatly affects the performance of lithium sulfur cells as it can shift the equilibrium of speciation and significantly decreases the energy density of the cell. ${ }^{40}$ This parameter, the electrolyte to sulfur (E/S) ratio is currently often left out of research papers.

\subsubsection{Non-Aqueous Organic Liquid Electrolytes}

As with all battery systems, desirable electrolyte characteristics include high ionic conductivity, no electronic conductivity, compatibility with cathode and anode materials, stability at operation temperature and voltage, low cost, and a high degree of safety. The viscosity and dielectric constant of the solvent affect the electrolyte's conductivity; a low viscosity and high dielectric constant are favorable for better ionic conductivity. It has been found that using a mixture of solvents can sometimes yield a more electronically resistive and ionically conductive electrolyte. An example is the use of one solvent with a high dielectric constant and high viscosity and a second having a medium dielectric constant and low viscosity. ${ }^{41}$ The donor number (DN) of the solvent also plays an important role in Li-S battery electrolytes. The DN measures Lewis basicity and the ability of a solvent to solvate cations and Lewis acids. It is the negative enthalpy value, in kcal per mole, to form a 1:1 adduct between the described Lewis base and the standard Lewis acid, $\mathrm{SbCl}_{5}{ }^{42}$ 
Some of the first electrolytes investigated for this chemistry used liquid aliphatic amines as the solvent. Herbet and Ulam first used sulfur as a positive electrode in 1962 with an alkaline perchlorate, iodide, bromide, or chlorate dissolved in aliphatic amines. ${ }^{43}$ Moss and Nole patented metal-sulfur batteries using non-aqueous, organic solvents such as ethylene carbonate, propylene carbonate, dimethoxyethane and $\gamma$-butyrolactone, for the electrolyte in $1968 .^{41}$ They recommended the use of lithium perchlorate as the salt. Other possible salts at the time included lithium aluminum chloride, lithium fluoroborate, lithium hexafluoroborate and lithium hexafluorophosphate. ${ }^{41}$

Carbonate electrolytes have since been largely dismissed due to irreversible side reactions with polysulfides. ${ }^{44}$

In 1976, dimethyl sulfoxide (DMSO) was investigated, but reduction stopped at $\mathrm{S}_{4}{ }^{2-}$ resulting in a low cell efficiency. ${ }^{44}$ Rauh et al. demonstrated the ability of Li-S batteries to be recharged ${ }^{25}$ by using a cathode composed of carbon, an anode of lithium, and a catholyte of $\sim 5 \mathrm{M}$ sulfur in the form of $\mathrm{Li}_{2} \mathrm{~S}_{\mathrm{n}}$ and $1 \mathrm{M} \mathrm{LiAsF} 6$ in THF. Although rechargeable, these batteries began to degrade significantly after only 10-20 cycles. THF was later shown to be unstable in the presence of lithium metal. ${ }^{44}$

In 1989, Peled et al. studied the performance of dioxolane (DOL) solvents in Li-S batteries. ${ }^{45}$ The conductivity at varying temperatures, compatibility with lithium, and discharge behavior were evaluated. DOL has a dielectric constant twice that of THFtoluene making it much more ionically conductive which decreases the internal resistance of the cell. Results from Peled et al. agreed with the expected trend: electrolytes having a greater fraction of DOL had a greater conductivity. It was also shown that DOL is much more compatible with lithium than THF or toluene and has a slower, more stable corrosion 
rate when lithium was soaked in each respective solvent for 70 days. The discharge behavior was also different when using DOL. The DOL solvent resulted in a sulfur utilization of only $50 \%$, as compared to $95 \%$ with THF-toluene, even at the low current density of $100 \mu \mathrm{A} / \mathrm{cm}^{2}$. In summary, DOL provides an order of magnitude increase in conductivity and is more compatible with lithium, however it decreases sulfur utilization as compared to THF-toluene. ${ }^{45}$

Ether based electrolytes, such as DOL, have high donor numbers and coordinate with the lithium cations. ${ }^{44}$ Two ether electrolytes in particular, in addition to DOL, have shown promise in the literature: Tetraethylene glycol, dimethylether (TEGDME) and 1,2-dimethoxyethane (DME). Mixtures of dioxolane with other such solvents have proved beneficial. DOL and glyme solvents typically have high lithium polysulfide solubility; despite the detrimental effects of the polysulfide shuttle, solubility has allowed for better initial electrochemical performance. ${ }^{44}$

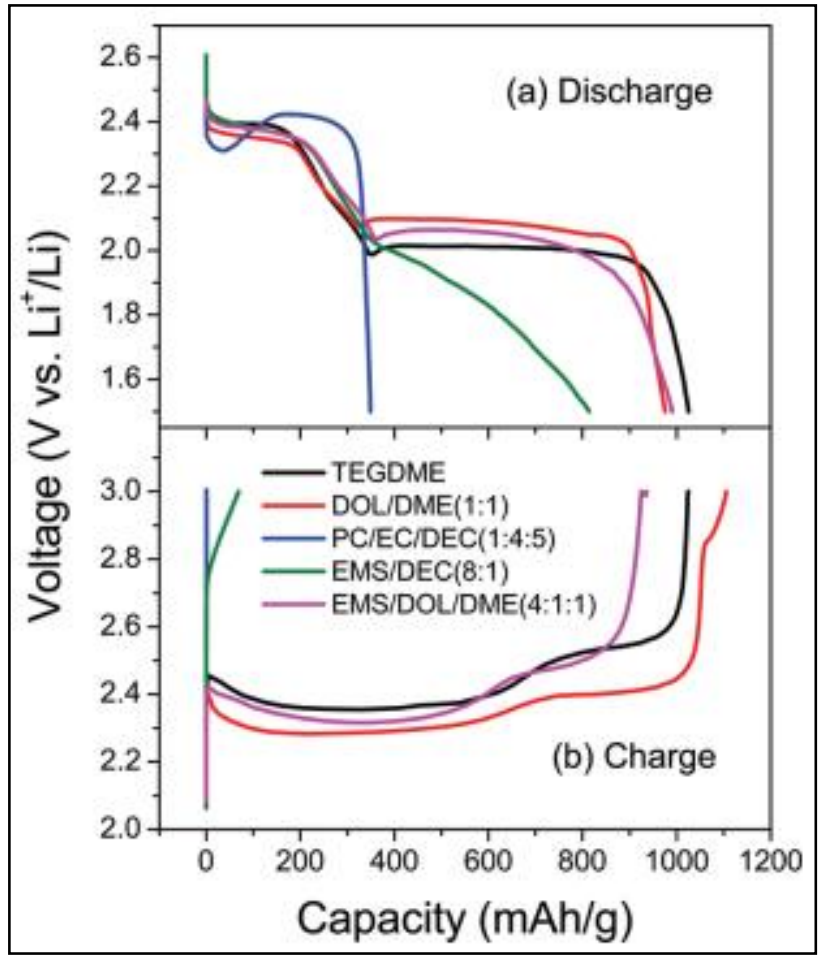

Figure 5: Discharge and charge profiles of various ether and carbonate solvents for the electrolyte. ${ }^{46}$

Gao et al. studied the performance of DME, DOL, TEGDME, and carbonate electrolytes. As can be seen in Figure $5,{ }^{46}$ from the charge/discharge profiles, the ether electrolytes perform better than carbonate based electrolytes. In 2013, Barchasz et al. investigated the cause for the poor performance when using carbonate electrolytes. They 
showed that changing the lithium salt did not affect the performance, indicating the solvent was most likely the component negatively affecting performance. Barchasz et al. concluded that the poor performance had two causes: (1) polysulfides have a low solubility in carbonate solvents and (2) the carbonate solvents are reactive and unstable in the presence of polysulfides ${ }^{47}$ The carbonate electrolytes thus have very low charge and discharge capacities and low active material utilization.

The salts dissolved in a solvent to create the electrolyte also play an important role. Examples of salts that have been used in Li-S batteries include LiTf, LiTFSI, LiPF 6 , and $\mathrm{LiClO}_{4}{ }^{48}$ These salts are popular for their thermal stability and compatibility with ether solvents. A complete listing of Li-S battery salts with chemical structures is shown in

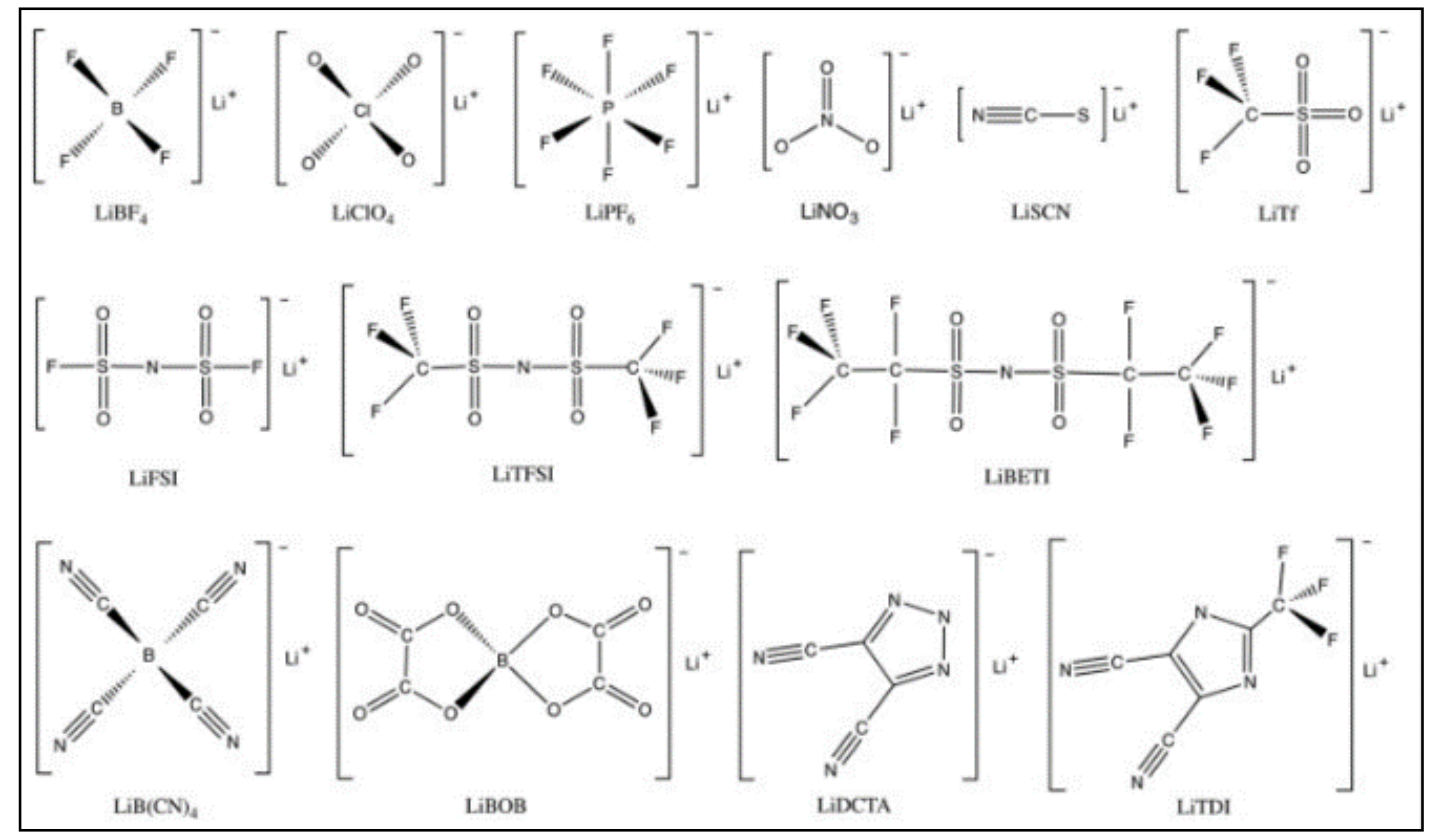

Figure 6: Lithium salts used in Li-S battery electrolytes. ${ }^{48}$

Figure 6. LiTf and LiTFSI are the two most commonly used salts. LiTFSI has largely taken the place of other salts due to a two-fold increase in conductivity over its closest competitor, LiTf, and high dissociation ability. Typically, these salts are dissolved in the solvent at a concentration of $\sim 1 \mathrm{M}$. However, greater concentrations have been explored. Greater 
concentrations of salts generally decrease polysulfide solubility and slow the diffusion of polysulfides through the electrolyte. ${ }^{48}$ In the extreme case of solvent in salt (SIS) electrolytes, the salt concentration can be up to $7 \mathrm{M}$, and the salt becomes the majority component by volume and weight. ${ }^{48,49}$ The SIS electrolyte decreases lithium polysulfide dissolution and protects the $\mathrm{Li}$ anode by limiting dendrite growth ${ }^{49}$ The greatest downside to SIS electrolytes is the cost of using such a large quantity of salt.

The success of ether solvents and salts such as LiTFSI and LiTf in Li-S batteries is possible due to the lower operation voltage as compared to other lithium battery systems. ${ }^{48}$ Additives are commonly used in lithium ion batteries. The most prevalent example in the Li-S system is lithium nitrate $\left(\mathrm{LiNO}_{3}\right) . \mathrm{LiNO}_{3}$ stabilizes the lithium anode in DOL electrolytes by reacting with polysulfides and forming a passivating film on the anode surface. ${ }^{48} \mathrm{LiNO}_{3}$ improves coulombic efficiency and stabilizes the reversible discharge capacity. ${ }^{50}$ In contrast to this desired effect, $\mathrm{LiNO}_{3}$ can be irreversibly reduced at low potentials, forming a film on the cathode and decreasing cell performance. This is prevented by stopping cell discharge at $1.6 \mathrm{~V}$. Below this value, the undesired reduction of $\mathrm{LiNO}_{3}$ will occur. ${ }^{48}$

Another common additive to non-aqueous electrolytes is polysulfides. Polysulfides have been added to electrolytes both as a catholyte, where the only sulfur is in the electrolyte, and as an addition to a sulfur-carbon cathode. Polysulfides, along with LiTFSI, can also form a protective layer on the $\mathrm{Li}$ anode. ${ }^{48}$

Thus, the evolution of solvents for Li-S battery electrolytes progressed from saturated aliphatic amines to propylene carbonate, THF-toluene, and lastly to dioxolanebased electrolytes. ${ }^{43}$ Dioxolane-based solvents are commonly used for Li-S batteries today. 


\subsubsection{Ionic Liquid Electrolytes}

Ionic liquids (ILs) are another candidate for electrolytes. They have gained interest for a variety of electrochemical systems due to their non-flammability, non-volatility, safety, high ionic conductivity, and large electrochemical stability window. Their greatest drawback is a high viscosity leading to poor mobility. Their application in Li-S batteries has not been heavily researched. Since Li-S batteries have a smaller voltage range than other Li battery systems, the main advantage to ILs is the ability to design for varying levels of polysulfide solubility. The first case of a pure, room temperature ionic liquid in a Li-S cell was studied by Yuan et al. in $2006 .{ }^{48,51} \mathrm{~N}$-methyl-N-butyl-piperidinium (PP14) bis(trifluoromethane)sulfonimide (TFSI) was used with a lithium anode and 1:3, sulfur: acetylene black carbon, cathode. This combination resulted in a first discharge capacity of $1055 \mathrm{mAh} / \mathrm{g}$ and a reversible capacity, up to 10 cycles, of $750 \mathrm{mAh} / \mathrm{g}$. The sulfur utilization was $63 \%$ which was higher than organic liquid electrolytes at that time. ${ }^{51}$

TFSI, the same anion used in liquid organic electrolytes, is the most common anion used in ILs for Li-S batteries. Conversely, cations in ILs vary greatly in the literature, but are typically in the imidazolium and pyrrolidinium families. ${ }^{48}$ Park et al. studied a variety of binary mixtures of ionic liquids and lithium salts. The solubility of polysulfides in the IL was found to be largely dependent on the structure and donor number of the anion. It was shown that Nbutyl-N-methylpyrrolidinium ([P14]+) with trifluoromethanesulfonate ([OTf]-) [P14][OTf], with a large donor number had a high saturation concentration of polysulfides, comparable to that in TEGDME electrolytes. The less basic (lower donor number) ILs, with bis(trifluoromethanesulfonyl)amide ([TFSA]-) as the anion, had a much lower polysulfide solubility. This corresponded to a higher capacity retention after 50 
cycles when using [P13][TFSA] ( 750 mAh/g sulfur) as compared to [P14][OTf] ( 200 $\mathrm{mAh} / \mathrm{g}$ sulfur $).{ }^{52}$

Mixtures of non-aqueous organic and ionic liquids have also been investigated due to a lower cost. Examples include mixtures of IL with DOL-DME or with pure DME. A mixture of 10\% EMIMBETI and BMIMPF6 and 0.5 M LiTf or 0.5 M LiPF6 DOL:DME $(1: 4 \mathrm{v} / \mathrm{v})$, the discharge capacity and cyclability were improved at $-20^{\circ} \mathrm{C}$ and $-10^{\circ} \mathrm{C}$. At $0.5 \mathrm{C}$ and over 100 cycles, the capacity remained greater than $600 \mathrm{mAh} / \mathrm{g}$ sulfur. ${ }^{48}$

IL electrolytes in Li-S batteries is still an under-researched field; there are opportunities for further research into balancing ratios of organic and ionic liquids as well as further research into various cations and anions. ${ }^{48}$

\subsubsection{Solid Electrolytes}

Solid electrolytes define the last major category of electrolytes for Li-S batteries. Advantages to solid electrolytes include inherent safety, improved Li anode stability, and potential to control solubility of polysulfides. Solid electrolytes are safer because they are more thermally stable, less likely to leak, and less volatile. With these advantages comes the issue of poor ionic conductivity at room temperature and poor rate capability; solid state lithium sulfur batteries tend to operate at elevated temperatures limiting their applications.

There are three main areas of research for solid electrolytes: gel polymer, solid polymer, and glassy electrolytes.

An example of a gel polymer electrolyte was demonstrated by Ryu et al. A PVDF gel electrolyte was used with a sulfur-carbon black cathode and $\mathrm{Li}$ anode at room temperature. The first discharge had a capacity of $1268 \mathrm{mAh} / \mathrm{g}$ sulfur at a rate of $0.10 \mathrm{C}$ 
and had the same two plateaus as in ether liquid electrolytes. Performance decreased to $1028 \mathrm{mAh} / \mathrm{g}$ sulfur after the first cycle and the first characteristic plateau of the reduction of long chain polysulfides was no longer present. This could be indicative of decreased solubility of long chain polysulfides in the solid electrolyte. ${ }^{48,53}$

Solid polymer electrolytes require operation at temperatures between 70 and $90^{\circ} \mathrm{C}$. They are typically based on short chain polyethylene oxides (PEO). Mixtures of salts and PEO have led to poor ionic conductivities. In an attempt to decrease the operation temperature and increase rate capability, nanoparticles have been incorporated into the PEO matrix as fillers. The performance is believed to be enhanced by the nanoparticles interacting with the PEO oxygen atoms and electrolyte anions, which causes decreased interaction with $\mathrm{Li}^{+}$and increased $\mathrm{Li}^{+}$mobility. ${ }^{48}$ Syzdek et al. studied the preparation and application of alumina and titania based fillers of different grain sizes in polymer electrolytes and found that preparation method, in addition to nanoparticle filler material, greatly affects electrolyte properties and performance. ${ }^{54} \mathrm{~A}$ promising filler, $\mathrm{ZrO}_{2}$, was proposed by Hassoun and Scrosati. With $10 \% \mathrm{ZrO}_{2}$ added to the solid PEO electrolyte, an improved ionic conductivity, $\mathrm{Li}+$ transference number, and electrode-electrolyte stability was observed. ${ }^{48,55}$ A first discharge capacity of $900 \mathrm{mAh} / \mathrm{g}$ sulfur was obtained at $0.05 \mathrm{C}$. Rate capability and cycle life still need to be improved. ${ }^{55}$

Lastly, glassy electrolytes have been studied. Nagao et al. used a carbon-sulfur cathode, a $\mathrm{Li}_{2} \mathrm{~S}-\mathrm{P}_{2} \mathrm{~S}_{5}$ glass-ceramic solid electrolyte, and a lithium metal anode. A lithium thin film, synthesized by vacuum evaporation, was inserted between the lithium and electrolyte. The lithium thin film aided reversible Li dissolution and deposition. This solid 
state battery achieved a discharge capacity of $900 \mathrm{mAh} / \mathrm{g}$ sulfur after 20 cycles, but at the low rate of $0.03 C^{48,56}$

\subsubsection{Conclusions}

Lithium sulfur batteries are gaining interest as the next high energy density battery. This section provided a brief sampling of the current and past research in this fast-growing field. Further research into the retention of the polysulfides near the cathode and the prevention of parasitic reactions between the polysulfides and lithium anode is required. New passivation techniques, cathodes, and alternative anodes are needed to help increase the cycle life of the lithium-sulfur battery. Lastly, a better understanding of the polysulfide shuttle and the reaction mechanism of the reduction of sulfur will aid in these developments.

This work will focus on addressing the high solubility and mobility of polysulfides in electrolyte as well as chemical side reactions. Insight into the mechanism of the sulfur redox reaction can be gained by a better understanding of polysulfide speciation including at what state of charge a certain polysulfide species appears, where it is located in the cell with respect to the electrode, and what the speciation is when the cell is at equilibrium. In situ and ex situ characterization techniques, including Raman spectroscopy, can provide this information, which can potentially aid in methods to suppress the polysulfide dissolution and shuttle.

\subsection{Characterization of Lithium Polysulfides}

\subsubsection{Characterization Techniques}

Many in situ and ex situ characterization techniques have been used to study the cathode, anode, separator, and electrolyte of lithium sulfur batteries. Table 2 lists a brief 
summary of techniques used in the literature to characterize Li-S batteries along with their strengths and limitations. In addition to this table, techniques such as scanning electron microscopy, transmission electron microscopy, x-ray microscopy, and atomic force microscopy have been used to study the structure and morphology of electrodes. ${ }^{15}$ More detail will be given on the major techniques used in studying solvated polysulfides.

Table 2: Summary of some of the major characterization techniques used to study lithium sulfur batteries.

\begin{tabular}{|c|c|c|c|}
\hline Technique & Strengths & Limitations & Lit \\
\hline $\mathrm{UV}-\mathrm{V}$ is & $\begin{array}{l}\text { Quantitative, polysulfides strongly } \\
\text { absorb UV }\end{array}$ & $\begin{array}{l}\text { Liquids only, not spatially } \\
\text { specific }\end{array}$ & $\begin{array}{l}19,21, \\
57\end{array}$ \\
\hline HPLC & $\begin{array}{l}\text { Potential to separate polysulfides } \\
\text { based on chain length }\end{array}$ & $\begin{array}{l}\text { Requires different solvents to } \\
\text { separate the polysulfides }\end{array}$ & 21,58 \\
\hline $\begin{array}{l}\text { XANES, } \\
\text { XAS }\end{array}$ & $\begin{array}{l}\text { Information on local electronic } \\
\text { structure, oxidation state, atomic } \\
\text { coordination. Can differentiate } \\
\text { between solid and solvated } \\
\text { polysulfides and see polysulfide } \\
\text { distribution }\end{array}$ & $\begin{array}{l}\text { Difficult to identify varying } \\
\text { lithium polysulfides due to } \\
\text { lack of standards }\end{array}$ & $\begin{array}{l}46,59- \\
62\end{array}$ \\
\hline NMR & $\begin{array}{l}\text { Li NMR can differentiate between } \\
\text { Li nuclei in different environments: } \\
\text { Solids vs. liquids }\end{array}$ & $\begin{array}{l}\text { Convoluted spectra due to } \\
\text { peak overlap making data } \\
\text { analysis difficult }\end{array}$ & $\begin{array}{l}61,63 \\
64\end{array}$ \\
\hline Raman & $\begin{array}{l}\text { Liquids and solids. Good spatial } \\
\text { resolution and differentiation } \\
\text { between polysulfides }\end{array}$ & $\begin{array}{l}\text { Convoluted spectra due to } \\
\text { peak overlap. Lack of } \\
\text { standards }\end{array}$ & $\begin{array}{l}39,65- \\
67\end{array}$ \\
\hline XRD & $\begin{array}{l}\text { Crystalline vs. amorphous structure. } \\
\text { Ability to look at anode passivation } \\
\text { and solid formation on the cathode. }\end{array}$ & Solids only & $68-70$ \\
\hline FTIR & $\begin{array}{l}\text { Solids and liquids. Identification of } \\
\text { functional groups. Study of anode } \\
\text { passivation. }\end{array}$ & $\begin{array}{l}\text { Convoluted spectra with } \\
\text { complex solutions }\end{array}$ & 71 \\
\hline XPS & $\begin{array}{l}\text { Surface characterization including } \\
\text { anode passivation }\end{array}$ & $\begin{array}{l}\text { Solids only. Requires } \\
\text { ultrahigh vacuum }\end{array}$ & 72 \\
\hline
\end{tabular}

Ultraviolet-visible (UV-Vis) spectroscopy has been used to determine the concentration of various polysulfides in solution. Zou and Lu used operando UV-Vis to follow the time evolution during cycling of polysulfide species in various electrolytes. ${ }^{19}$ From this they conjectured possible $\mathrm{S}_{8}$ reduction mechanisms. Ex situ UV-Vis experiments can also provide information on the adsorptive characteristics of polysulfides to high 
surface area carbons as done by Jozwiuk et al. ${ }^{57}$ Barchasz et al. used a combination of ex situ high performance liquid chromatography (HPLC) and UV-Vis to discuss disproportionation reactions and the reduction of $\mathrm{S}_{8}{ }^{21}$

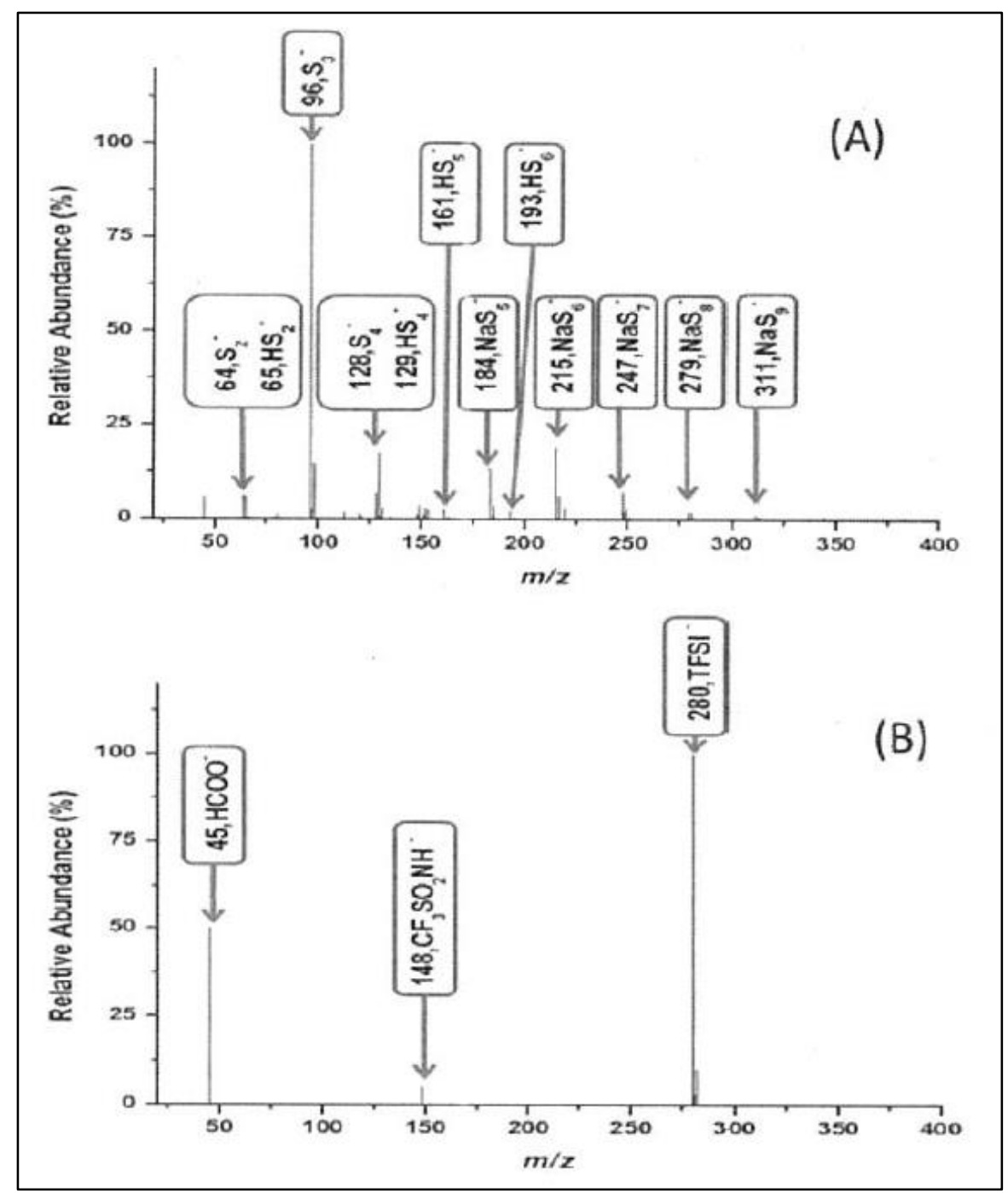

Figure 7: A.) (-) ESI/MS spectra of $\mathrm{Na}_{2} \mathrm{~S}$ and $\mathrm{S}_{8}$ in DME, molar ratio of $\mathrm{Na}_{2} \mathrm{~S}: \mathrm{S}$ is 1:3 through direction infusion. B.) (-)ESI/MS spectrum of electrolyte sample from a discharged Li-S battery by HPLC (-) ESI/MS ${ }^{58}$

HPLC has been used in conjunction with electron spray ionization (ESI) mass spectroscopy to study derivatized polysulfides removed from a lithium sulfur cell. ${ }^{58}$ The direct injection of sodium polysulfide standards (in solvent without salt) into an ESI-mass spectrometer was also looked at during this study. The results are shown in Figure 7. The 
LiTFSI signal overwhelms the mass spectrometer and no polysulfide peaks are seen. The use of HPLC requires the use of polysulfides in varying polar and nonpolar solvents to achieve any separation, so it must be noted that the speciation almost certainly changes from that seen in electrolyte.

X-ray absorption spectroscopy (XAS) and x-ray absorption near edge structure (XANES) spectroscopy have been popular characterization techniques in the Li-S literature for their ability to differentiate between polysulfide oxidation states. Gao et al. used in situ XAS to show that carbonate based electrolytes chemically react with solvated polysulfide species leading to poor battery performance. ${ }^{46}$ Cuisiner et al. studied polysulfide speciation using in situ XANES along with solid polysulfide reference standards. ${ }^{59}$ They were able to study the $\mathrm{S}_{8}$ and $\mathrm{Li}_{2} \mathrm{~S}$ dissolution and deposition during cycling as well as provide evidence for the initial stepwise reduction of $\mathrm{S}_{8}$ to $\mathrm{Li}_{2} \mathrm{~S}_{6}$ and $\mathrm{Li}_{2} \mathrm{~S}_{4}$.

Work from the same group used in situ Li NMR to distinguish between solvated and precipitated polysulfides. ${ }^{63}$ This analysis provided insight into the polysulfide shuttle that occurs despite the presence of $\mathrm{LiNO}_{3}$, which impedes, but does not stop the process. A greater quantity of solid $\mathrm{Li}_{2} \mathrm{~S}$ precipitate was observed on the lithium anode over the cathode after cycling; this result verifies the presence of the polysulfide shuttle.

The last major technique used to study solvated polysulfides is Raman spectroscopy. Raman spectroscopy was chosen for the present work because it can be used to gain information from both the solid and liquid states. It also has good spatial resolution allowing spectra to be obtained from a specific location relative to the electrodes. Lastly, polysulfides are highly Raman active, although there is some peak convolution due to peak overlap. 


\subsubsection{Polysulfide Standards}

Most characterization techniques used to analyze Li-S batteries suffer from a lack of lithium polysulfide standards to compare spectra peaks to. It is difficult, if not impossible, to isolate a single polysulfide chain length in solution due to disproportionation reactions and rapid equilbirum. ${ }^{39,58,59}$

Due to the lack of lithium polysulfide reference materials, many have researched ways to synthesize standards. Rauh et al. studied ways to form lithium polysulfides in various aprotic solvents and studied the resulting solutions using UV-Vis spectroscopy. ${ }^{73}$ The two chemical methods explored included the chemical reaction of $\mathrm{S}_{8}$ solid and lithium metal (Equation 7) and the reaction of $\mathrm{S}_{8}$ and $\mathrm{Li}_{2} \mathrm{~S}$ (Equation 8).

$$
\begin{aligned}
& 2 L i+\frac{n}{8} S_{8} \rightarrow L i_{2} S_{n} \\
& L i_{2} S+\frac{(n-1)}{8} S_{8} \rightarrow L i_{2} S_{n}
\end{aligned}
$$

The reaction of $\mathrm{Li}_{2} \mathrm{~S}$ and $\mathrm{S}_{8}$ is faster and more easily controlled than Equation 7 and has been used as a standard for a variety of characterization techniques. ${ }^{39,58}$ Despite the appearance of chemically synthesized lithium polysulfides as standards, there does not seem to be a standardized reaction time. The stability of the lithium polysulfides are also unknown.

Hagen et al. chemically synthesized polysulfide standards and analyzed them using Raman. The standards were sealed under air and the $\mathrm{S}_{3}$ - radical peak was the only intense polysulfide peak observed. ${ }^{39}$

Cuisinier et al. did have some success in isolating $\mathrm{Li}_{2} \mathrm{~S}_{6}$ as a solid, however the other chain lengths were found to be unstable. Upon re-solvating the $\mathrm{Li}_{2} \mathrm{~S}_{6}$ reference, a mixture of polysulfides was observed. ${ }^{59}$ 


\subsection{Confocal Raman Microscopy}

Confocal Raman microscopy couples a Raman spectrometer with an optical microscope. Raman is a popular characterization method and is used in a wide range of fields from biology to physics. It has applications in space, medicine, and biology to specify chemical substances, determine dynamics of structural changes, and identify the signals of various diseases. The pairing of confocal microscopy with Raman spectroscopy has allowed for chemical mapping and imaging with a single instrument. ${ }^{74}$

\subsubsection{Confocal Microscopy}

A combination of concave and convex lenses are used in objectives and microscopes in order to achieve achromatic performance to magnify a sample. Confocal microscopes use a point light source, typically a laser, that is detected through an aperture or pinhole. Only light from the point source will be seen by the detector through the pinhole. The spot size is determined by the light wavelength, $\lambda .^{74}$ There are several advantages to confocal over conventional microscopes. Confocal microscopes have the ability to adjust the analysis area in the $\mathrm{XY}$ and $\mathrm{Z}$ directions, allowing for the formation of a 3D image by changing the distance of the sample from the objective. Optical cross sections can be sampled without physically cutting the specimen. Detection through the aperture reduces the scattering of light and increases the image contrast. The lateral resolution is also enhanced by a factor of $\sqrt{2}$ when an appropriate pinhole size is chosen. ${ }^{74}$

The numerical aperture (NA) is important because it, along with wavelength, determines the resolution of the microscope. NA is defined in Equation 9. It is dependent on one half of the acceptance angle, $\theta \cdot{ }^{74}$ The acceptance angle is half the angle of the cone 
of light that can possibly pass through the objective. The refractive index, $\mathrm{n}$, is based on the material the light is traveling through, $n=1$ in air.

$$
N A=n \sin \theta
$$

The larger the NA, the smaller the diffraction limit and the greater the resolution. This can be seen from Abbe diffraction limit (Equation 10).

$$
d=\frac{0.61 \lambda}{N A}
$$

The light spot diameter (d) is directly proportional to the wavelength divided by the numerical aperture and is indicative of the smallest feature that can be resolved. Thus it is important to note the objective (magnification and NA), wavelength, and detector used in experiments.

\subsubsection{Raman Spectroscopy}

Raman is a vibrational spectroscopy technique based on the inelastic scattering of

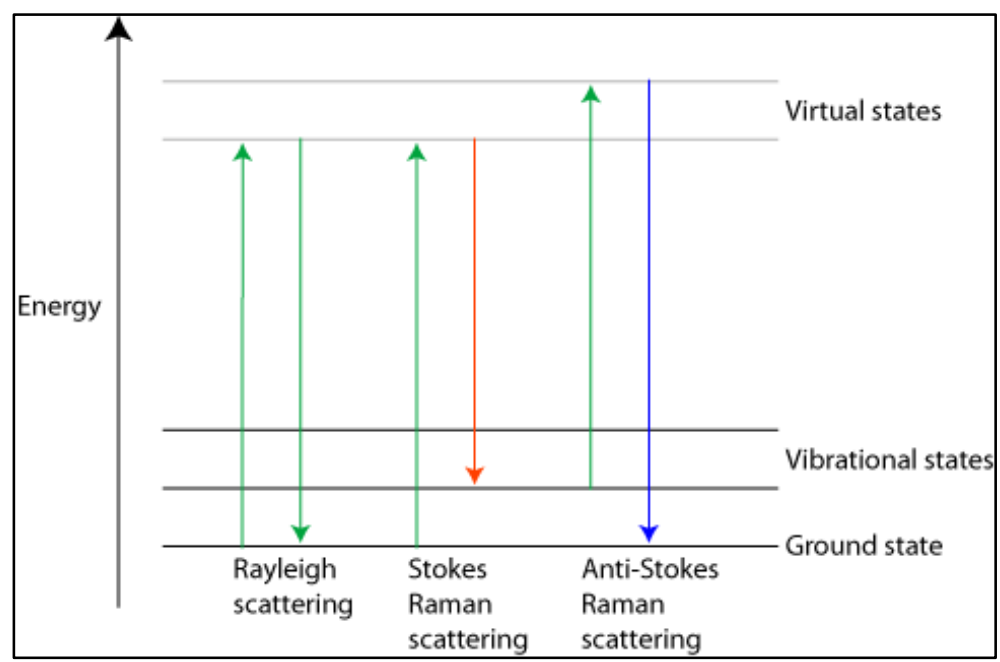

Figure 8: Jablonski Diagram depicting Rayleigh, Stokes, and AntiStokes scattering. ${ }^{75}$ light. There are three types of light scattering. First, is Rayleigh, elastic light scattering. It is present when the polarizability of the molecule is at equilibrium and is always nonzero when an external electric field is applied; it has the same frequency as the incident light. The second two types of light scattering are inelastic and represent a shift away from polarizability equilibrium. Stokes scattering, scatters light with a lower energy than the 
excitation source, resulting in a final state at higher energy than the ground state. AntiStokes scattering, scatters light at a higher energy than the incident light. The differences between Rayleigh, Stokes, and Anti-Stokes scattering can be seen in Figure $8 .^{74}$ Stokes Raman scattering is what typically gives rise to a Raman spectrum.

Raman spectroscopy compliments infrared (IR) spectroscopy because vibrations with weak or nonexistent IR signals may have strong Raman signals, and vice versa. This contrast is due to a difference in selection rules between the two spectroscopies. IR is also a vibrational spectroscopy, but it looks at light absorption rather than light scattering. Thus, IR measures a change in permanent dipole moment as a vibrational motion occurs, instead of a change in polarizability as the motion occurs. Therefore, symmetrical vibrations can be seen using Raman, but not IR because there is no change in permanent dipole moment.

One major disadvantage to Raman is that signals are generally very weak. Two main approaches have been developed to help enhance the Raman signal: resonance Raman scattering and surface-enhanced Raman scattering. These methods attempt to increase the square of the polarizability and electric field, which are directly proportional to the intensity of inelastic, scattered light as seen in Equation $11 .{ }^{74}$

$$
I_{\text {Stokes }} \propto\left(\frac{\partial \alpha}{\partial q}\right)_{q_{0}}^{2}\left(\omega_{0}-\omega_{q}\right)^{4} E_{0}^{2}
$$

Where $\alpha$ is the polarizability, $\mathrm{q}$ is the $\mathrm{q}^{\text {th }}$ normal coordinate, $\left(\omega_{0}-\omega_{q}\right)$ is the frequency of the scattered light, and $E_{0}$ is the external electric field amplitude of the incident light. The two parameters that can be varied experimentally to change the intensity 
are $\omega_{0}$ and $E_{0}$ which correspond to adjustments in the laser frequency and laser power respectively. $^{74}$

The already weak Raman signal is further reduced when focused with confocal microscopy. While the signal of interest is decreased, confocal focus also reduces fluorescence which can be useful when using Raman. Fluorescence often overwhelms the signal of interest because it is usually a more efficient relaxation method than inelastic scattering. ${ }^{76}$ Due to weak signals, the Raman spectrometer settings, such as laser wavelength, laser power, location within sample, and integration time are paramount to obtaining successful spectra.

The wavelength contributes to the determination of spot size (Equation 10). Wavelengths between $400 \mathrm{~nm}$ and $900 \mathrm{~nm}$ are often used. Wavelengths below $400 \mathrm{~nm}$ provide stronger Raman scattering, but it is difficult to find an objective that will work in this range. As the wavelength increases, the fluorescence also increases. ${ }^{74}$

The excitation power of the laser is directly proportional to the Raman scattering intensity. A higher power can yield a better spectrum; however, a higher value can also damage the sample. An acceptable power setting depends on the properties of the material and can vary between a few microwatts and hundreds of milliwatts. ${ }^{74}$

Since the Raman signal is weak, taking averages of spectra can help separate the significant signals from noise. Integration time is the period of time over which the detector collects photons before the data are processed. The number of accumulations specifies how many spectra will be taken. Often all accumulations are averaged to create a single spectrum. Increasing the number of accumulations and the integration time will provide a clearer spectrum; however, it also increases the experiment's duration. 
The invention of the charge-coupled device (CCD) camera greatly reduced Raman testing times. The CCD camera allows for line scanning rather than point scanning as was done by photomultiplier tubes (PMTs). PMTs were also only sensitive for a small range of wavelengths; CCDs have a higher quantum efficiency for a wider range of wavelengths. ${ }^{74}$

Before the signal reaches the $\mathrm{CCD}$, the light goes through a grating. The grating diffracts the various incoming wavelengths of light to different regions of the CCD. A higher density grating means there are more diffraction lines and a higher spectral dispersion and resolution can be achieved. ${ }^{76}$

To enable experiments to be reproduced, the following should be reported: Raman system used, grating, resolution, laser wavelength, laser power, objective, integration time, and the number of accumulations.

\subsubsection{Raman to Analyze Lithium Sulfur Batteries}

The behavior of dissolved polysulfides during the cycling of $\mathrm{Li}-\mathrm{S}$ batteries is important to understanding the mechanisms of capacity fade, self-discharge, and other relevant battery metrics. The use of in situ Raman can reveal the polysulfide speciation as a function of state of charge. Particular attention is given to changes in peak intensity, width, and position.

Polysulfide anions have been studied before using Raman spectroscopy and have been shown to have strong Raman signals between 100 and $600 \mathrm{~cm}^{-1} \cdot{ }^{67}$ Janz et al. demonstrated the Raman activity of polysulfides through the Raman characterization of polycrystalline polysulfides, including inorganic potassium, ${ }^{77}$ barium, ${ }^{78}$ and sodium ${ }^{79}$ polysulfides. Each of these inorganic polysulfides had Raman peaks between 20 and 600 
$\mathrm{cm}^{-1}$. El Jaroudi also studied the effect of the coordinating cation in solid polysulfides by looking at sodium, potassium and rubidium. ${ }^{80,81}$ The change in coordinating cation changed the bond length of the sulfur- sulfur bonds.

Polysulfides have also been studied in various solvent systems using Raman. ${ }^{82-85}$ Dubois et al. studied polysulfide speciation in liquid ammonia using Raman. ${ }^{85} \mathrm{Li}_{2} \mathrm{~S}_{4}$ solutions were generated by dissolving stoichiometric amounts of sulfur and lithium sulfide in ammonia. The $\mathrm{S}_{3}{ }^{-}$radical peak was present at $535 \mathrm{~cm}^{-1}$, but was very weak. At room temperature, the other polysulfide peaks occurred at 490m, 472m, 430vs, 236vw, and 188vs (letters symbolize relative strength of peak intensities, with vs indicating very strong, $\mathrm{m}$ indicating moderate, and $\mathrm{vw}$ indicating very weak). The $\mathrm{S}_{3}{ }^{-}$radical was found to be in equilibrium with $\mathrm{S}_{6}{ }^{2-}$ and $\mathrm{S}_{4}{ }^{2-}$. Other radicals were not observed. The temperature dependence of the speciation was also studied and it was shown that as temperature decreased, the $535 \mathrm{~cm}^{-1}$ peak was no longer present. When the same experiment was done with $\mathrm{Na}_{2} \mathrm{~S}_{4}$, different peaks were observed at 535vs, 485m, 469m, 437vs, and $191 \mathrm{vs}$.

Work done by Yeon et al ${ }^{86}$ used ex situ Raman to study the change in the cathode with cycling in TEGDME and DOL electrolytes. They were able to see $\mathrm{Li}_{2} \mathrm{~S}$ at the fully discharged state. They also observed the $\mathrm{S}_{3}{ }^{-}$radical ex situ and concluded that it is fairly stable.

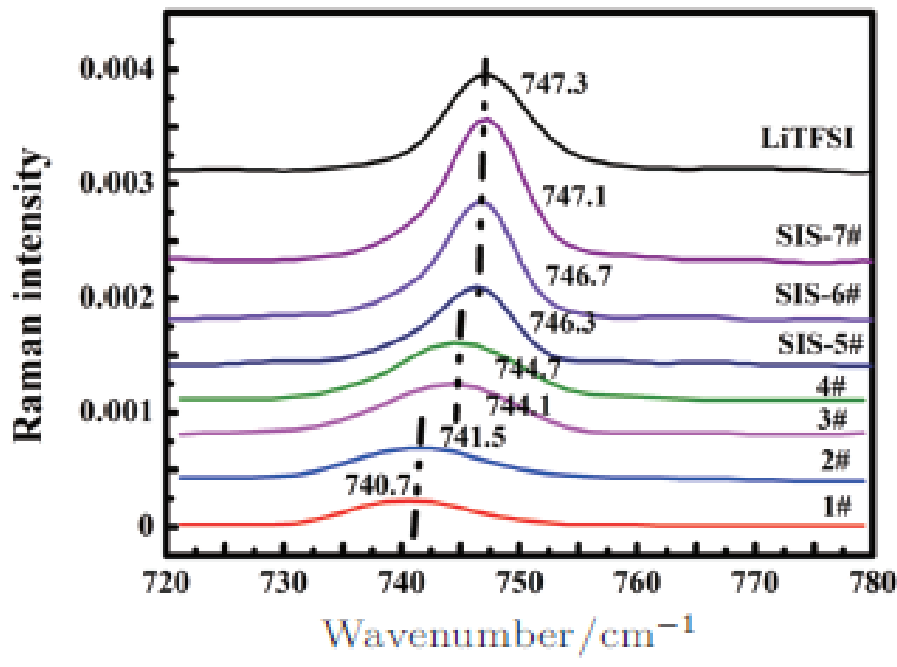

Figure 9: Figure from Suo et al ${ }^{66}$ showing the effect of LiTFSI concentration variation in 1:1 DME:DOL electrolyte on Raman spectrum. 
Raman has also been used to study common Li-S electrolytes, without polysulfides present. Suo et al. examined how the Raman spectrum changed when the concentration of LiTFSI in a 1:1 v/v solvent of dimethoxyethane (DME) and 1,3-dioxolane

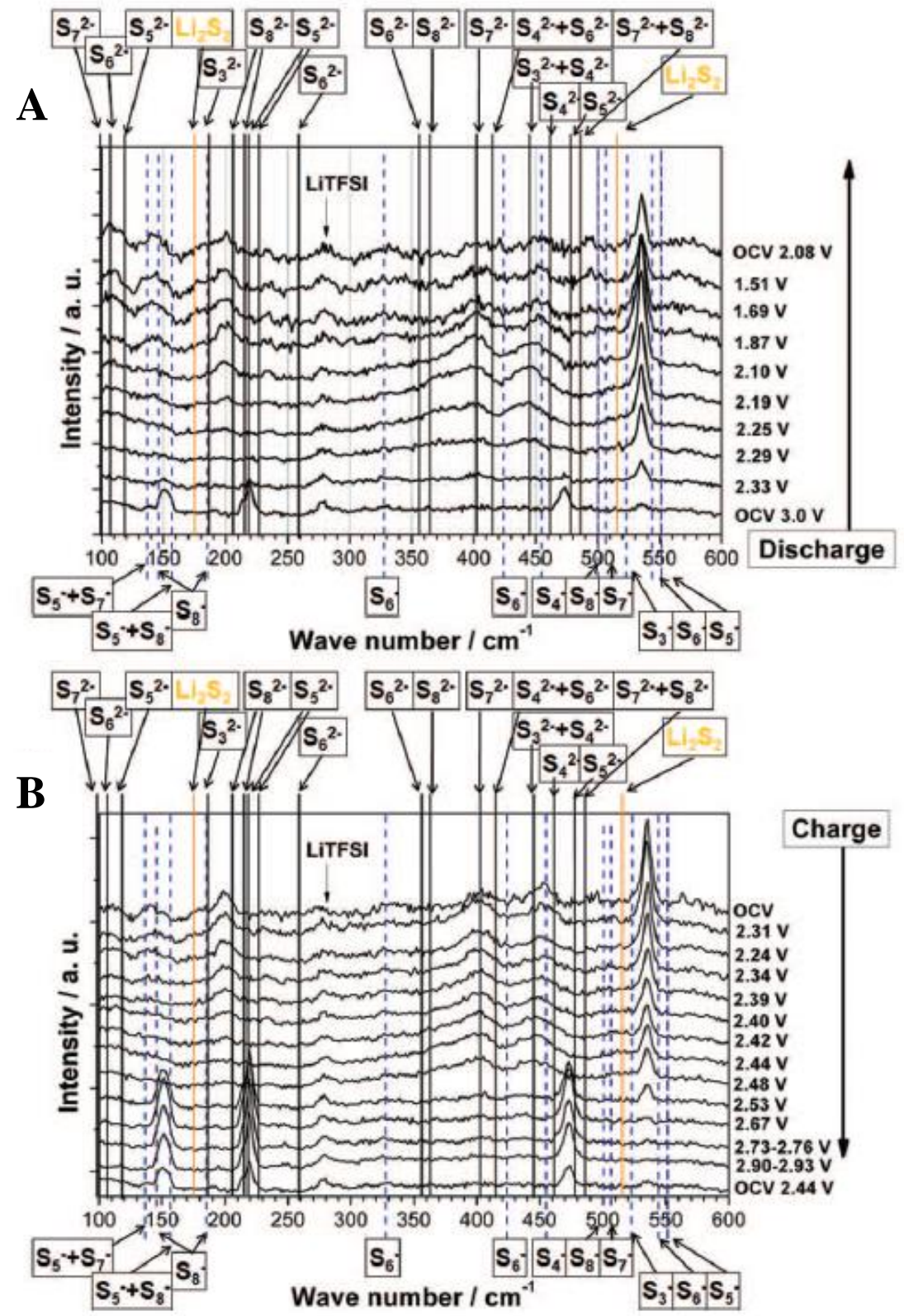

Figure 10: Raman spectra during the discharge (A) and charge (B) of a lithium sulfur in situ cell. The dotted lines are monoanions based on DFT calculations and literature values gathered by Hagen et al. ${ }^{39}$ 
(DOL) was varied ${ }^{66}$ As shown in Figure 9, varying the LiTFSI concentration can shift its most intense peak by $7 \mathrm{~cm}^{-1}$, from $747.3 \mathrm{~cm}^{-1}$ (pure LiTFSI) to $740.7 \mathrm{~cm}^{-1}(1 \mathrm{M}$ LiTFSI).

All these studies demonstrate that system properties, such as concentration, solvent, coordinating cation, state (liquid vs. solid), and temperature can greatly affect peak positions and intensities.

Two in situ Raman studies of polysulfide speciation in Li-S batteries have been published in the literature.

In 2013, Hagen et al. used density functional theory (DFT) to calculate theoretical vibrational modes of lithium polysulfides as well as gather an extensive summary of polysulfide peaks seen in the literature. ${ }^{39}$ The DFT calculations and literature values were then compared to experimental results from in situ Raman spectroscopy. The Raman spectra taken during discharge are shown in Figure 10. Full oxidation back to $\mathrm{S}_{8}$ was observed upon recharging. It was also seen that both mono-anions and di-anions of the polysulfides were present at all states of charge. Chemically synthesized lithium polysulfide standards were made and sealed under air to compare to the in situ spectra. The $\mathrm{S}_{3}{ }^{-}$radical was observed in the standards, but not other polysulfide peaks. The experiments in this paper utilized a DME-DOL solvent system with LiTFSI and $\mathrm{LiNO}_{3}$.

In 2015, Wu et al. performed a similar study of polysulfides as a function of state of charge. Raman was supplemented with cyclic voltammetry (CV) experiments. The intensities of the different polysulfide signals were tracked as a function of state of charge (Figure 11). 


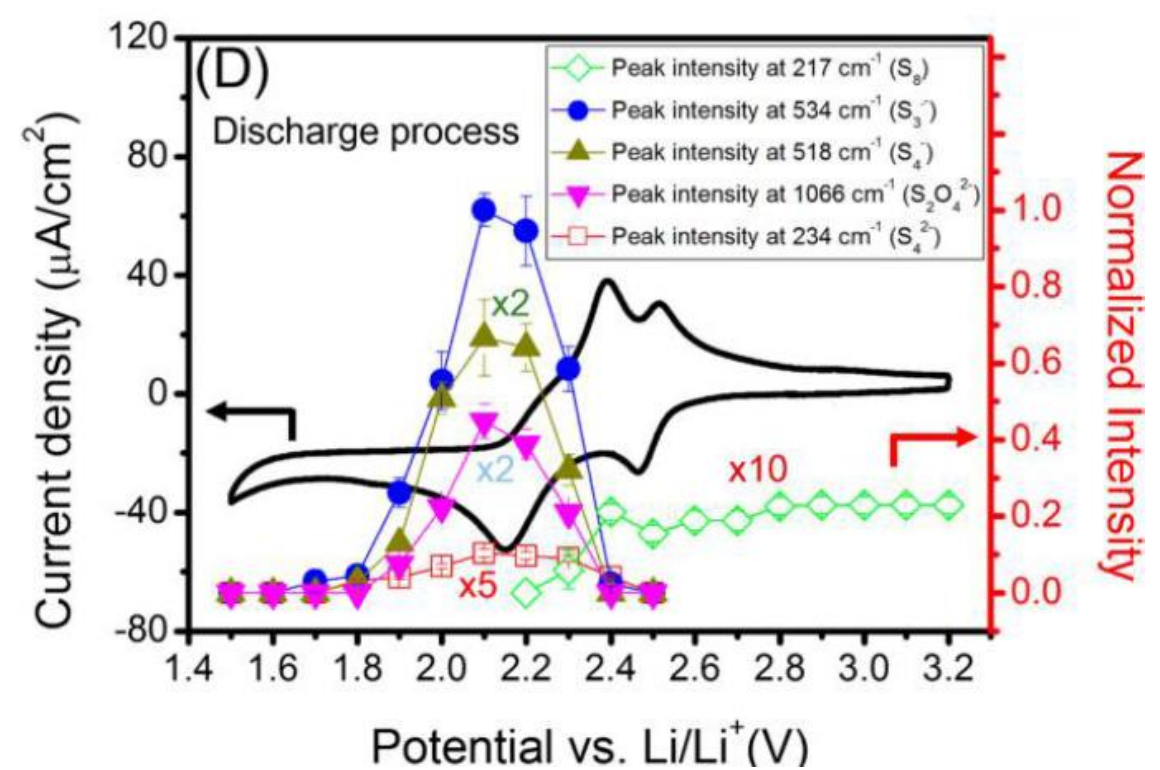

Figure 11: Figure from Wu et al. depicting a cyclic voltammogram of a Li$\mathrm{S}$ cell (black y-axis) and changes in polysulfide peak intensities during discharge (red axis). ${ }^{67}$

$\mathrm{S}_{8}$ decreased in intensity, but was present until $2.2 \mathrm{~V}$. At $2.4 \mathrm{~V}$ the intensity of $\mathrm{S}_{8}$ dropped by $\sim 50 \%$ and the peaks corresponding to polysulfide anions $\mathrm{S}_{4}^{-}, \mathrm{S}_{4}{ }^{2-}$, and $\mathrm{S}_{3}{ }^{-}$begin to increase in intensity. These species disappeared again at $1.8 \mathrm{~V}$. These transitions were substantiated by the CV experiments, which showed reduction and oxidation peaks at similar voltages.

Table 3: Comparison of important parameters for the Wu et al ${ }^{67}$ and Hagen et al.$^{39}$ papers

\begin{tabular}{|c|c|c|}
\hline Parameter & Hagen et al. ${ }^{39}$ & Wu et al. ${ }^{67}$ \\
\hline Laser Power $(\mathrm{mW})$ & 20 & Unknown \\
\hline $\begin{array}{l}\text { Laser Wavelength } \\
(\mathbf{n m})\end{array}$ & $\mathrm{HeNe}, 632.8$ & $\mathrm{HeNe}, 632.8$ \\
\hline Objective & $100 x$ & Unknown \\
\hline Numerical Aperture & Unknown & Unknown \\
\hline $\begin{array}{l}\text { Integration time } \\
\text { (sec) }\end{array}$ & Unknown & $75-150$ \\
\hline Location in cell & $\begin{array}{l}\text { Near electrode surface to see } \\
\text { solvated and solid species }\end{array}$ & Unknown \\
\hline Electrolyte & $\begin{array}{l}200 \mu \text { L DME: DOL (2:1 v/v), } \\
0.7 \text { M LiTFSI, } 0.25 \text { M LiNO3 }\end{array}$ & $\begin{array}{l}20 \mathrm{~mL} \text { TEGDME: DOL } \\
(1: 1 \mathrm{v} / \mathrm{v}), 1 \mathrm{M} \text { LiTFSI }\end{array}$ \\
\hline $\begin{array}{l}\text { E/S Ratio } \\
(\mathrm{mL} / \text { gram S) }\end{array}$ & 45 & Unknown \\
\hline
\end{tabular}


A comparison of vital information from these papers is summarized in Table 3. Both papers fail to mention several important parameters required to reproduce their work. In particular $\mathrm{Wu}$ et al. did not mention their $\mathrm{E} / \mathrm{S}$ ratio, however since $20 \mathrm{~mL}$ was used with a standard 60:30:10 sulfur: Super P: PVDF cathode, the ratio is assumed to be around 100 times that of Hagen et al.

\subsection{Research Motivation}

The high solubility and mobility of polysulfides in common Li-S battery electrolytes, along with chemical side reactions, create a complex equilibrium of polysulfide species and have a detrimental effect on battery performance. To gain a better understanding of the Li-S battery chemistry, Raman microscopy was used to track polysulfide speciation during the cycling of a Li-S cell.

Both of the in situ Raman studies discussed above used electrochemical cells specially designed for Raman, rather than a standard battery prototype. Wu et al. used $20 \mathrm{~mL}$ of electrolyte. ${ }^{67}$ The quantity and type of the electrolyte, as well as the cell setup, can greatly affect the polysulfide speciation. ${ }^{40}$ The research reported here attempted to use in situ confocal Raman microscopy to study the polysulfide speciation in lithium sulfur batteries as a function of state of charge and position while in a more realistic cell setup.

The use of chemically synthesized standards has only been studied using Raman when sealed under air as done in the work of Hagen et al. ${ }^{39}$ Additionally, the literature arbitrarily analyzes the polysulfide standards immediately after mixing overnight. A standardized definition of the stability of the polysulfides or when the standards should be analyzed has not been defined. 
Therefore, the current research evaluated the stability of chemically synthesized polysulfide standards and related the resulting Raman peaks to those of an in situ Li-S battery. By providing both a set of oxygen free standards and working with technically relevant $\mathrm{E} / \mathrm{S}$ ratios, a more realistic and accurate accounting of speciation within a cycling Li-S cell was sought. 


\section{Experimental Setup}

\subsection{Raman System and Raman Data Acquisition}

Raman spectra were obtained at room temperature on a WiTec Alpha300M with a back illuminated charge coupled device detector cooled by the Peltier effect to $-60^{\circ} \mathrm{C}$. The grating and accuracy for the system were $600 \mathrm{1} / \mathrm{mm}$ and $\pm 1 \mathrm{~cm}^{-1}$ respectively. A $532 \mathrm{~nm}$ frequency doubled Nd:YAG laser was used for all spectra in this report. A schematic of the Raman system is depicted in Figure 12. A Zeiss EC 'Epiplan' DIC 10x objective with a numerical aperture of 0.25 and working distance of $11 \mathrm{~mm}$ was predominately used. The power, integration time, and number of accumulations were material-dependent. Power

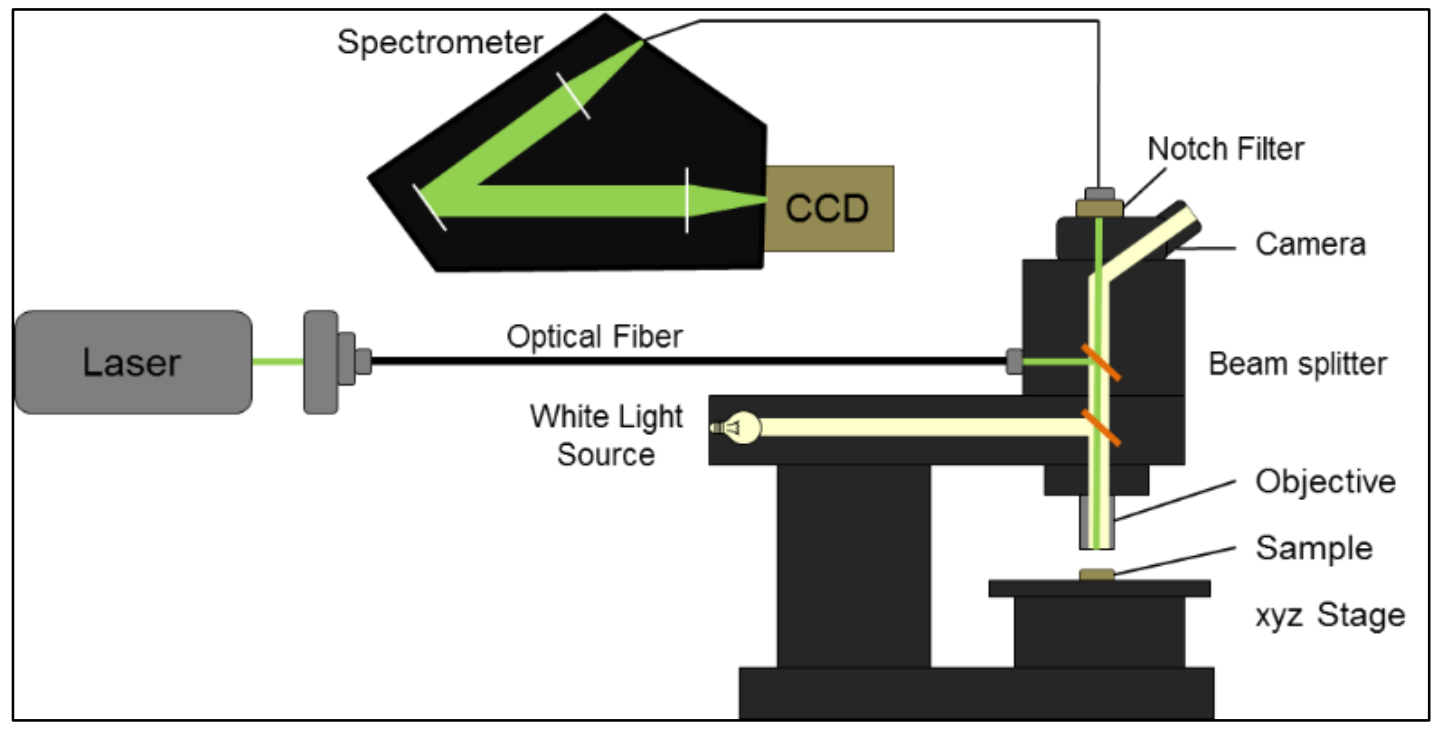

Figure 12: WiTec Alpha300M Raman schematic.

ranged from $0.5 \mathrm{~mW}$ to $8 \mathrm{~mW}$ and the acquisition time ranged from $30-240$ seconds.

The Raman system was calibrated prior to each use with silicon, graphite, and Tylenol@. A Witec calibration MATLAB® program written by Dr. Thomas Beechem from 
Sandia National Laboratories was used to adjust the $\mathrm{x}$-axis of all spectra. An example calibration curve is shown in Figure 13.

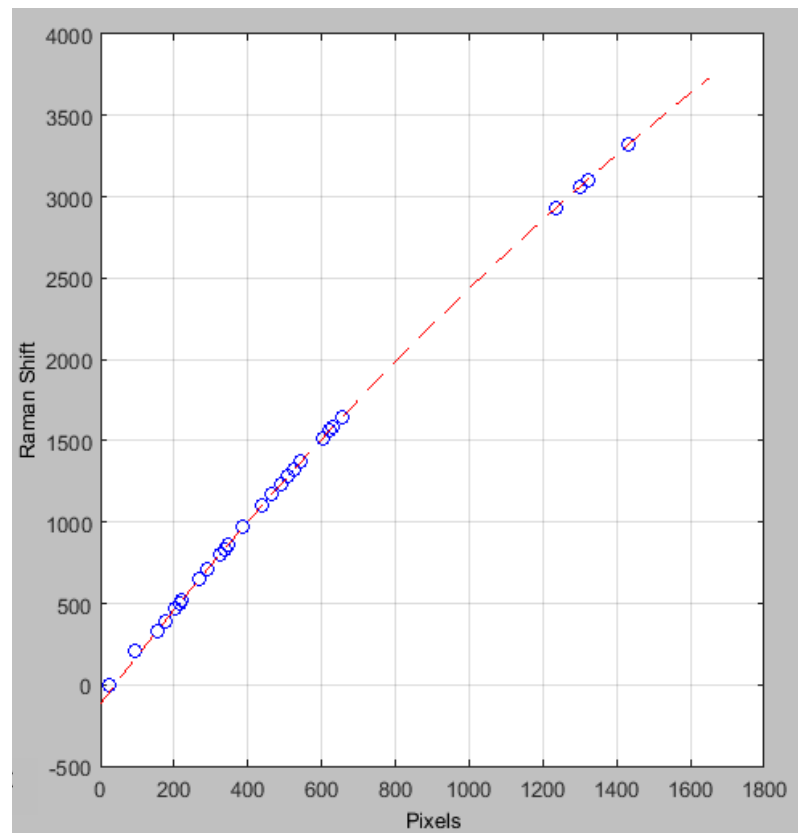

Figure 13: Example Raman calibration curve. Generated by matching peaks from silicon, graphite, and Tylenol.

\subsection{Electrolyte Composition}

The electrolyte used in all experiments was 1:1 1,2-dimethoxyethane (DME): 1,3dioxolane (DOL) with $1 \mathrm{M}$ lithium bis(trifluoromethane)sulfonimide (LiTFSI) and $0.25 \mathrm{M}$ $\mathrm{LiNO}_{3}$. 1,2-dimethoxyethane anhydrous, 99.5\%, inhibitor free and 1,2-dioxolane anhydrous, 99.8\%, containing $~ 75$ ppm BHT as inhibitor were purchased from Sigma Aldrich. $\mathrm{LiNO}_{3}$ was purchased from Alfa Aesar (99.999\%) and from Johnson Matthey Material Technology UK. LiTFSI was purchased from Sigma Aldrich (99.95\% trace metals basis) and Ossila (99.99\% pure). Alumina (Sigma Aldrich, 99.5\%) was activated under vacuum at $150{ }^{\circ} \mathrm{C}$ for 20 hours and used to dry the electrolyte by allowing them to mix overnight. If needed, the activated alumina was then filtered from the electrolyte using HPLC certified GHP Acrodisc ${ }^{\circledR} 25 \mathrm{~mm}$ syringe filters with $0.45 \mu \mathrm{m}$ GHP membranes from Life Sciences. 


\subsection{Raman Polysulfide Standards}

Raman standards were synthesized by mixing stoichiometric ratios of $\mathrm{S}_{8}$ and $\mathrm{Li}_{2} \mathrm{~S}$ together in $5 \mathrm{~mL}$ of full electrolyte, including LiTFSI and $\mathrm{LiNO}_{3}$. This corresponded to $0.012 \pm 0.003 \mathrm{~g} \mathrm{Li} 2 \mathrm{~S}$ for all standards and $0.056 \pm 0.002 \mathrm{~g}, 0.040 \pm 0.002 \mathrm{~g}$, and $0.024 \pm$ $0.002 \mathrm{~g} \mathrm{~S}_{8}$ to theoretically make $50 \mathrm{mM}$ of $\mathrm{Li}_{2} \mathrm{~S}_{8}, \mathrm{Li}_{2} \mathrm{~S}_{6}$, and $\mathrm{Li}_{2} \mathrm{~S}_{4}$ respectively. For simplicity, these standards will be labeled as such even if their speciation does not actually indicate this. The general chemical reaction to form a certain chain length is shown in Equation 12. $\mathrm{S}_{8}$ was purchased from Sigma Aldrich with a purity $\geq 99.5 \%$ and $\mathrm{Li}_{2} \mathrm{~S}$ was purchased from Sigma Aldrich with a purity of $99.98 \%$.

$$
\frac{n-1}{8} S_{8}+L i_{2} S \rightarrow L i_{2} S_{n}
$$

The solutions were mixed in $20 \mathrm{~mL}$ scintillation vials on a hotplate set for $60^{\circ} \mathrm{C}$ and 600 RPM within an argon-filled glovebox with water and oxygen content $<1 \mathrm{ppm}$ and $<$

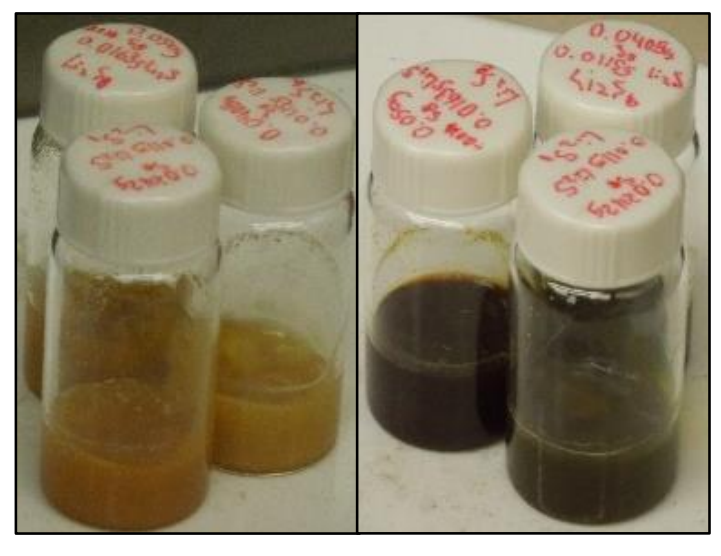

Figure 14: Polysulfide standards at reaction initiation (left) and just prior to removal from hot plate (right).
$10 \mathrm{ppm}$ respectively. Once the reaction was initiated, the standards were mixed for $\sim 15$ hours. Since standards could only be characterized sequentially, the reactions were started sequentially in an attempt to keep timing consistent during the time study of Raman standards. Figure 14 shows the vials at the initiation of the reaction and just prior to removing from the stir plates. The standards $(3 \mathrm{~mL})$ were then moved into Starna quartz cuvettes with silicon-PTFE tape seals. All Raman spectra were obtained within a dry room with a dew point less than $-40{ }^{\circ} \mathrm{C}$. The standards remained sealed under argon and were covered with aluminum foil once removed 
from the glovebox. Raman spectra were obtained 1-2 times daily for 7 days. The cuvettes were stored, covered with aluminum, and kept in an opaque flammables cabinet when not being actively analyzed.

Raman spectra were obtained from the bulk of the solution, $50 \mu \mathrm{m}$ below the solutionargon interface. Due to the absorptivity of the polysulfides, obtaining spectra deeper into the solution was not possible. To ensure there were not surface effects from the quartz cuvette, the cuvettes were not filled to capacity, so that spectra were obtained $0.5 \mathrm{~cm}$ below the quartz surface. 


\subsection{ESI Mass Spectroscopy Polysulfide Standards}

For electrospray ionization (ESI) mass spectroscopy, the standards were synthesized in an argon-filled glovebox with stoichiometric quantities of $\mathrm{S}_{8}$ and $\mathrm{Li}_{2} \mathrm{~S}$ as described previously, but were combined with 1:1 DME:DOL without salt. In an attempt to replicate the work of Zheng et al., $\mathrm{Na}_{2} \mathrm{~S}$ and $\mathrm{S}_{8}$ were also combined in $5 \mathrm{~mL}$ of DME, DOL, acetonitrile (ACN), and 1:1 DME:DOL in proportions of $0.2 \mathrm{mmol}$ and 0.075 mmol respectively. Images of the standards showing variation in color are shown in Figure 15. The standards were then immediately filtered in the dry room to

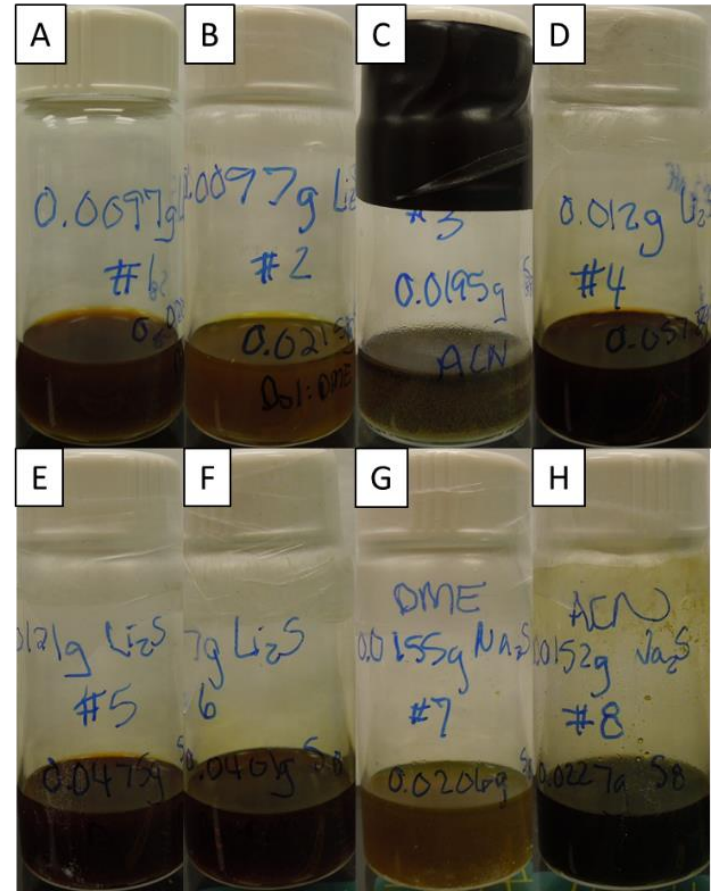

Figure 15: EIS mass spectroscopy polysulfide standards prior to dilution where A.) is $0.2 \mathrm{mmol}$ $\mathrm{Li}_{2} \mathrm{~S}, 0.075 \mathrm{mmol} \mathrm{S}$ in $5 \mathrm{~mL} \mathrm{DME}$, B.) is $0.2 \mathrm{mmol}$ $\mathrm{Li}_{2} \mathrm{~S}, 0.075 \mathrm{mmol} \mathrm{S}_{8}$ in $5 \mathrm{~mL} \mathrm{1:1} \mathrm{DME:} \mathrm{DOL,} \mathrm{C.)}$ is $0.2 \mathrm{mmol} \mathrm{Li}_{2} \mathrm{~S}, 0.075 \mathrm{mmol} \mathrm{S}_{8}$ in ACN, D.) is 50 $\mathrm{mM}$ " $\mathrm{Li}_{2} \mathrm{~S}_{8}$ " in 1:1 DME: DOL, E.) is $50 \mathrm{mM}$ " $\mathrm{Li}_{2} \mathrm{~S}_{6}$ " in 1:1 DME: DOL, F.) is $50 \mathrm{mM}$ " $\mathrm{Li}_{2} \mathrm{~S}_{4}$ " in 1:1 DME: DOL, G.) is $0.2 \mathrm{mmol} \mathrm{Li}_{2} \mathrm{~S}, 0.075 \mathrm{mmol}$ $\mathrm{S}_{8}$ in $5 \mathrm{~mL}$ DME, and $\mathrm{H}$.) is $0.2 \mathrm{mmol} \mathrm{Li}_{2} \mathrm{~S}, 0.075$ $\mathrm{mmol} \mathrm{S}_{8}$ in $5 \mathrm{~mL} \mathrm{ACN}$. remove any unreacted material, diluted

to $2-5 \mu \mathrm{M}$ using 1:1 DME: DOL, and taken to be analyzed via negative mode ESI mass spectroscopy. The settings, including all source parameters, on the ESI mass spectrometer were set to the same
Table 4: ESI mass spectroscopy parameters.

\begin{tabular}{ll} 
Mode & Negative \\
Capillary & $3.50 \mathrm{kV}$ \\
Cone & $3.50 \mathrm{kV}$ \\
Extractor & $5.0 \mathrm{~V}$ \\
RF Lens & $0.1 \mathrm{~V}$ \\
Source Temperature & $90{ }^{\circ} \mathrm{C}$ \\
Desolvation Temperature & $200{ }^{\circ} \mathrm{C}$ \\
Nitrogen Gas Flow For Nebuliser & $500 \mathrm{~L} / \mathrm{hr}$ \\
Nitrogen Gas Flow For Desolvation & $500 \mathrm{~L} / \mathrm{hr}$ \\
m/z Ratio Range & $20-600$ \\
\hline
\end{tabular}


values as in Zheng et al. ${ }^{58}$ but were done on a Xevo G2-XS QTof Quadrupole Time-ofFlight mass spectrometer. The parameters are listed in Table 4.

\subsection{In Situ Raman Cell Design}

\subsubsection{Generation 1}
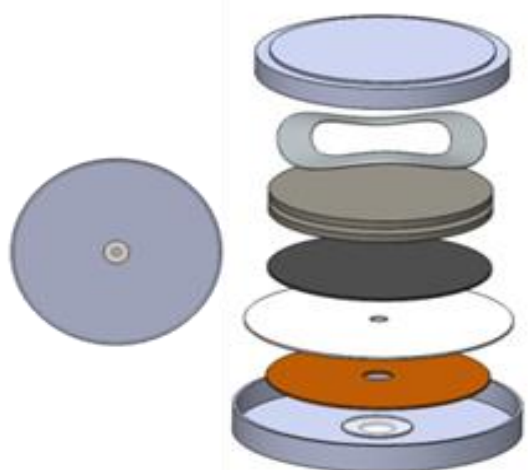

Figure 16: Generation 1 cell schematic. In order from bottom to top is the cathode cup, cover slip, anode, separator, cathode, 2 spacers, a wave spring, and the anode cup.
The first generation of the in situ cell design was a 2032 coin cell with a $2 \mathrm{~mm}$ hole precision punched into the cathode cup. Figure 16 shows the initial cell setup. Starting from what is typically the cathode cup, the cell arrangement was then a $5 \mathrm{~mm}$ wide, $0.15 \mathrm{~mm}$ thick borosilicate glass slip (Warner Instruments) or a $10 \mathrm{~mm}$ wide, $0.1 \mathrm{~mm}$ thick quartz cover slip (UQG Optics), an anode composed of 5/8" diameter, $10 \mu \mathrm{m}$

thick lithium on a $10 \mu \mathrm{m}$ thick copper current collector (Rockwood Lithium), 2 layers of $25 \mu \mathrm{m}$ thick separator (3501 Celgard), a carbon-sulfur cathode, 2 stainless steel spacers, and a stainless steel wave spring. This is inverted from a traditional coin cell arrangement. The anode and separator were precision punched such that the cathode was visible through the cover slip.

Three different variations in the location of the coverslip were studied in an attempt to achieve the best Raman spectra.
Table 5: List of adhesives tested for compatibility with the Li-S system and with the DME: DOL electrolyte.

1. Superchlon in toluene

2. PVDF in NMP

3. SBR/LI133 in water

4. Sylgard 184 silicone elastomer

5. Double/Bubble® 2 part adhesive: extra fast setting

6. Double/Bubble ${ }^{\circledR} 2$ part adhesive: water-clear-transparent

7. Torr Seal@ Low Vapor Pressure Epoxy

8. Loctite® E-30CL Hysol® Epoxy 
This included inside the cathode cup as in Figure 16, on top of the cathode cup outside of the cell, and in both positions.

Prior to assembly, an adhesive was used to secure the cover slip to the stainless steel cathode cup. Several different adhesives were investigated for compatibility with the Li-S system and are summarized in Table 5. 


\subsubsection{Generation 2}

The second generation cell was a commercial in situ Raman cell purchased from MTI Corporation and was only briefly considered. A schematic of the cell design is shown in Figure 17.

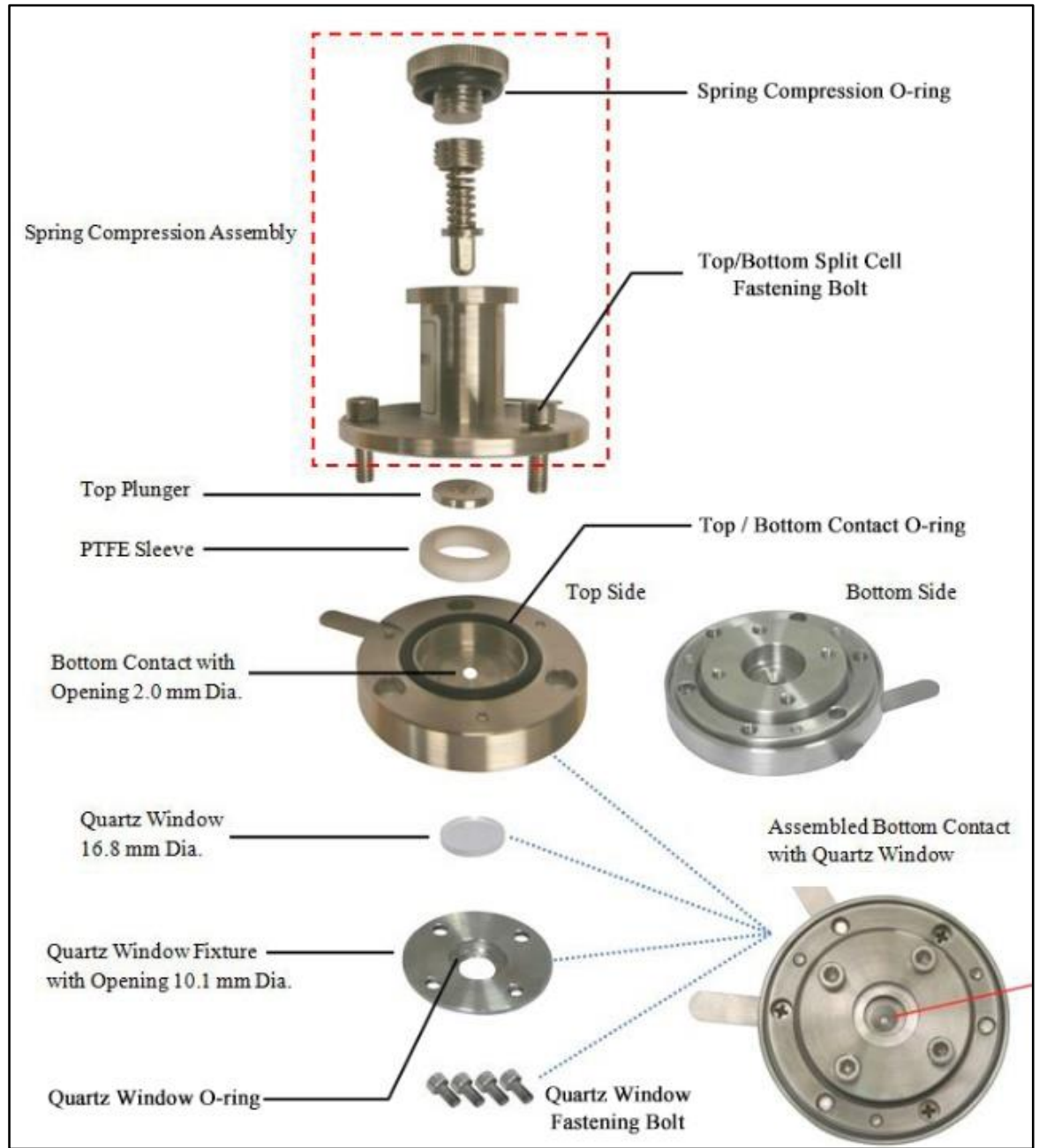

Figure 17: Generation 2 cell schematic of a commercial in situ cell from MTI Corporation. $^{87}$ 


\subsubsection{Generation 3}

The generation 3 cell was a Swagelok PTFE 0.5" T-cell with a quartz viewing window

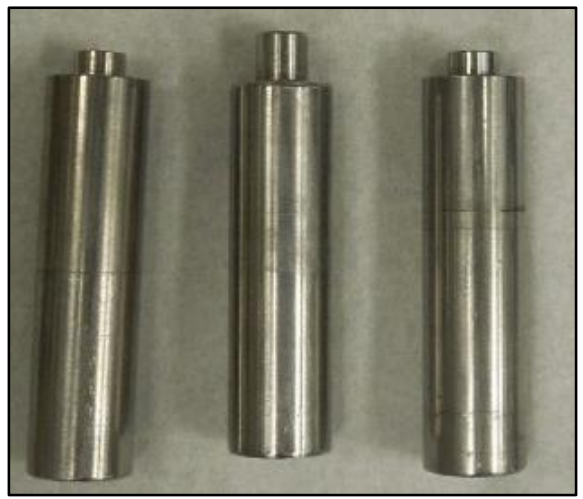

Figure 19: Stainless steel electrode leads.

on one side. There were three iterations on the window seal. Three, 0.5 " diameter stainless steel rods with 0.25 " electrode contacts (see Figure 19) were used as leads to the electrodes. The three rods allowed for the possibility of a three-electrode or two-electrode cell. In all cases, a 0.39" diameter, 25 mil thick

lithium metal (Foote Mineral Corporation high purity Li foil under argon) anode was cold welded to one of the leads with a carbon-sulfur cathode on another lead. The lithium was mechanically abraded to remove surface oxide prior to use. The final lead was left as bare

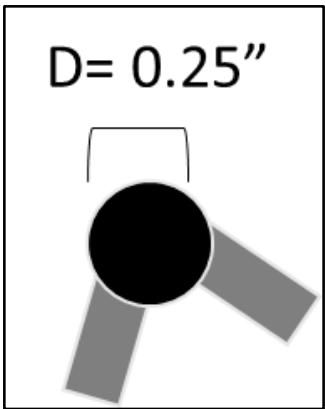

Figure 18: Cathode (black) and tabs (grey) used to attach the cathode to the stainless steel rod leads. stainless steel.

The cathode had a diameter of $0.25 "$ and was hand-cut to have tabs that were then secured to the stainless steel rods with 0.25" PTFE tubing. The tabs were gently cleaned with a knife to remove all active material, so that the only active material was

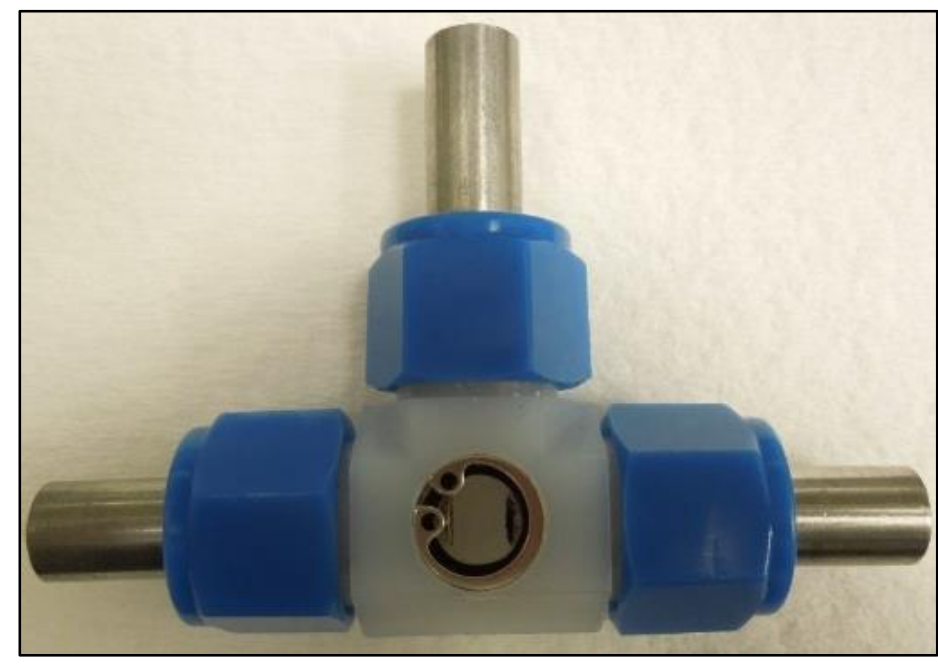

Figure 20: Generation 3A cell schematic. 
in the black region of Figure 18. The electrodes were separated by a distance of $0.8 \mathrm{~mm}$ rather than using a separator.

The T-cell was filled with $2 \mathrm{~mL}$ of electrolyte which corresponds to the very large E/S ratio of $1850 \mathrm{~mL} /$ gram sulfur.

The generation $3 \mathrm{~A}$ cell is depicted in Figure 20. The viewing window was sealed by a \#013 DuPont ${ }^{\mathrm{TM}}$ Kalrez ${ }^{\circledR}$ O-ring and a $15 \mathrm{~mm}$ internal stainless steel retaining ring (McMaster-Carr).
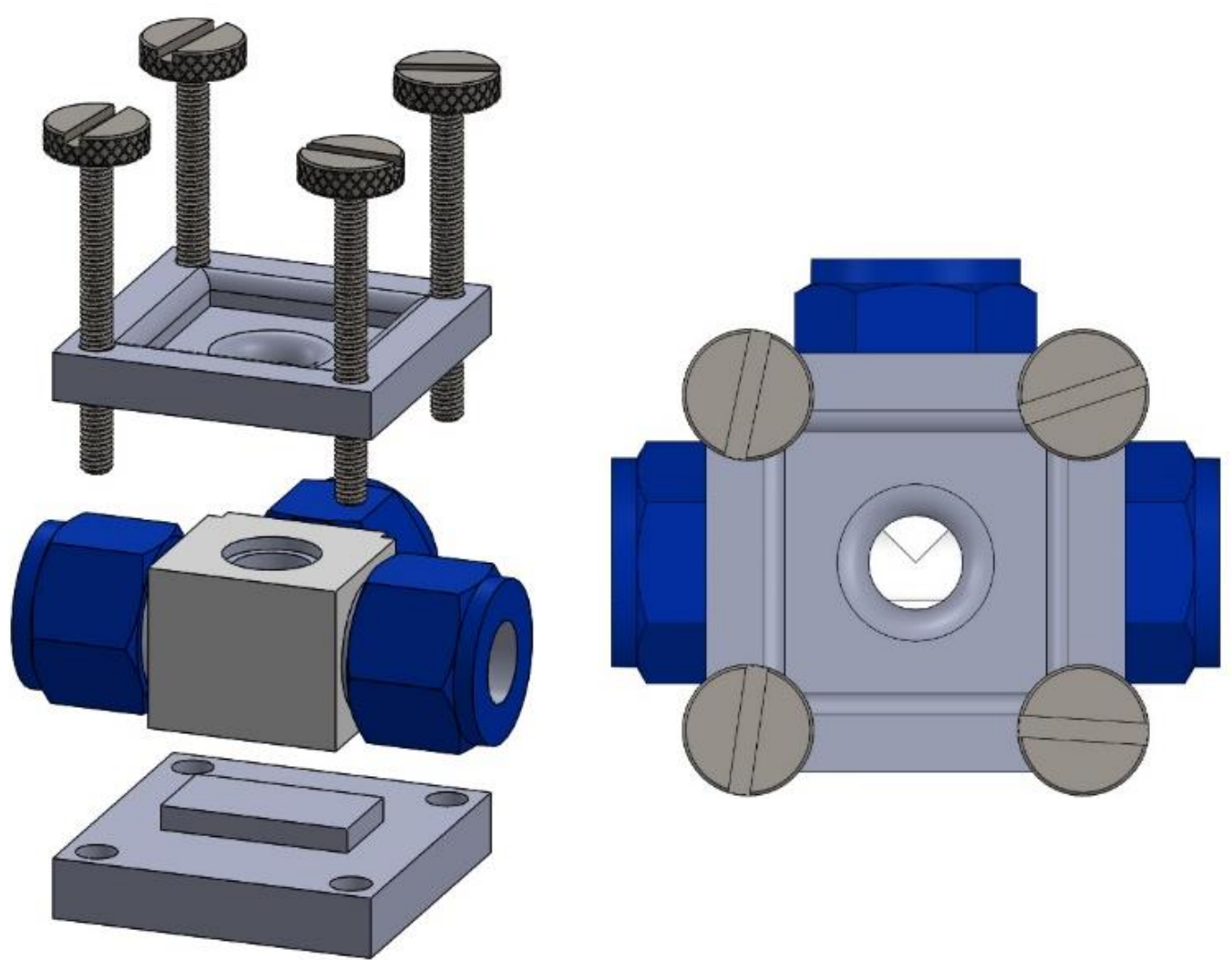

Figure 21: Generation 3B cell schematic.

The generation 3B cell shown in Figure 21. In an attempt to create a better seal, top and bottom plates were printed using a 3D printer and pulled together using knurled thumb screws. 
The final version (generation 3C) of the T-cell shifted back to the more compact design shown in Figure 22. The T-cell was re-machined such that the $2.5 \mathrm{~mm}$ thick quartz window sat above the face of the PTFE tee as seen in Figure 23. A 3D printed plate was then screwed down, pressing down on the window which compressed the O-ring and sealed the T-cell.
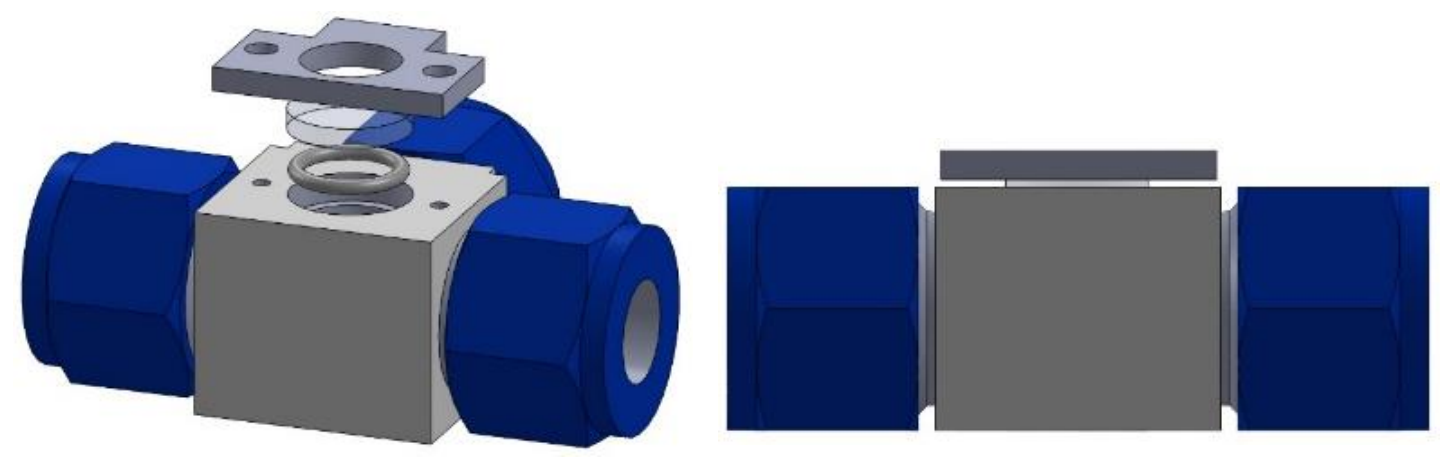

Figure 23: Generation 3C cell schematic: dimetric view (left) and side view (right).

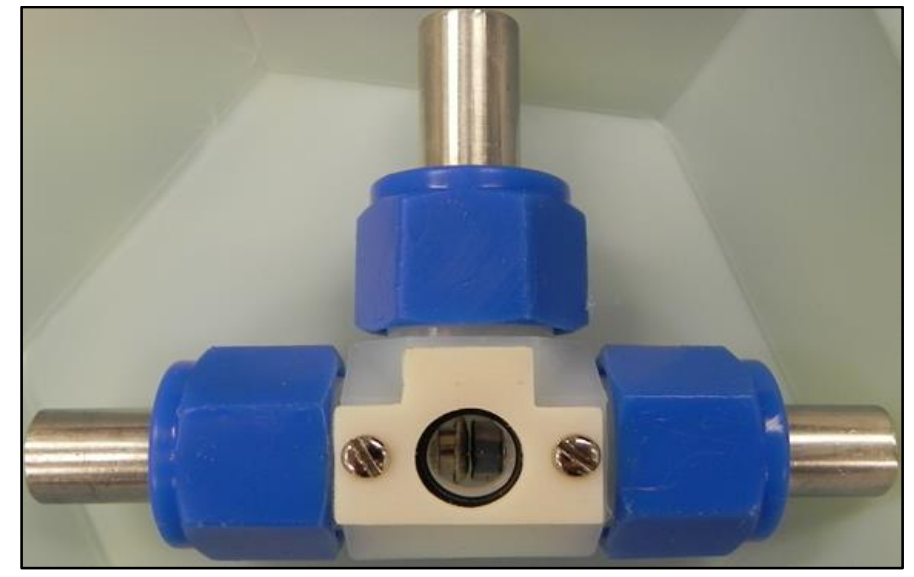

Figure 22: Generation 3C cell photograph.

\subsection{In Situ Raman Cell Preparation}

\subsubsection{Cleaning}

The generation $3 \mathrm{C}$ cell was cleaned prior to each use to avoid contamination that could affect the electrochemistry of the cell or the fluorescence background. First, all components of the cell were rinsed with IPA and DI water. The stainless steel rods were then polished using 1200 grit silicon carbide paper (Electron Microscopy Science) to 
ensure good electrical contact to the electrodes. The cell components were then sonicated for 30 minutes at $27^{\circ} \mathrm{C}$ using a 3510 Branson sonicator. Next, all parts were dried under vacuum to a pressure $<500$ mTorr.

\subsubsection{Cathodes}

The majority of in situ cells and 2032 coin cells utilized a 60:30:10 sulfur: Super $P ®$ carbon (TIMCAL): poly(acrylonitrile (LI133) and styrene-butadiene rubber (SBR) 8 mil wet film thickness coating on a carbon-coated aluminum current collector. The average cathode loading was $2.75 \pm 0.09 \mathrm{mg}$ sulfur $/ \mathrm{cm}^{2}$. Two initial in situ coin cell tests were done using 60:30:10 sulfur: DENKA BLACK carbon: poly(vinylidene fluoride) (PVDF, Solvay 5130) 4 mil wet film thickness coatings. The DENKA BLACK carbon was purchased from Denka Company Limited.

Both cathodes were produced by first grinding together sulfur and the respective carbon in the ratio of 80:20 using a mortar and pestle. The mixture was then fused at $150{ }^{\circ} \mathrm{C}$ and 50 mTorr for 12 hours. After fusing, the mixture was allowed to vent overnight in a dry room (maintained at a dew point $\leq-40{ }^{\circ} \mathrm{C}$ ) before being ground into a fine powder again. The powder was then further processed on a Turbula T2F overnight with $\sim 30,3-5 \mathrm{~mm}$ zirconia beads (BYK Gardner).

For the DENKA coating, the fused mixture was combined with the appropriate masses of PVDF and additional DENKA carbon to create a 60:30:10 slurry. The PVDF was dissolved in n-methyl-2-pyrrolidone (NMP, Sigma Aldrich) before adding sulfur and carbon. The slurry was mixed at 600-1000 RPM for at least 2 hours. All processing was performed in a dry room with a dew point $\leq-40{ }^{\circ} \mathrm{C}$. 
For the Super $\mathrm{P} \circledast$ coating, the fused carbon-sulfur was added to a mixture of $2.5 \mathrm{wt} \%$ LI133 and $2.5 \mathrm{wt} \%$ SBR suspended in water. Enough Super P® carbon was added to create a ratio of 60:30:10. The solution was mixed overnight at 600-1000 RPM.

For both coatings, once an adequate consistency was achieved, the slurries were cast onto carbon-coated aluminum, within the dry room, using a doctor blade Elcometer (4340 Automatic Film Applicator) to create the desired wet film thickness.

The coatings dried in the dry room overnight and then were placed in a vacuum oven at room temperature for at least 12 hours.

\subsection{Electrochemical Testing}

The in situ T-cell were built in an argon-filled glovebox and left to sit overnight to allow for full wetting of the cathode. Three replicates were discharged at a constant rate of

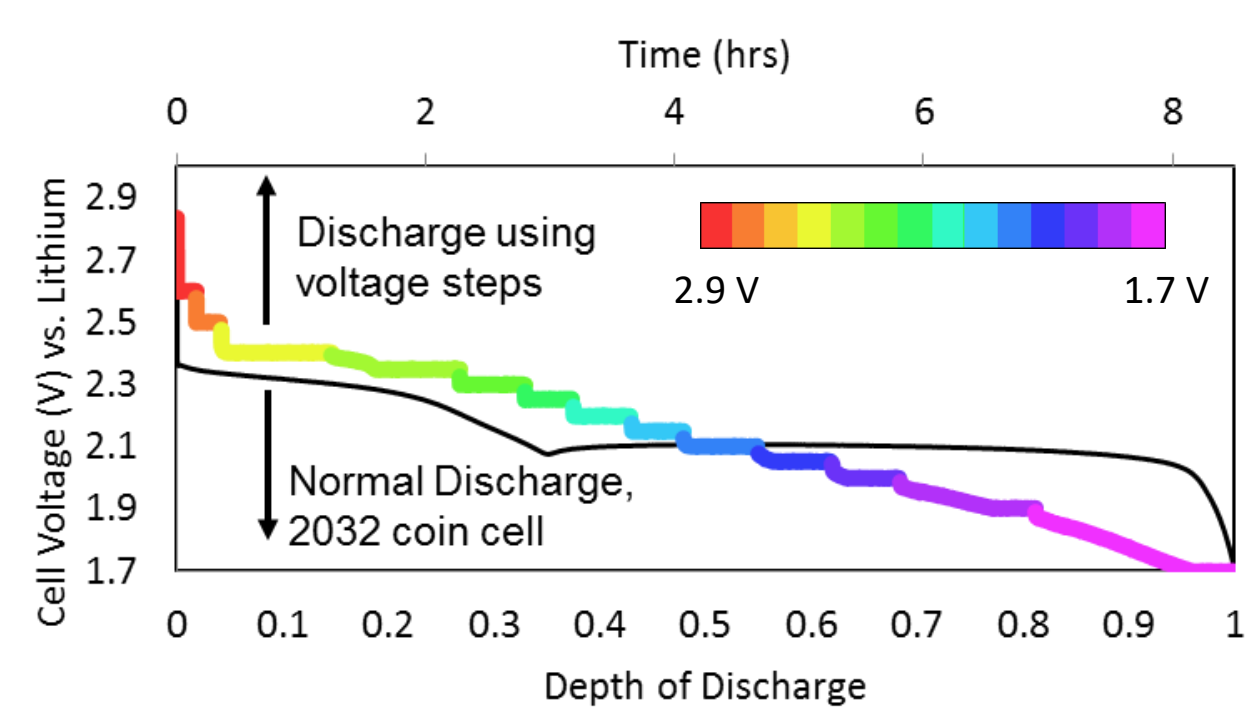

Figure 24: The normal discharge curve of a 2032 coin cell with a 60:30:10 sulfur: Super P: SBR/LI133 cathode and lithium on copper anode (black) and example of voltage steps used while obtaining Raman spectra. The change in color indicates a change in step voltage. The in situ cells were discharged at $\mathrm{C} / 10$ between voltage holds.

$\mathrm{C} / 10$ between voltage holds which corresponds to a current of $104 \mu \mathrm{A}$ or a current density of $328 \mu \mathrm{A} / \mathrm{cm}^{2}$. The C-rate was calculated based on the average capacity, $1019 \mathrm{mAh} / \mathrm{g}$ sulfur, achieved in a 2032 coin cell with the same 60:30:10 sulfur: Super P: LI133/SBR 
cathode. The cell was run with an excess of $130 \mu \mathrm{L}$ of the same 1:1 DME: DOL electrolyte. The first discharge curve for the 2032 coin cell is depicted in Figure 24, where the cell reached a capacity of $1019 \mathrm{mAh} / \mathrm{g}$ sulfur at a depth of discharge of 1 . An example of the voltage steps used for the in situ cells is also shown in Figure 24. Each voltage step was held until the current decay reached the pre-defined, quasi-equilibrium of $\left|\frac{d I}{d t}\right| \leq 0.015$ $\mu \mathrm{A} / \mathrm{sec}$. The quantity of sulfur in the cathode was calculated based on the average mass of a 0.25 " cathode without tabs. The discharge and voltage control of the T-cells were done using a Bio-Logic SP-200 potentiostat.

Coin cells were discharged at a constant rate of C/10 using a MACCOR battery tester. 


\section{Results and Discussion}

\subsection{Analysis of Cell Components using Raman}

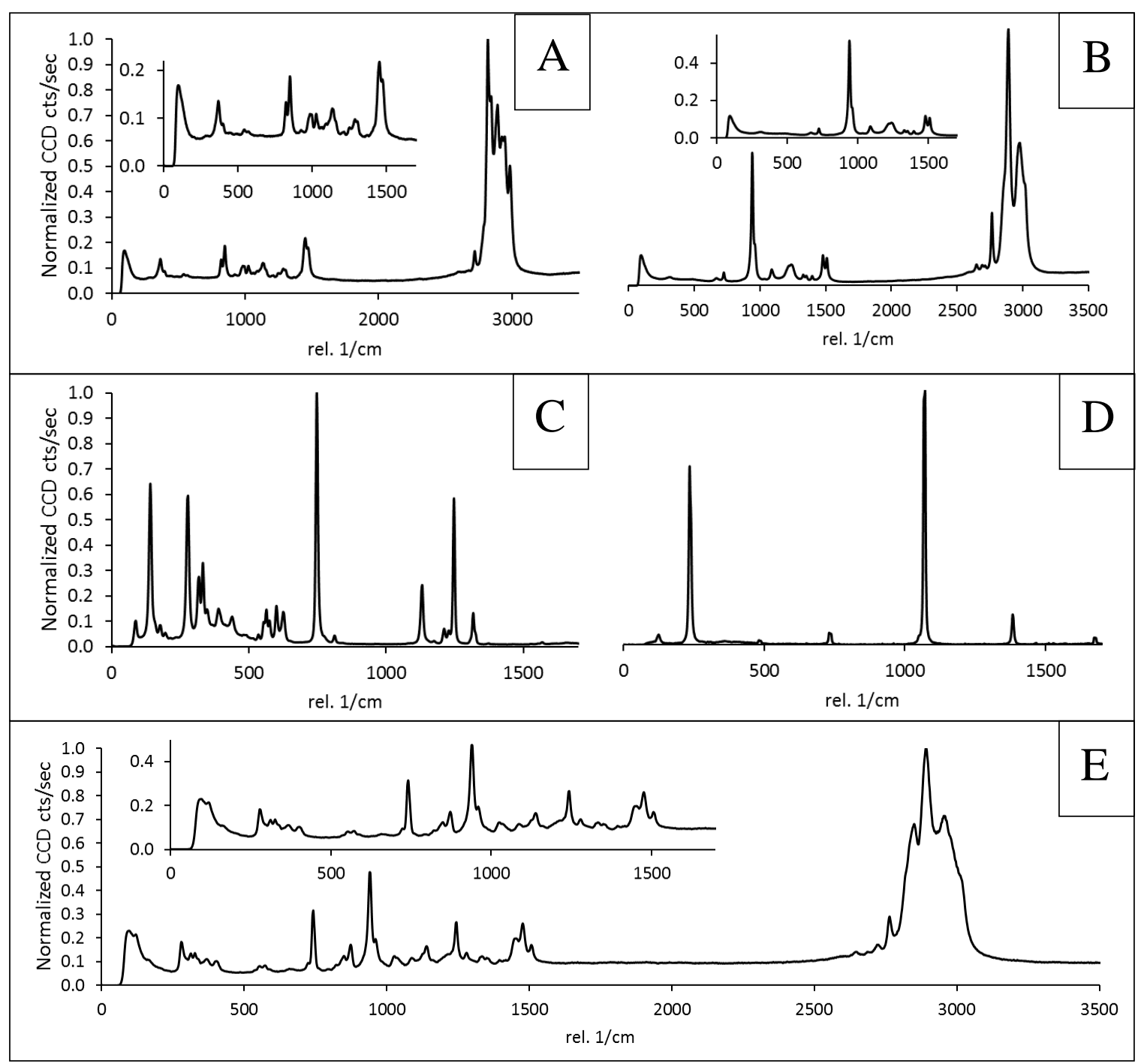

Figure 25: Spectra of components composing the electrolyte including A.) DME, B.) DOL, C.) Osilla LiTFSI, D.) $\mathrm{LiNO}_{3}$, and E.) the entire electrolyte of 1:1 DME: DOL, $1 \mathrm{M} \mathrm{LiTFSI}$, and 0.25 $\mathrm{M} \mathrm{LiNO}_{3}$. A, B, and $\mathrm{E}$ contain insets showing the region of wave numbers with the most Raman activity above the full spectrum with the $\mathrm{C}-\mathrm{H}$ peaks in the $3000 \mathrm{~cm}^{-1}$ range. All materials were kept under argon in quartz cuvettes.

Raman spectra were obtained for all components of the electrolyte under argon in quartz cuvettes, so that peaks from materials in the cell would not be mistaken for polysulfide peaks. 
Individual spectra of DOL, DME, LiTFSI, and $\mathrm{LiNO}_{3}$ are depicted in Figure 25 AD and the full electrolyte is shown in Figure 25 E. The spectra in Figure 25 are normalized, but do not have their backgrounds subtracted (other than subtraction of the dark spectrum) in order to show background fluorescence that can potentially swamp the signal from polysulfides during in situ measurements. As shown, none of the spectra have a large fluorescence background. All spectra in Figure 25 were obtained using the 10x objective and an optimized power of $8 \mathrm{~mW}$ with 30 seconds integration time and 10 accumulations.

Consistent within two wave numbers of the results of Suo et al. ${ }^{66}$, pure LiTFSI has its most intense peak at approximately $748.9 \mathrm{~cm}^{-1}\left(747.3 \mathrm{~cm}^{-1}\right.$ Suo et al.) while $1 \mathrm{M}$ LiTFSI in the electrolyte is located at approximately $741.5 \mathrm{~cm}^{-1}\left(740.7 \mathrm{~cm}^{-1}\right.$ Suo et al. $)$.

Since the electrolyte has several intense peaks in the $100-600 \mathrm{~cm}^{-1}$ range, polysulfide peaks were more difficult to identify where there were already peaks.

Exposure to oxygen affects the fluorescence background, in the region of interest

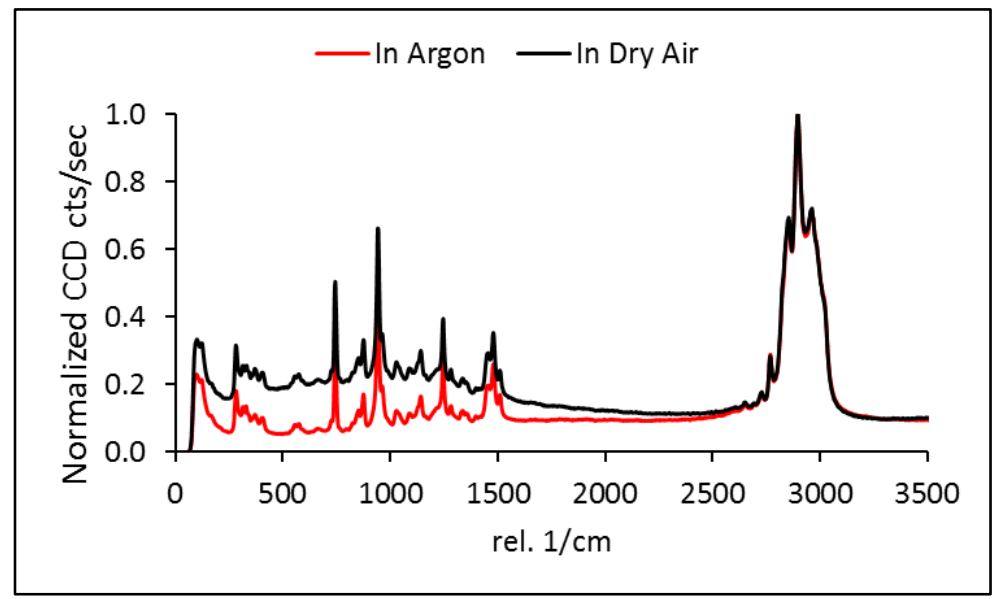

for polysulfides, as seen in Figure 26. In some cases, at longer exposure times, the increase was so intense, that smaller peaks were difficult to distinguish from the

Figure 26: Difference in fluorescence background when electrolyte background, therefore it was was under argon vs. under dry air.

important for everything to remain under argon in order to obtain useful spectra. Additionally, some photo-bleaching was observed, especially when exposed to oxygen. If lower powers and longer integration time were utilized to decrease photo-bleaching, the 
spectrum became noisy, the fluorescence background increased, and peaks were difficult to identify. The fluorescence background could also be increased through the introduction of contaminants, so sample preparation and cleaning, including sonication, were found to be important.

To determine the source of fluorescence and photo-bleaching behavior, a brief study was performed on the components of the electrolyte while in air. The electrolyte as

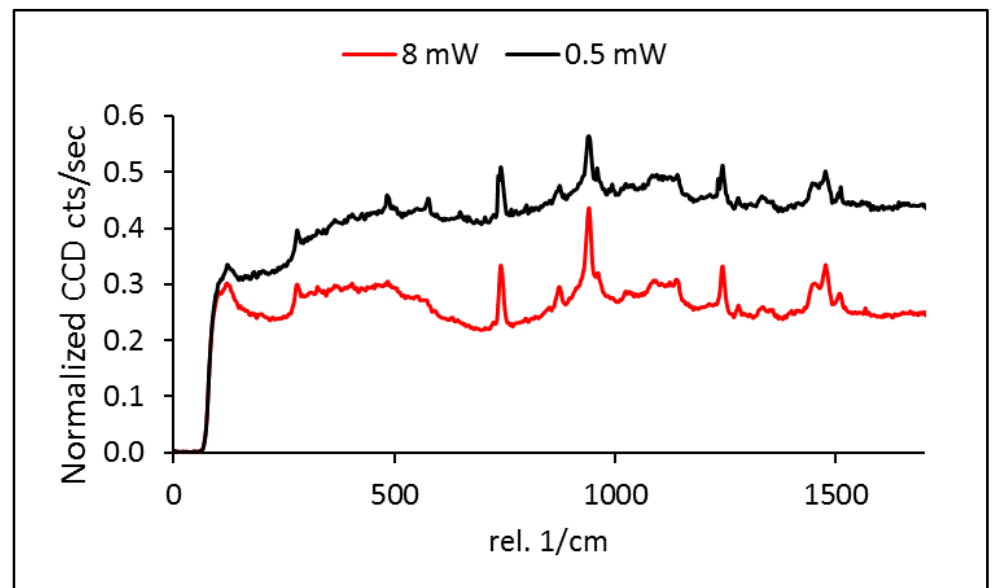

Figure 27: Raman spectra of the electrolyte using a laser power of 8 $\mathrm{mW}$ (red) with 30 seconds integration time and 10 accumulations and a laser power of $0.5 \mathrm{~mW}$ (black) with 240 seconds integration time and 20 accumulations. a whole, while exposed to air, using an $8 \mathrm{~mW}$ and 0.5 $\mathrm{mW}$ beam, is shown in Figure 27. The $0.5 \mathrm{~mW}$ power was used with 240 seconds integration time and 20 accumulations while the 8 $\mathrm{mW}$ power was used with 30 seconds integration time and 10 accumulations. The spectra can then be more fairly compared because the same total amount of energy was input into the system in both cases. As seen in Figure 27, decreasing the power and increasing integration time does not yield a better spectrum, but greatly increases the time needed to acquire a spectrum ( 5 minutes vs. 80 minutes).

Next, the solvent and LiTFSI were analyzed separately to pin point the source of the fluorescence. 1:1 DME: DOL did not show any change from that of Figure $25 \mathrm{~A}$ and B when decreasing the power below $8 \mathrm{~mW}$. LiTFSI however, appeared to be the source of photo-bleaching and the large fluorescence background. As seen in Figure 28, using the 
lower power of $0.5 \mathrm{~mW}$ results in less distinct peaks, particularly in the range of $250-500$ $\mathrm{cm}^{-1}$. The LiTFSI spectrum, when in air, using an $8 \mathrm{~mW}$ power becomes cleaner with

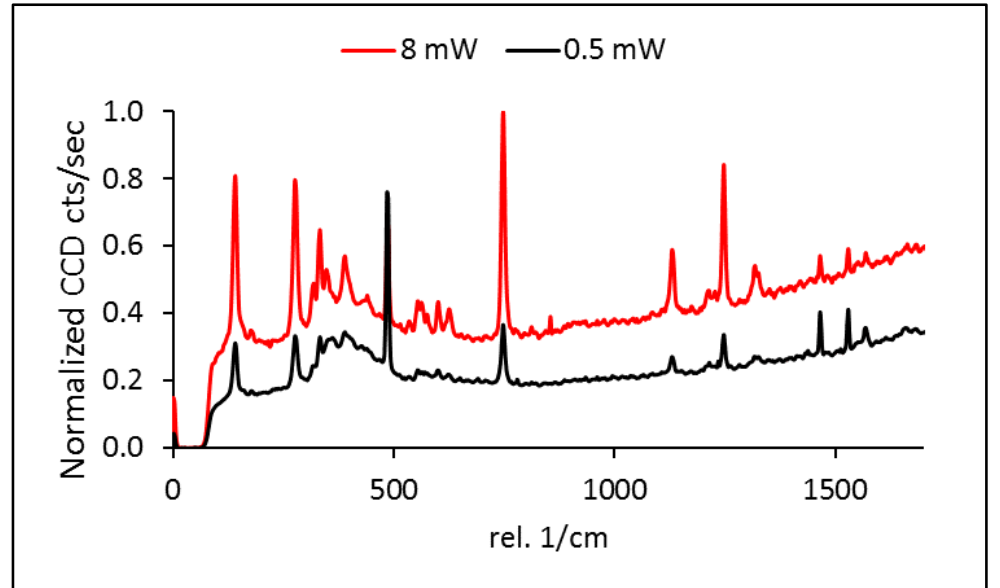

Figure 28: LiTFSI in air using a laser power of $8 \mathrm{~mW}$ (red) with 30 seconds integration time and 10 accumulations and a laser power of $0.5 \mathrm{~mW}$ (black) with 240 seconds integration time and 20 accumulations. greater laser illumination time as the fluorescent background is photobleached. This was studied by taking a spectrum every 2 seconds, $\quad 30 \quad$ times. Representative spectra across the 60 second experiment are shown in Figure 29 A. This photobleaching behavior was not observed when the same experiment was performed under argon (Figure 29 B). The background and peaks remain consistent when analyzed under argon with the exception of peaks near 142

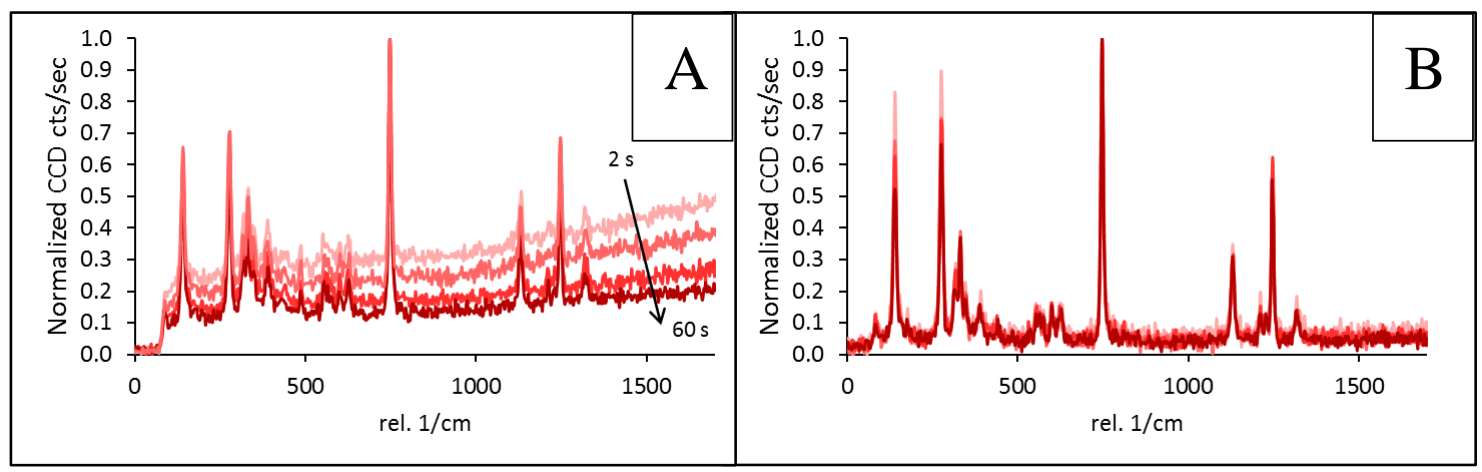

Figure 29: LiTFSI time study in A.) air and B.) argon from 2 seconds illumination time to 60 seconds illumination time showing the effect of photo-bleaching at a power of $8 \mathrm{~mW}$.

and $274 \mathrm{~cm}^{-1}$ which decrease in intensity with increasing illumination time. The power of $8 \mathrm{~mW}$, optimized for the liquid electrolyte, is too intense for solid LiTFSI. However, since the Raman laser can be used to study both solids and liquids, it is important to know how both solids and liquids react to the optimized power. 
Another important factor in the variability of LiTFSI spectra was ambient light. The presence of light sometimes introduced peaks at approximately $2400 \mathrm{~cm}^{-1}$ and $485 \mathrm{~cm}^{-1}$ as well as dampened peaks in the $250-500 \mathrm{~cm}^{-1}$ range.

Despite the problems that LiTFSI introduced to the system, it was preferable to keep LiTFSI as the salt rather than changing to another because it is used as a standard in the literature. Most of the issues caused by LiTFSI could be solved by covering the Raman microscope during data acquisition and keeping everything sealed under argon.

For these reasons, all standards and T-cells were analyzed under argon and with the microscope covered in order to use the optimized power of $8 \mathrm{~mW}$ and obtain a clean spectrum.

The spectra of the reactant $\left(\mathrm{S}_{8}\right)$ and final discharge product $\left(\mathrm{Li}_{2} \mathrm{~S}\right)$ of the reactions in Equations 1-3 were also obtained and are shown in Figure 30. Both $\mathrm{S}_{8}$ and $\mathrm{Li}_{2} \mathrm{~S}$ are insoluble in the electrolyte and thus were only observed in solid form.

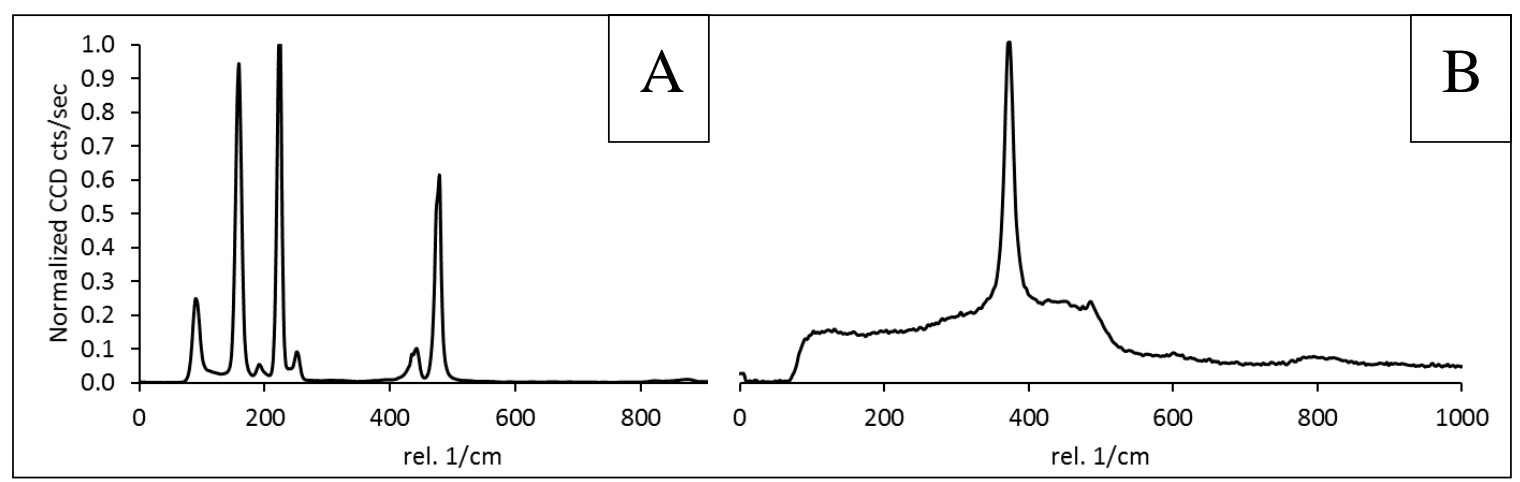

Figure 30: Raman spectra for $\mathrm{A}$.) $\mathrm{S}_{8}$ in air and $\mathrm{B}$.) $\mathrm{Li}_{2} \mathrm{~S}$ under argon using a laser power of $8 \mathrm{~mW}, 30$ seconds integration time, and 10 accumulations.

Lastly, spectra of the 60:30:10 sulfur: Super P: LI133/SBR cathode and 3501 Celgard separator were obtained (Figure 31). As expected, the cathode contained sulfur as evident by the peaks located between 100 and $500 \mathrm{~cm}^{-1}$ with similar relative peak 
intensities as seen in pure sulfur in Figure 30 A. There was also the presence of two carbon peaks between 1000 and $2000 \mathrm{~cm}^{-1}$.

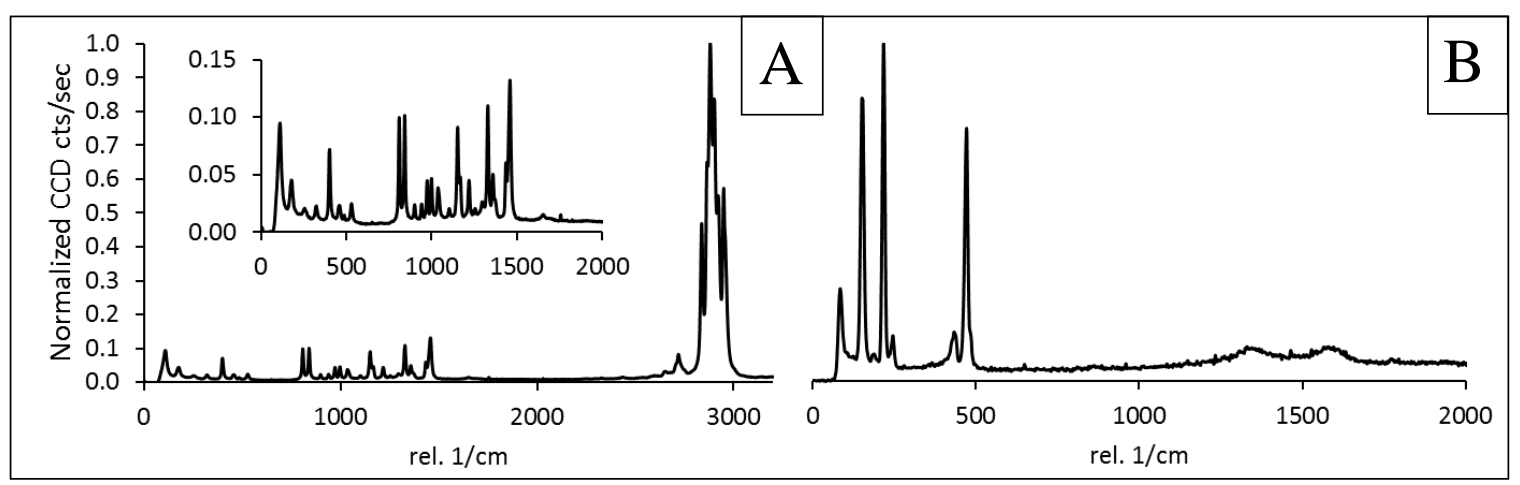

Figure 31: Raman spectra of A.) 3501 Celgard separator using $8 \mathrm{~mW}$ power, 35 seconds integration time, and 20 accumulations and B.) 60:30:10 sulfur: Super P: LI133/SBR 8 mil WFT cathode using 0.8 mW power, 150 seconds integration time, and 1 accumulation. .

Now that an understanding of all $\mathrm{Li}-\mathrm{S}$ cell components has been established, the results of the introduction of polysulfides into the system via either chemical (standards) or electrochemical (in situ cell) means will be discussed.

\subsection{ESI Mass Spectroscopy Results}

Ideally, the use of multiple characterization techniques should be used to confidently identify polysulfide peaks in the chemically synthesized standards. ESI mass spectroscopy was one such characterization method considered. ESI mass spectroscopy was chosen because it could potentially give information on the exact distributions of chain lengths present in solution which could then be related to the peaks seen using Raman. The electron spray ionization method was chosen because it was gentler and optimally would not cause fragmentation of the polysulfides.

Representative results of direct infusion of the polysulfide standards (samples D and $\mathrm{G}$ in Figure 15), are given in Figure 32. Comparing these results to those seen by Zheng et al. ${ }^{58}$ in Figure 7, it is evident that they are not similar. The spectra for the other 6 samples 
are similar to Figure 32 with peaks located predominately above $200 \mathrm{~m} / \mathrm{z}$ and can be found in Appendix Figure 57.

Figure $7 \mathrm{~A}$ and Figure $32 \mathrm{~A}$ should be identical because they have the same concentrations of $\mathrm{Na}_{2} \mathrm{~S}$ and are in the same solvent. The long chain polysulfides, such as $\mathrm{S}_{8}{ }^{-}$and $\mathrm{S}_{8}{ }^{2-}$ should have an $\mathrm{m} / \mathrm{z}$ of 256 and 128 respectively. Figure $32 \mathrm{~A}$ has many peaks located above $300 \mathrm{~m} / \mathrm{z}$, but even the largest, expected polysulfides, including coordination with lithium, would not have such a large $\mathrm{m} / \mathrm{z}$. This could have been due to contamination or because, although these standards were synthesized in a glovebox, they were briefly exposed to oxygen DME.

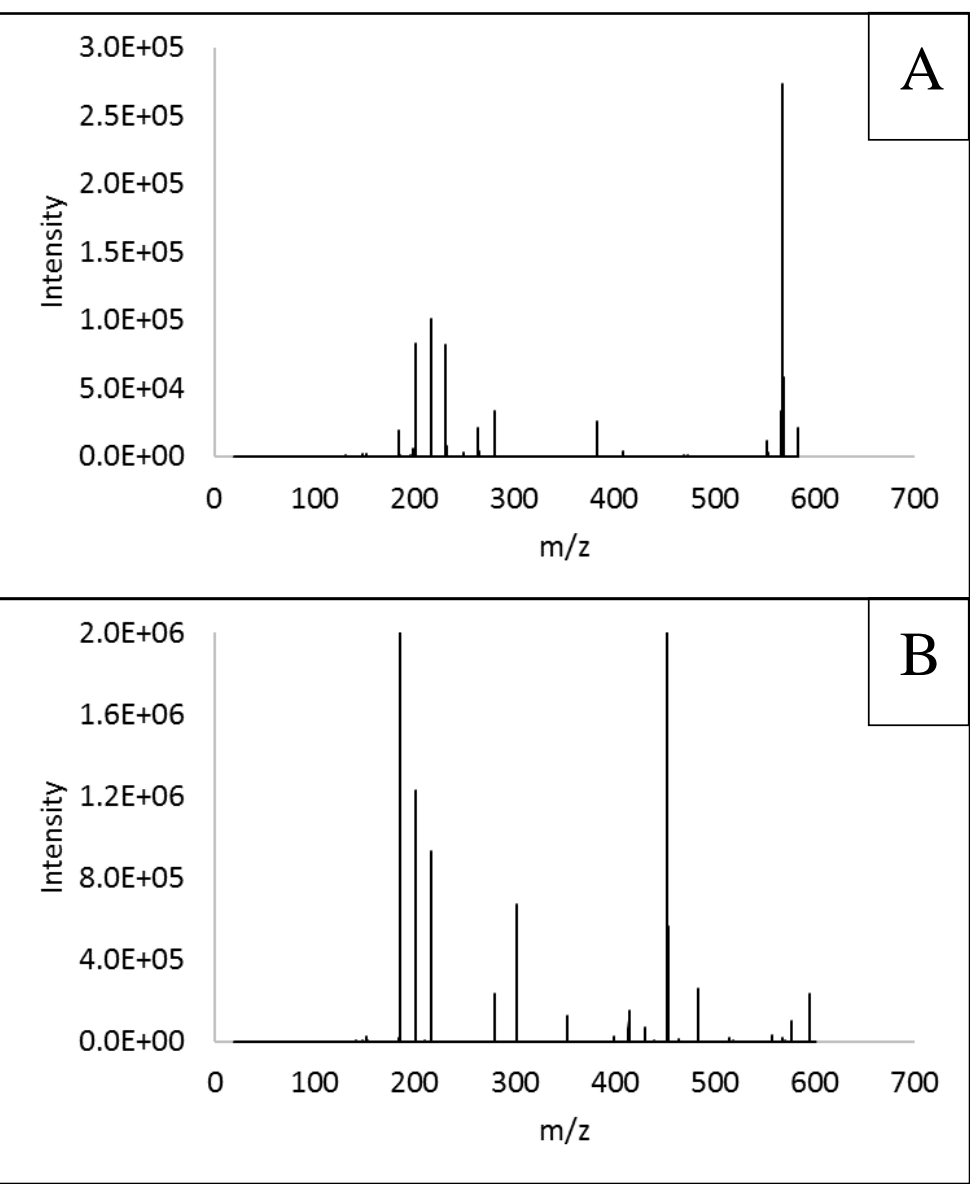

Figure 32: ESI mass spectra of A.) Sample D, $50 \mathrm{mM}^{\prime} \mathrm{Li}_{2} \mathrm{~S}_{8}$ " in $1: 1$ DME: DOL and B.) Sample G, $0.2 \mathrm{mmol} \mathrm{Na}_{2} \mathrm{~S}$ and $0.075 \mathrm{mmol} \mathrm{S}_{8}$ in

while being diluted and injected into the mass spectrometer.

This experiment was to be repeated with the entire process maintained under argon, however the samples caused damage to a probe within the mass spectrometer. As a result, ESI-mass spectroscopy was not evaluated further. 


\subsection{Raman of Lithium Polysulfide Standards}

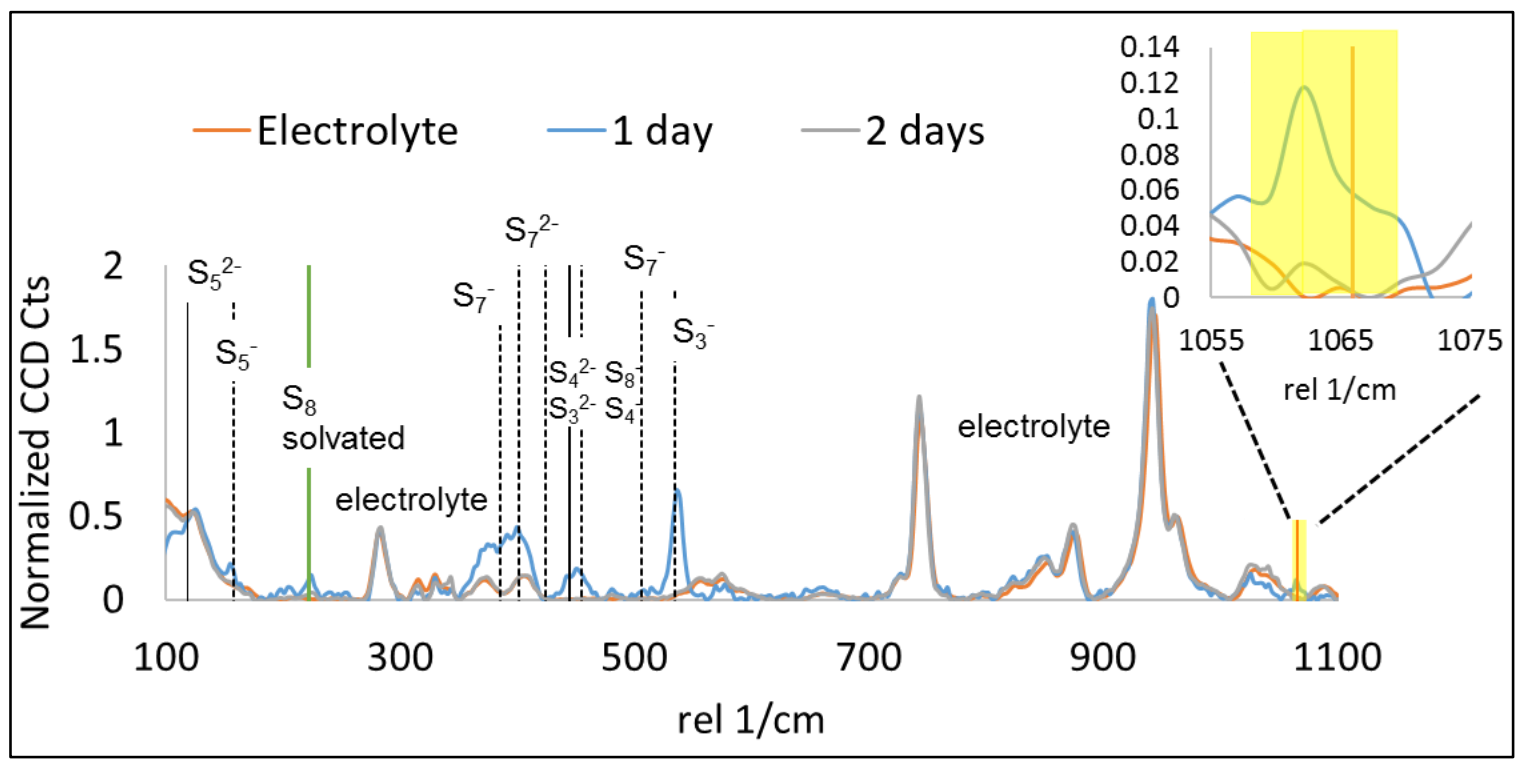

Figure 33: Polysulfides exposed to air 1 and 2 days after being synthesized (blue and grey). The electrolyte sealed under argon is shown for comparison of peaks (orange). An inset of the dithionite anion, $\mathrm{S}_{2} \mathrm{O}_{4}{ }^{2-}$, is shown in the top right. Dotted and solid lines correspond to polysulfide monoanions and dianions from the literature ${ }^{39,67}$ respectively. The background of all spectra has been removed, but electrolyte peaks are still present.

Since ESI-mass spectroscopy was not successful, it was decided to use Raman spectroscopy alone and to rely on literature values for peak assignments.

Chemically synthesized lithium polysulfide standards were made and sealed under argon to see if more polysulfide peaks were present than Hagen et al. ${ }^{39}$ observed when the standards were sealed under air. For comparison, an $\mathrm{Li}_{2} \mathrm{~S}_{6}$ standard was synthesized and sealed under air (Figure 33). One day after being synthesized, there are several polysulfide peaks present (blue). There is also the presence of the $\mathrm{S}_{2} \mathrm{O}_{4}{ }^{2-}$, dithionite anion, ${ }^{67}$ with a peak at approximately $1066 \mathrm{~cm}^{-1}$ indicating that polysulfides are being oxidized. Two days after synthesis, the polysulfide and dithionite

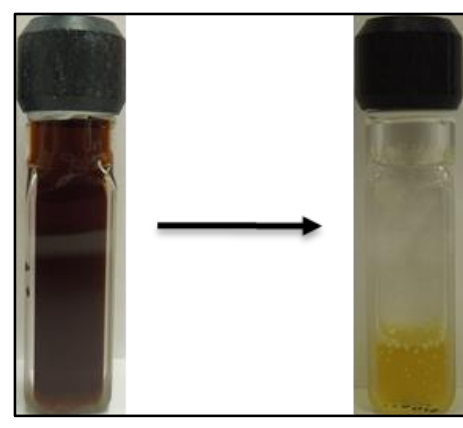

Figure 34: Example of color change of polysulfide standards prior to exposure to air (left) to exposed to air for several days (right). 
peaks decrease in intensity significantly (grey). Thus the polysulfide standards are not stable when exposed to air.

However, they are stable when in argon (Figure 35). The spectra taken 1 and 2 days after synthesis are the same; a reduction in the polysulfide peaks is not observed as with

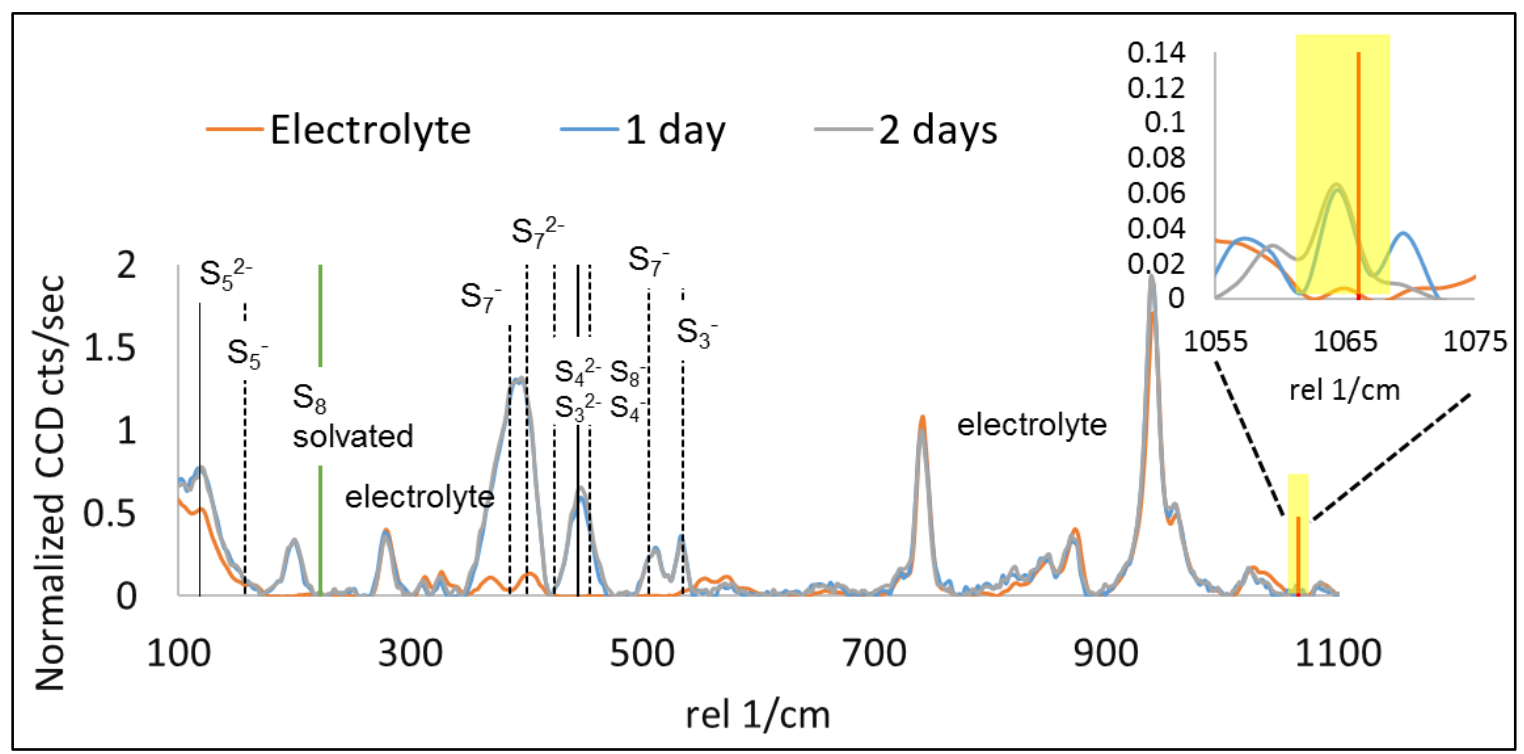

Figure 35: Polysulfides under argon 1 and 2 days after being synthesized (blue and grey). The electrolyte sealed under argon is shown for comparison of peaks (orange). An inset of the dithionite anion, $\mathrm{S}_{2} \mathrm{O}_{4}{ }^{2-}$, is shown in the top right. Dotted and solid lines correspond to polysulfide monoanions and dianions from the literature ${ }^{39}$ respectively. The background of all spectra has been removed, but electrolyte peaks are still present.

the air samples. Additionally, the equilibrium speciation of polysulfides is different when exposed to air. Notably the $\mathrm{Li}_{2} \mathrm{~S}_{6}$ standard in air does not have a peak near $200 \mathrm{~cm}^{-1}$ or at $506 \mathrm{~cm}^{-1}$. The peaks are also much cleaner in the argon sample. The dithionite anion, at approximately $1066 \mathrm{~cm}^{-1}$, is present in both, but is twice the intensity in the air samples. The presence of the dithionite anion in the argon samples is most likely due to small amounts of oxygen present in the glovebox during synthesis.

The nominal $\mathrm{Li}_{2} \mathrm{~S}_{8}, \mathrm{Li}_{2} \mathrm{~S}_{6}$, and $\mathrm{Li}_{2} \mathrm{~S}_{4}$ standards in argon, 17 hours from reaction initiation, and their variability between two replicates are depicted in Figure 36. The background and electrolyte peaks were subtracted to more clearly identify the polysulfide 
peaks, especially in cases where polysulfide and electrolyte peaks overlapped. For a detailed explanation of spectral processing, see Appendix B.

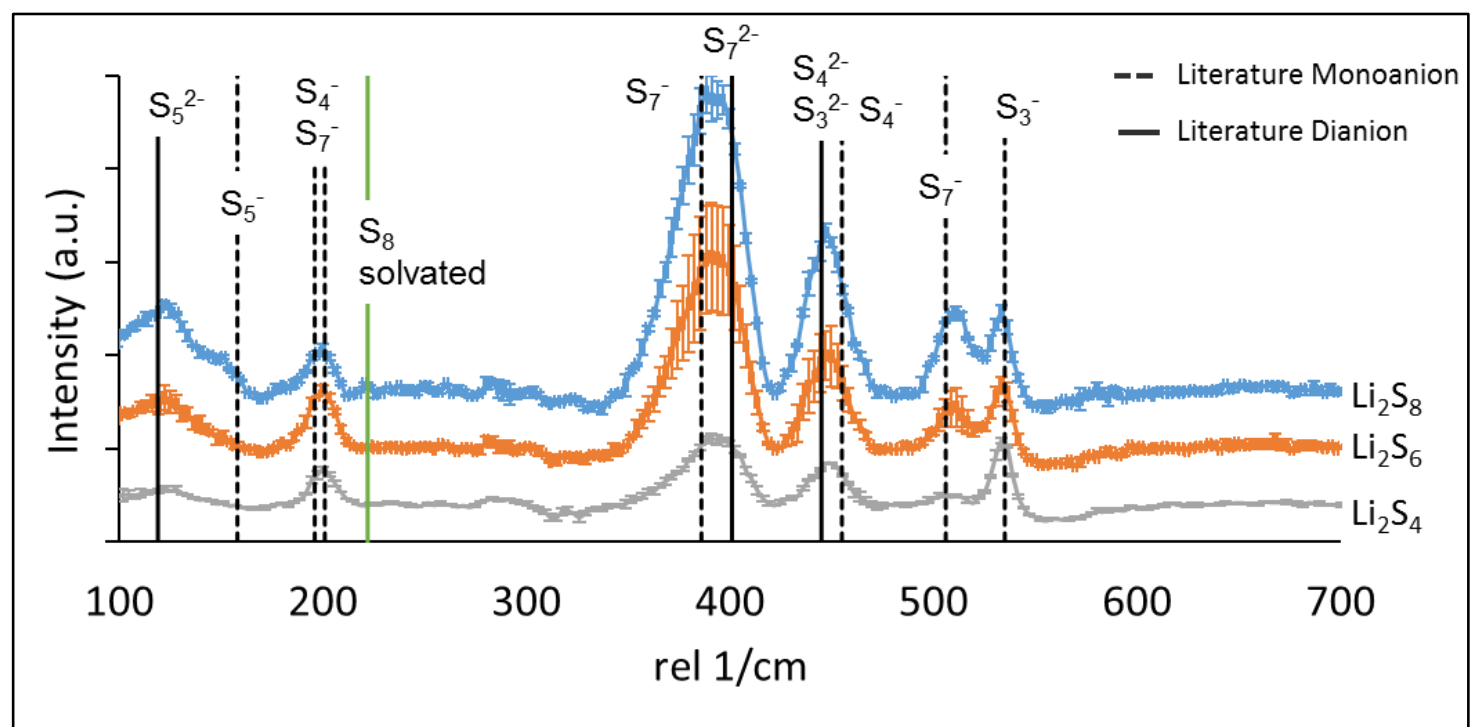

Figure 36: Nominal $\mathrm{Li}_{2} \mathrm{~S}_{8}$ (blue), $\mathrm{Li}_{2} \mathrm{~S}_{6}$ (orange), and $\mathrm{Li}_{2} \mathrm{~S}_{4}$ (grey) standards under argon at 17 hours from reaction initiation with peak positions from the literature (dashed lines are monoanions and solid lines are dianions). ${ }^{39}$ All peaks are relative to the LiTFSI peak at approximately $740.7 \mathrm{~cm}^{-1}$ and the background and electrolyte peaks have been removed.

Despite differences in reactant stoichiometries, the three standards equilibrate to have the same species present and have similar peak positions (though peak intensities still vary between the three standards). Several polysulfide assignments from the literature are within a few wave numbers of broad peaks, such as $\sim 390$ and $450 \mathrm{~cm}^{-1}$. These broad peaks are most likely a combination of multiple peaks for several polysulfide chain lengths.

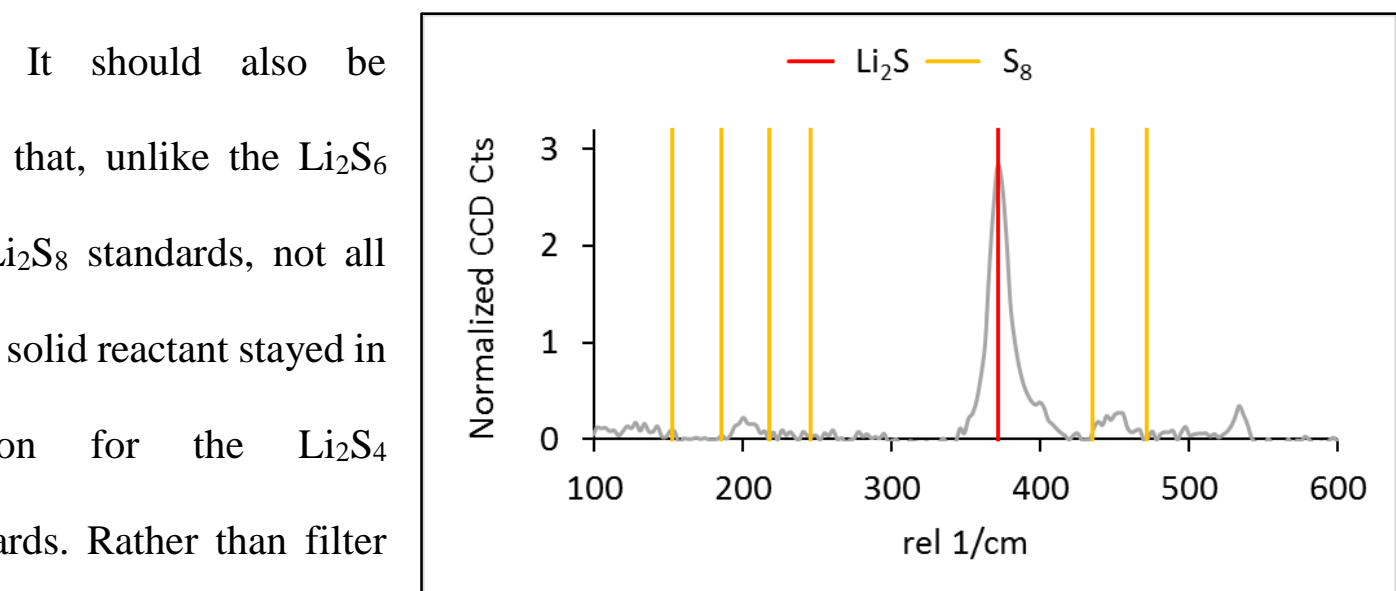
out this solid and risk shifting

Figure 37: Solid identified as $\mathrm{Li}_{2} \mathrm{~S}$ in the $\mathrm{Li}_{2} \mathrm{~S}_{4}$ standards. Yellow and red lines show comparison to the spectra of $\mathrm{S}_{8}$ and $\mathrm{Li}_{2} \mathrm{~S}$ respectively. 
equilibrium, care was taken to allow all solids to settle before taking a spectrum, so that only the solution was analyzed. Focusing the laser far from the cuvette wall also mitigated this problem. The solid was identified as $\mathrm{Li}_{2} \mathrm{~S}$ rather than $\mathrm{S}_{8}$ as seen from its spectrum in solution before the particulates settled (Figure 37). There is a strong peak at approximately $372 \mathrm{~cm}^{-1}$ which matches Figure $30 \mathrm{~B}$ for $\mathrm{Li}_{2} \mathrm{~S}$. There are no peaks corresponding to $\mathrm{S}_{8}$ solid. Since $\mathrm{Li}_{2} \mathrm{~S}_{6}$ and $\mathrm{Li}_{2} \mathrm{~S}_{8}$ were completely transparent (no solid matter present) and $\mathrm{Li}_{2} \mathrm{~S}_{4}$ was transparent once the solids settled, this $\mathrm{Li}_{2} \mathrm{~S}$ peak most likely does not contribute to the peak observed at $390 \mathrm{~cm}^{-1}$ as $\mathrm{Li}_{2} \mathrm{~S}$ is insoluble in the electrolyte.

Despite these difficulties, the three standards can be distinguished from each other through differences in coloration (Figure 38) and relative peak intensities.

The peak intensities were obtained by fitting the peaks to a Lorentzian function (Equation 13) which provides information on the peak intensity, full width half max (FWHM, symbolized as $\Gamma$ ), and peak position $\left(\mathrm{p}_{0}\right)$. The FWHM is defined as the width of the peak at half its maximum intensity. The variable $\mathrm{z}$ is equal to $\frac{2}{\pi \Gamma}$ and functions as a scaling factor. The offset term shifts the function in the y-direction to match the sample's spectrum. If

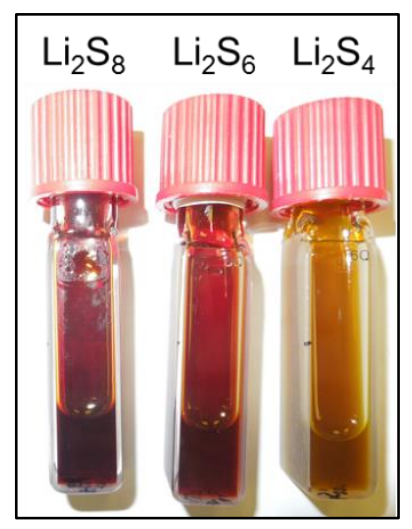

Figure 38: Difference in coloration of the $\mathrm{Li}_{2} \mathrm{~S}_{8}$, $\mathrm{Li}_{2} \mathrm{~S}_{6}$, and $\mathrm{Li}_{2} \mathrm{~S}_{4}$ standards in argon multiple peaks are fit at once, the overall fit function becomes a linear combination of the individual fits.

$$
f\left(x, p_{0}, \Gamma\right)=z \frac{\left(\frac{\Gamma}{2}\right)^{2}}{\left(x-p_{0}\right)^{2}+\left(\frac{\Gamma}{2}\right)^{2}}+\text { offset }
$$

Examples of the fits for $\mathrm{Li}_{2} \mathrm{~S}_{8}, \mathrm{Li}_{2} \mathrm{~S}_{6}$, and $\mathrm{Li}_{2} \mathrm{~S}_{4}, 17$ hours after reaction initiation, 
are shown for the approximate positions of $390,450,510$, and $533 \mathrm{~cm}^{-1}$ in Figure 39. The peaks of 390 and $450 \mathrm{~cm}^{-1}$ and 510 and $533 \mathrm{~cm}^{-1}$ were fit in pairs.

The peaks at 390 and $450 \mathrm{~cm}^{-1}$ are more difficult to fit to a Lorentzian function due to some irregularities in peak shape including peaks that have a plateau or bumps at the top of the peak and bumps off-center from the peak maximum. For example, in Figure 39 A, there are two bumps on the top of the peak as well as at $\sim 370$ and $410 \mathrm{~cm}^{-1}$. This is most likely due to the presence of several peaks combining to form the observed broad peaks.

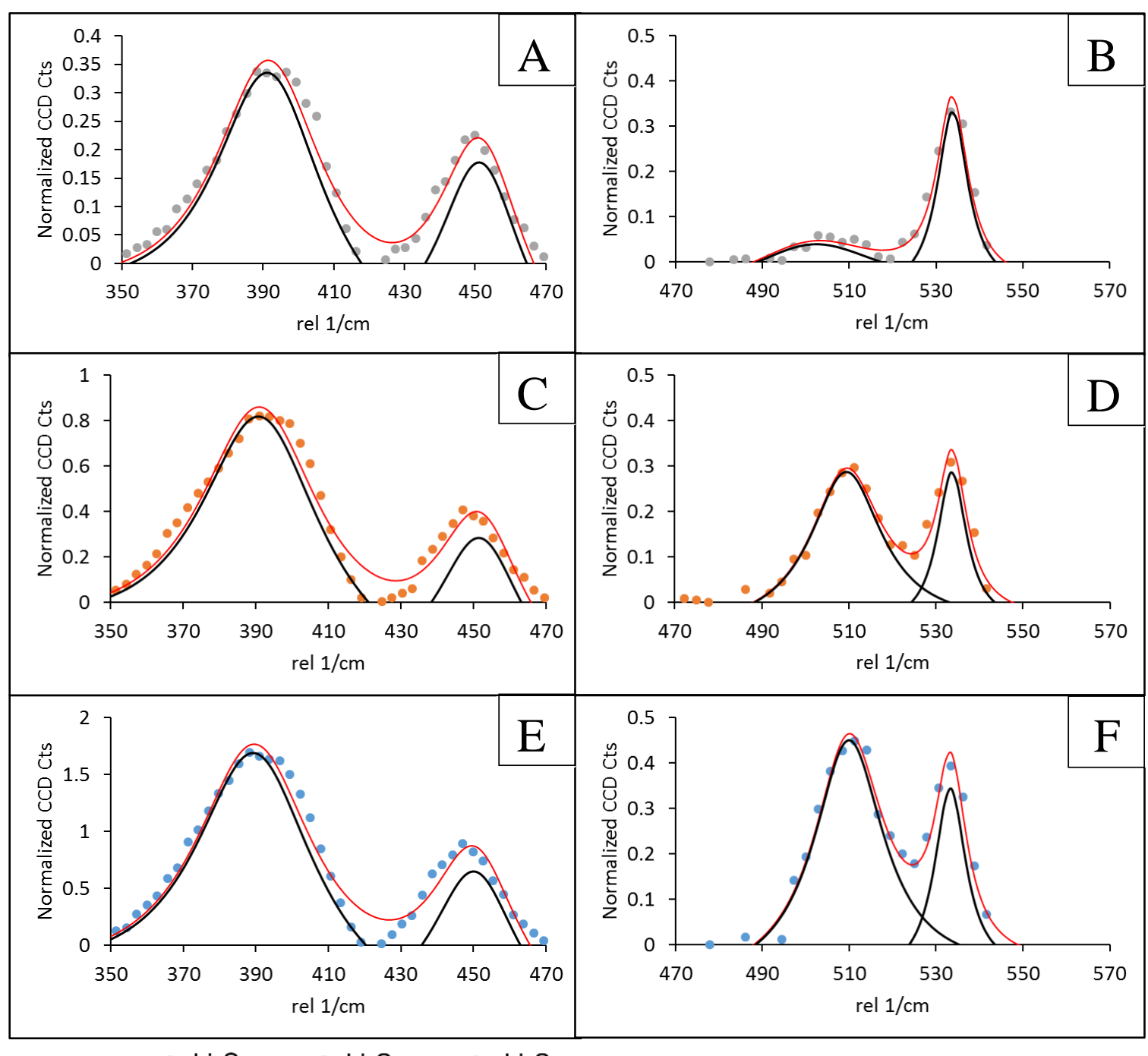

$$
\text { - } \mathrm{Li}_{2} \mathrm{~S}_{8} \quad-\mathrm{Li}_{2} \mathrm{~S}_{6} \quad \cdot \mathrm{Li}_{2} \mathrm{~S}_{4} \quad \text { - Overall fit - Individual Fits }
$$

Figure 39: Examples of Lorentzian fits for peaks located approximately at 390, 450, 510, and $533 \mathrm{~cm}^{-1}$ at 17 hours from reaction initiation for $\mathrm{Li}_{2} \mathrm{~S}_{4}$ (A and B), $\mathrm{Li}_{2} \mathrm{~S}_{6}\left(\mathrm{C}\right.$ and D), and $\mathrm{Li}_{2} \mathrm{~S}_{8}(\mathrm{E}$ and $\mathrm{F})$. 
Additional analysis using techniques such as multivariate analysis would be required to further analyze these peaks; but for this effort, these methods were deemed sufficient for the analysis.

The fits in Figure 39 provide a consistent method of determining peak intensities, however the FWHMs from the fits have large confidence bounds. Since no obvious peak broadening was observed over the time of the experiment, the peak intensity and position were tracked instead.

The peak position varied slightly between the standards. Most confidence bounds

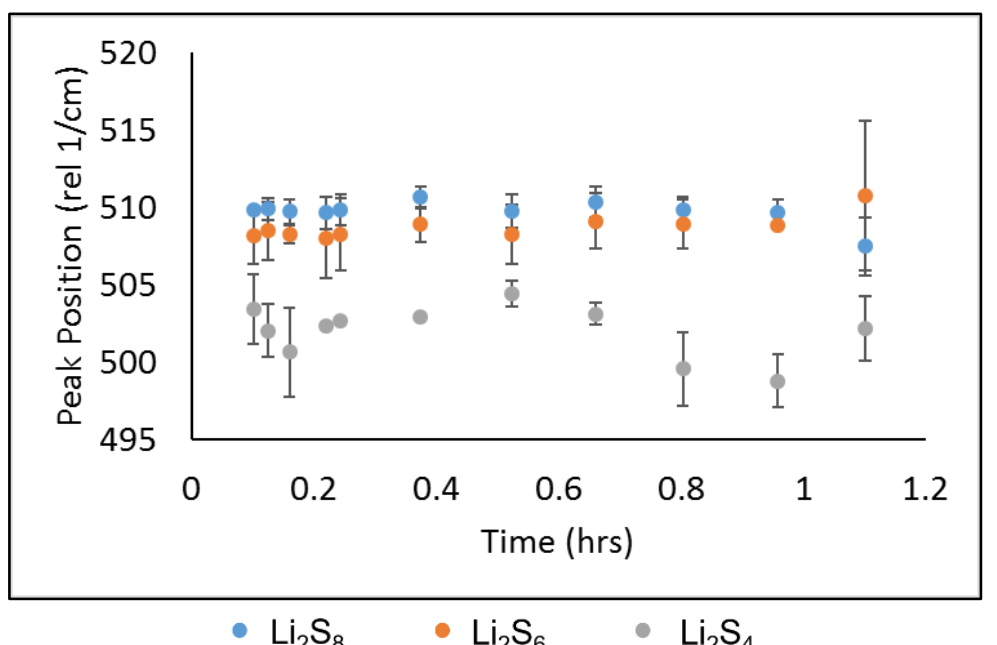

Figure 40: Peak position in the $510 \mathrm{~cm}^{-1}$ range for the $\mathrm{Li}_{2} \mathrm{~S}_{8}, \mathrm{Li}_{2} \mathrm{~S}_{6}$, and $\mathrm{Li}_{2} \mathrm{~S}_{4}$ standards over a week period. for the peak positions derived from the fit were $\pm 3 \mathrm{~cm}^{-1}$. For all three standards, there is always a peak at $533 \pm 1$ $\mathrm{cm}^{-1}$. The peak at approximately $510 \mathrm{~cm}^{-1}$ is less consistent across the standards as shown in Figure

40. Both $\mathrm{Li}_{2} \mathrm{~S}_{8}$ and $\mathrm{Li}_{2} \mathrm{~S}_{6}$ have a peak between 507 and $511 \mathrm{~cm}^{-1} . \mathrm{Li}_{2} \mathrm{~S}_{4}$ has a peak between 498 and $505 \mathrm{~cm}^{-1}$. This shift in wave number of the $\mathrm{Li}_{2} \mathrm{~S}_{4} 505 \mathrm{~cm}^{-1}$ peak is accompanied by a decrease in relative intensity as is evident in Figure $39 \mathrm{~B}$.

For the remaining peaks, all standards are in the same ranges of $199 \pm 3,390 \pm 2$, and $452 \pm 3 \mathrm{~cm}^{-1}$. For simplicity and comparison, all of these peaks will be referred to as ranges of $200,390,450$, and $510 \mathrm{~cm}^{-1}$. 
Table 6: Observed peaks in current work (standards ${ }^{\mathrm{a}}$ and in situ ${ }^{\mathrm{b}}$ ) and peak assignments based on literature values. S indicates a symmetric stretch vibration, AS indicates an antisymmetric stretch vibration. The letter after the peak position indicates relative intensity $(\mathrm{w}=$ weak, $\mathrm{s}=$ strong, $\mathrm{m}=$ medium, $\mathrm{vs}=$ very strong).

All assignments are from Hagen et al. ${ }^{39}$ unless otherwise indicated.

\begin{tabular}{|c|c|c|}
\hline \multirow{2}{*}{$\frac{\text { Present Work }}{119^{\mathrm{a}}}$} & \multicolumn{2}{|c|}{ Possible Assignment (species and rel. $\mathrm{cm}^{-1}$ ) } \\
\hline & $\mathrm{S}_{5}^{2-}$ & $119 \mathrm{~s}$ \\
\hline $200^{\mathrm{a}}$ & $\begin{array}{l}\mathrm{S}_{7^{-}} \\
\mathrm{S}_{4}^{-}(\mathrm{S}) \\
\mathrm{S}_{3}{ }^{2-}(\mathrm{AS}) \\
\mathrm{S}_{4}{ }^{2-}(\mathrm{AS}) \\
\mathrm{S}_{5}{ }^{2-}\end{array}$ & $\begin{array}{l}204 \mathrm{w}, 201 \mathrm{w} \\
196 \mathrm{w} \\
184 \mathrm{~s} \\
212 \mathrm{~m} \\
219 \mathrm{~m}\end{array}$ \\
\hline $265^{\mathrm{b}}$ & $\begin{array}{l}\mathrm{S}_{8}^{2-} \\
\mathrm{S}_{7}^{2-}\end{array}$ & $\begin{array}{l}258 \mathrm{~m} \\
247 \mathrm{~m}\end{array}$ \\
\hline $365^{\mathrm{b}}$ & $\begin{array}{l}\mathrm{S}_{6}^{2-} \\
\mathrm{S}_{8}^{2-}\end{array}$ & $\begin{array}{l}358 \mathrm{~s} \\
362 \mathrm{~s}\end{array}$ \\
\hline $390^{\mathrm{a}, \mathrm{b}}$ & $\begin{array}{l}\mathrm{S}_{7}^{-} \\
\mathrm{S}_{7}{ }^{2-}\end{array}$ & $\begin{array}{l}386 \mathrm{~m} \\
368 \mathrm{~m}, 401 \mathrm{~s}\end{array}$ \\
\hline $450^{\mathrm{a}, \mathrm{b}}$ & $\begin{array}{l}\mathrm{S}_{4}^{-}(\mathrm{S}) \\
\mathrm{S}_{3}{ }^{2-}(\mathrm{AS}) \\
\mathrm{S}_{4}{ }^{2-}(\mathrm{AS}) \\
\mathrm{S}_{6}^{-} \\
\mathrm{S}_{8}{ }^{2-}\end{array}$ & $\begin{array}{l}455 \mathrm{vs} \\
444 \mathrm{~s}, 184 \mathrm{~s} \\
462 \mathrm{~s}, 445 \mathrm{~s}, 413 \mathrm{~s} \\
434 \mathrm{~s} \\
427 \mathrm{~s}, 487 \mathrm{~s}\end{array}$ \\
\hline $510^{\mathrm{a}}$ & $\begin{array}{l}\mathrm{S}_{4}^{-}(\mathrm{S}) \\
\mathrm{S}_{7^{-}}\end{array}$ & $\begin{array}{l}500 \mathrm{w}, 518^{67} \\
517 \mathrm{~m}, 506 \mathrm{~m}\end{array}$ \\
\hline $533^{\mathrm{a}, \mathrm{b}}$ & $\mathrm{S}_{3}^{-}$ & $535^{39,67,82,85,86}$ \\
\hline $568^{\mathrm{b}}$ & $\begin{array}{l}\mathrm{S}_{4}^{-}(\mathrm{S}) \\
\mathrm{S}_{5}^{-}\end{array}$ & $\begin{array}{l}558 \mathrm{~m} \\
552 \mathrm{~s}\end{array}$ \\
\hline
\end{tabular}

Peak identification is difficult as most polysulfides identified in the literature were in the solid form, in different solvents, or had a different coordinating cation. Most reports do not attempt to identify a certain Raman peak to a specific chain length. Hagen et al. used Gaussian03 and density functional theory to calculate theoretical peak positions in THF. They then did their own experiments in TEGDME. Since the currently discussed results are in a similar ether electrolyte and seem consistent with their analysis, the majority of 
peak assignments stem from their work and are listed in comparison to the current work in Table 6 . The peak at approximately $535 \mathrm{~cm}^{-1}$ is one of the few peaks that the literature consistently identifies as $\mathrm{S}_{3}{ }^{-39,67,82,85,86}$ Both Yeon et al. and Wu et al. identified $\mathrm{S}_{\mathrm{x}}{ }^{2-}(\mathrm{x}=4-$ 8) at $766 \mathrm{~cm}^{-1}$, however this is not consistent with other literature sources where the majority of polysulfide peaks are only present below $600 \mathrm{~cm}^{-1}$; this $766 \mathrm{~cm}^{-1}$ peak was not observed in any of the current experiments. The peak at $200 \mathrm{~cm}^{-1}$ is more likely a combination of $\mathrm{S}_{7}{ }^{-}$and $\mathrm{S}_{4}{ }^{-}$than the other species listed in Table 6 since it is relatively weak and these two species have strong peaks near the 390 and $450 \mathrm{~cm}^{-1}$ ranges. The other species that are close to that peak are located $\geq 15 \mathrm{~cm}^{-1}$ from $200 \mathrm{~cm}^{-1}$. The large quantity of possible assignments with each peak and the spread in wave numbers is consistent with the broad peaks having contributions from multiple polysulfide chain lengths.

The most intense peaks were tracked over a week to determine the stability of the

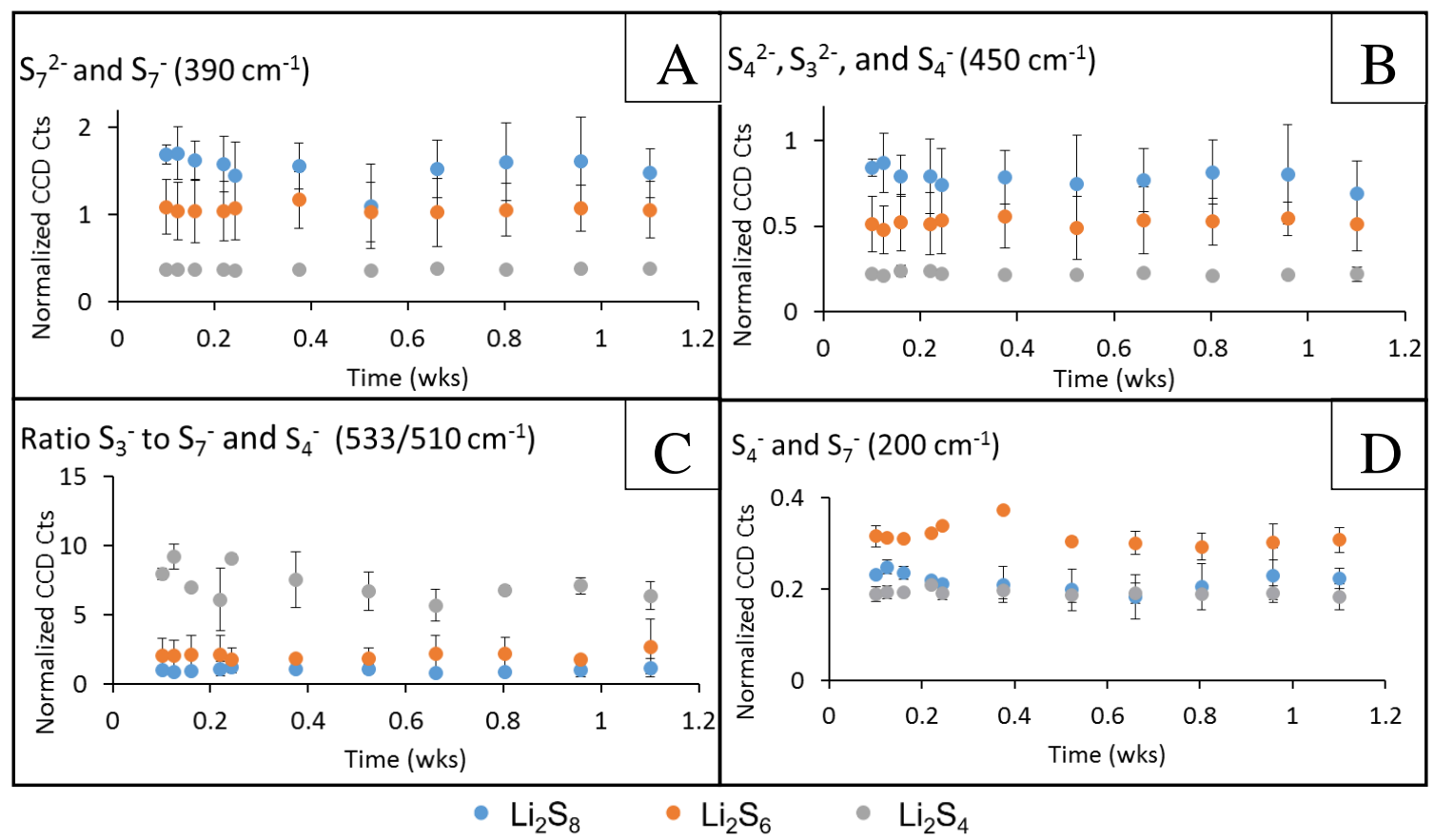

Figure 41: Stability study of polysulfide standards under argon. A.) $390 \mathrm{~cm}^{-1}$ most closely corresponding to $\mathrm{S}_{7}{ }^{2-}$ and $\mathrm{S}_{7}{ }^{2-}$ B.) $450 \mathrm{~cm}^{-1}$ most closely corresponding to $\mathrm{S}_{4}{ }^{2-}, \mathrm{S}_{3}{ }^{2-}$, and $\mathrm{S}_{4}^{-} \mathrm{C}$.) Ratio of the $533 \mathrm{~cm}^{-1} \mathrm{most}$ closely corresponding to $S_{3}{ }^{-}$and $510 \mathrm{~cm}^{-1}$ most closely corresponding to $S_{7}{ }^{-}$and $S_{4}{ }^{-}$D.) $200 \mathrm{~cm}^{-1}$ most closely corresponding to $\mathrm{S}_{8}{ }^{-}$and $\mathrm{S}_{7}{ }^{-}$. 
standards as shown in Figure 41 along with their most likely peak assignments. ${ }^{39} \mathrm{Li}_{2} \mathrm{~S}_{4}$ is less variable than $\mathrm{Li}_{2} \mathrm{~S}_{6}$ and $\mathrm{Li}_{2} \mathrm{~S}_{8}$ and even with error, is set apart from the $\mathrm{Li}_{2} \mathrm{~S}_{8}$ and $\mathrm{Li}_{2} \mathrm{~S}_{6}$ standards for the 390, 450, and ratio of 533 to 510 wave numbers as shown in Figure 41 A, $\mathrm{B}$, and $\mathrm{C}$ respectively. A ratio was used for Figure $41 \mathrm{C}$ because the peak intensities for $533 \mathrm{~cm}^{-1}$ were all within error of each other for the three standards. What is easily observed in the 500-550 $\mathrm{cm}^{-1}$ range in Figure 39 is the change in relative intensities between 510 and $533 \mathrm{~cm}^{-1}$ for the three different standards.

$\mathrm{Li}_{2} \mathrm{~S}_{6}$ is highly variable between the two replicates for all polysulfide peaks except at $200 \mathrm{~cm}^{-1}$. The $200 \mathrm{~cm}^{-1}$ peak distinguishes $\mathrm{Li}_{2} \mathrm{~S}_{6}$ from the other two standards (Figure 41 D).

The standards are fairly stable over the week long observation period. No new peaks developed and all peak intensities for a given standard and peak remained within 0.075 normalized CCD counts of each other. Despite having the same species present, the $\mathrm{Li}_{2} \mathrm{~S}_{8}, \mathrm{Li}_{2} \mathrm{~S}_{6}$, and $\mathrm{Li}_{2} \mathrm{~S}_{4}$ standards differed from each other in relative distributions of polysulfide species. This gives evidence that chemically synthesized standards, kept under argon and in the dark, can be used for comparison with samples for at least one week. This has implications for characterization techniques other than Raman as well. 


\subsection{Generation 1: In situ Coin Cell}

The initial in situ cell design involved a coin cell with a viewing window. A variety of sealants (Table 5) were tested for compatibility with the electrolyte to create a good seal. Double/Bubble ${ }^{\circledR}$ 2-part adhesive: extra fast setting and Loctite ${ }^{\circledR}$ E-30CL Hysol® Epoxy showed the most promise. The most important parameters that a sealant needed to have were to be 1) chemically resistant to the electrolyte since the sealant and the electrolyte were in direct contact, 2) be electrochemically stable in the voltage window of $3-1.7 \mathrm{~V}$ vs. lithium, and 3) not change the electrolyte chemistry.

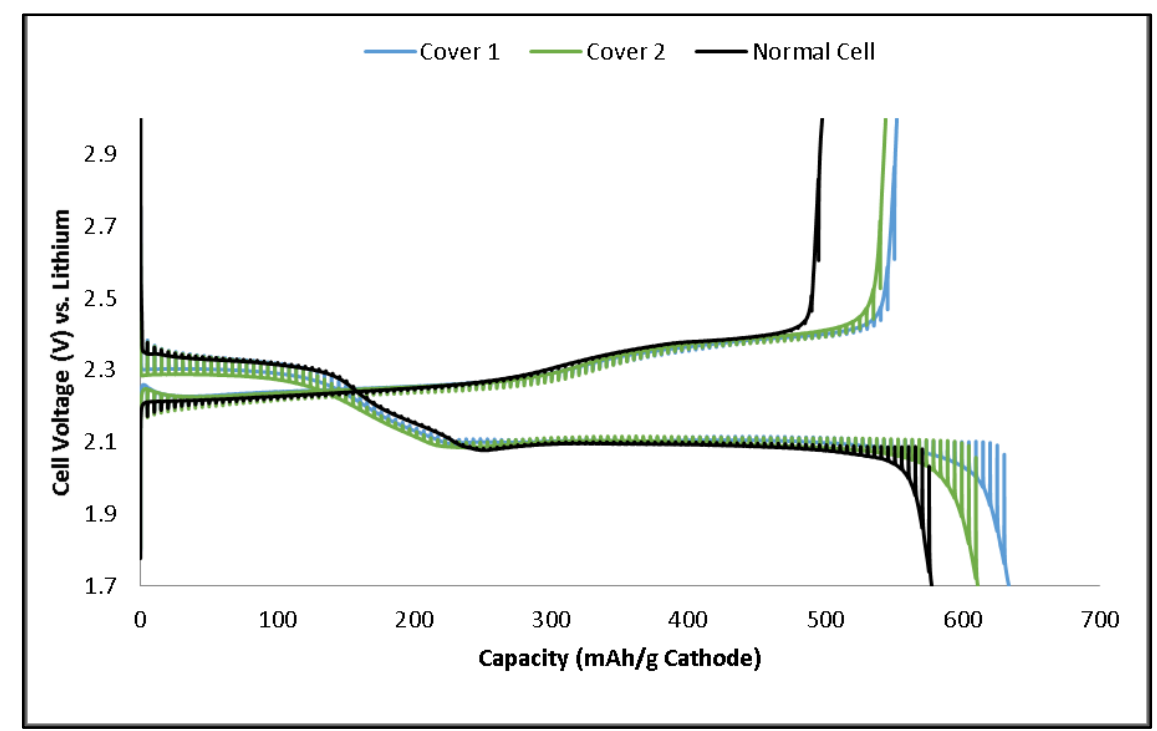

Figure 42: First discharge curves with current interrupts for a normal coin cell (black), and two replicates (green and blue) of coin cells sealed from the outside using Double/Bubble ${ }^{\circledR}$ extra fast setting epoxy. The cathode in these cells were 60:30:10 sulfur: Super P: PVDF with a lithium metal anode. Cells were cycled at $\mathrm{C} / 10$.

The Double/Bubble ${ }^{\circledR}$ extra fast setting epoxy did not change the Raman spectrum of the electrolyte after soaking it for several days, however in the presence of the electrolyte and lithium, this epoxy was very reactive as can be seen in Figure 44. Coin cells were built 


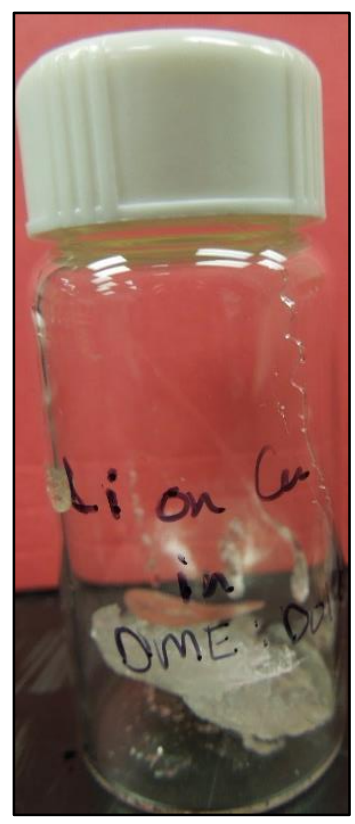

Figure 44: Result of soaking lithium metal and Double/Bubble ${ }^{\circledR}$ extra fast setting epoxy in electrolyte for one day. All electrolyte is gone and the epoxy has expanded.

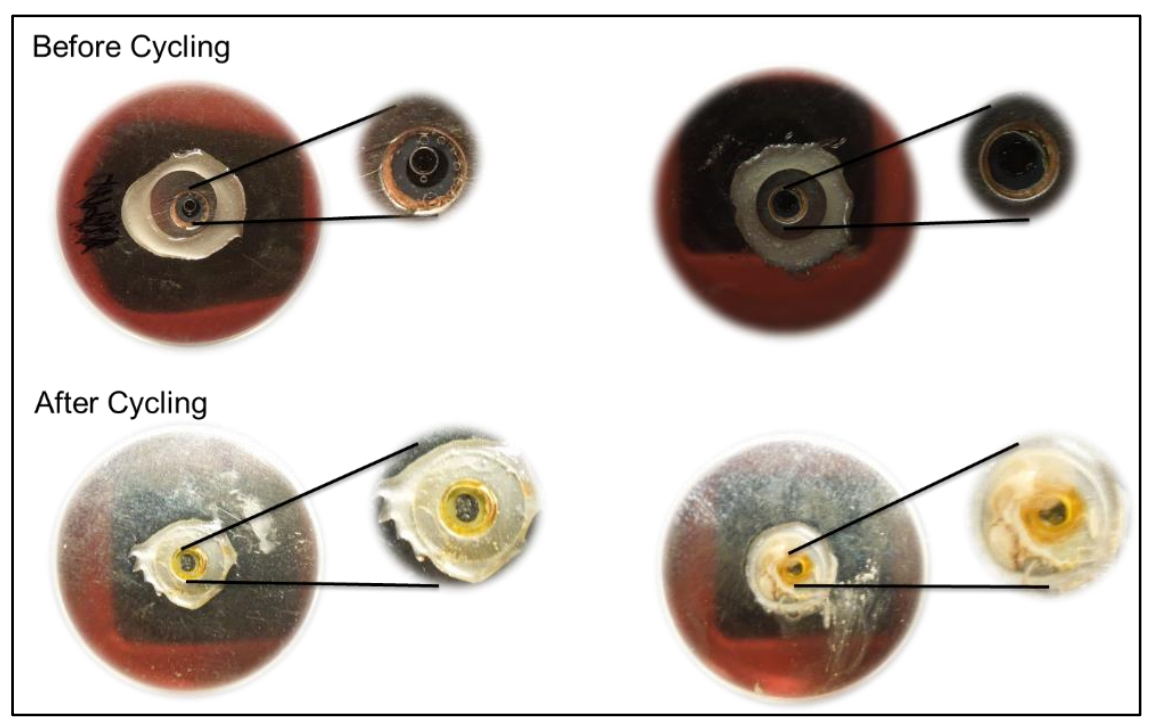

Figure 43: Coin cells sealed from the outside with Double/Bubble® extra fast setting epoxy before and after cycling.

with this epoxy by gluing the window to the outside of the coin cell. These cells actually cycled very well, as seen in Figure 42. Images of the cells before and after cycling are shown in Figure 43. Unfortunately, no Raman spectra of the electrolyte could be obtained once the cells started to discharge.

The Loctite® E-30CL Hysol® Epoxy was chemically resistant to the electrolyte and held its seal for several days. Again, upon discharge, an electrolyte signal could not be seen with the Raman microscope. Yellow crystals also formed around the viewing window of the coin cell, suggesting that this epoxy may have been reactive with the polysulfides or unstable in the voltage window of interest.

Due to the lack of a compatible sealant, the in situ cell design was changed to a less realistic design with a large E/S ratio in which an O-ring pressure seal could be used. 


\subsection{Generation 3: In situ T-Cell}

In situ Raman measurements were taken on the Generation 3 cell and several polysulfide peaks were successfully tracked during discharge and charge. As shown in

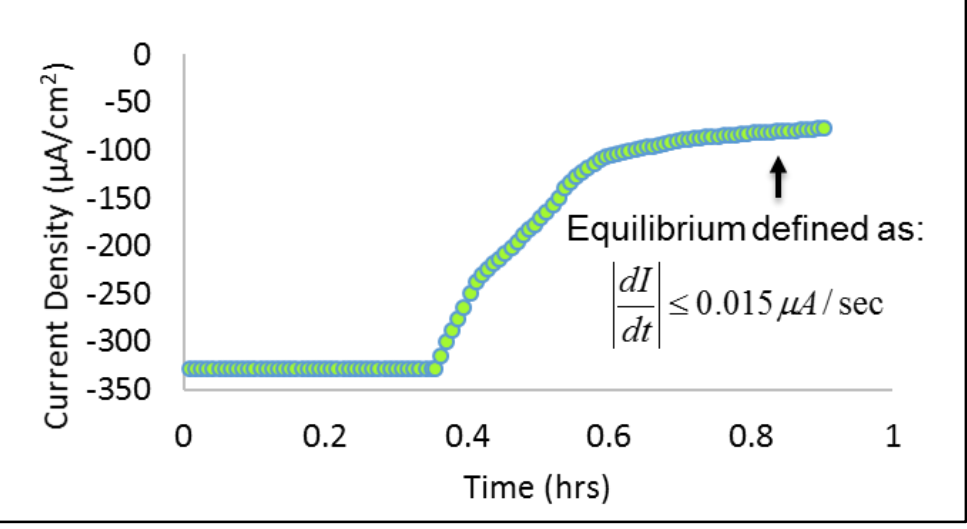

Figure 45: Example of current decay reaching equilibrium just prior to the acquisition of a Raman spectrum at $2.35 \mathrm{~V}$ during the discharge cycle.
Figure 24, the cells were discharged at a constant rate of $\mathrm{C} / 10$ in between voltage steps. A quasi-equilibrium was obtained at each step before taking a spectrum. Equilibrium was defined as

the current decaying at a rate of $\left|\frac{d I}{d t}\right| \leq 0.015 \mu \mathrm{A} / \mathrm{sec}$. This definition was used rather than a set percentage of the initial current because the current didn't always equilibrate to a current of zero as is evident in Figure 45. An example of the current decaying to equilibrium is shown for one replicate at $2.35 \mathrm{~V}$ during the discharge cycle in Figure 45.

The advantage to using voltage holds rather than performing constant discharge while taking a spectrum is that a quasi-equilibrium can be maintained while the spectrum is obtained, so that speciation is less likely to have changed during acquisition of the spectrum, which can last several minutes. The disadvantage is that variabilities in current decay cause more deviation in the state of charge at which a spectrum is taken. This is important to note since polysulfide speciation is a function of both voltage and state of charge. Lastly, during the charge cycle, it becomes impossible to look at speciation as a function of state of charge because for the voltages from $1.7 \mathrm{~V}$ to $2.2 \mathrm{~V}$, the current decay equilibrated to a negative current, so the battery was not effectively charged. This makes 
sense because the large electrolyte volume and electrode separation most likely increase the effect of the polysulfide shuttle, which is most detrimental during charge and can cause infinite re-charging, and was possibly the cause of the observed, equilibrated non-zero current.

The capacity of the three replicates were between 200 and $630 \mathrm{mAh} / \mathrm{g}$ sulfur. All voltage holds and current decays for the first replicate are shown in Figure 46. See Appendix $\mathrm{C}$ for the other two replicates and for the normal discharge of a $\mathrm{T}$-cell at $\mathrm{C} / 50$.

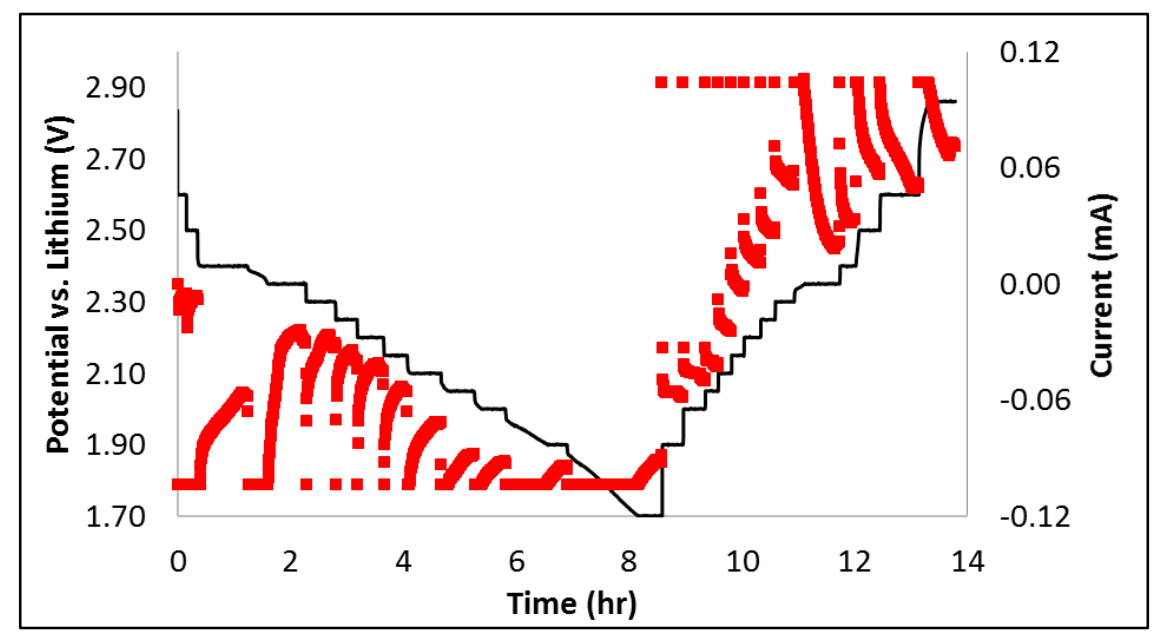

Figure 46: Voltage steps and current decays for T-cell replicate number one. Red is current on the right y-axis and black is voltage on the left y-axis.

Spectra were obtained in the bulk electrolyte due to the absorptivity of the polysulfides. The Raman was able to record a clean spectrum between the electrodes from $2.9 \mathrm{~V}$ until $2.4 \mathrm{~V}$ when polysulfides dissolved into the electrolyte. As a result, the focal point of the Raman was optimized such that clean spectra could be obtained throughout charge and discharge without having to reposition the Raman laser; this optimized position was in the bulk of the electrolyte rather than in between the electrodes.

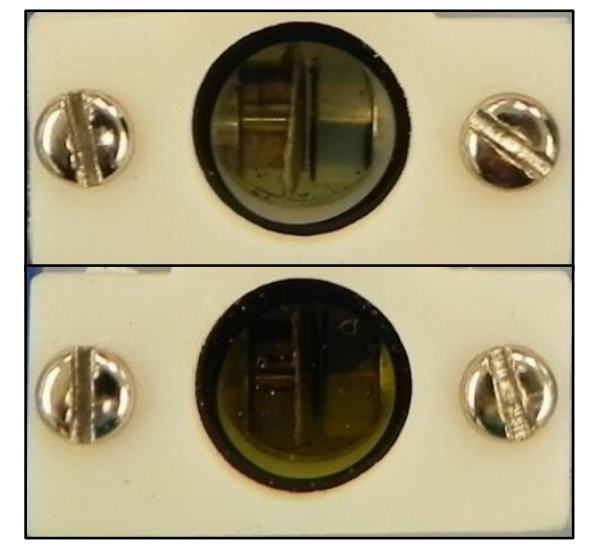

Figure 47: T-cell window before (top) and after (bottom) 1 discharge and charge cycle. 
The polysulfide concentration in the in situ T-cell is far less than that of the polysulfide standards, so it becomes completely necessary to subtract the electrolyte background from the polysulfide spectra in order to distinguish polysulfide peaks more clearly. Although the exact concentration of polysulfides cannot be calculated without the use of additional characterization techniques, the color of the solution is much lighter than that of the standards. Images of the T- cell window before and after cycling are shown in Figure 47.

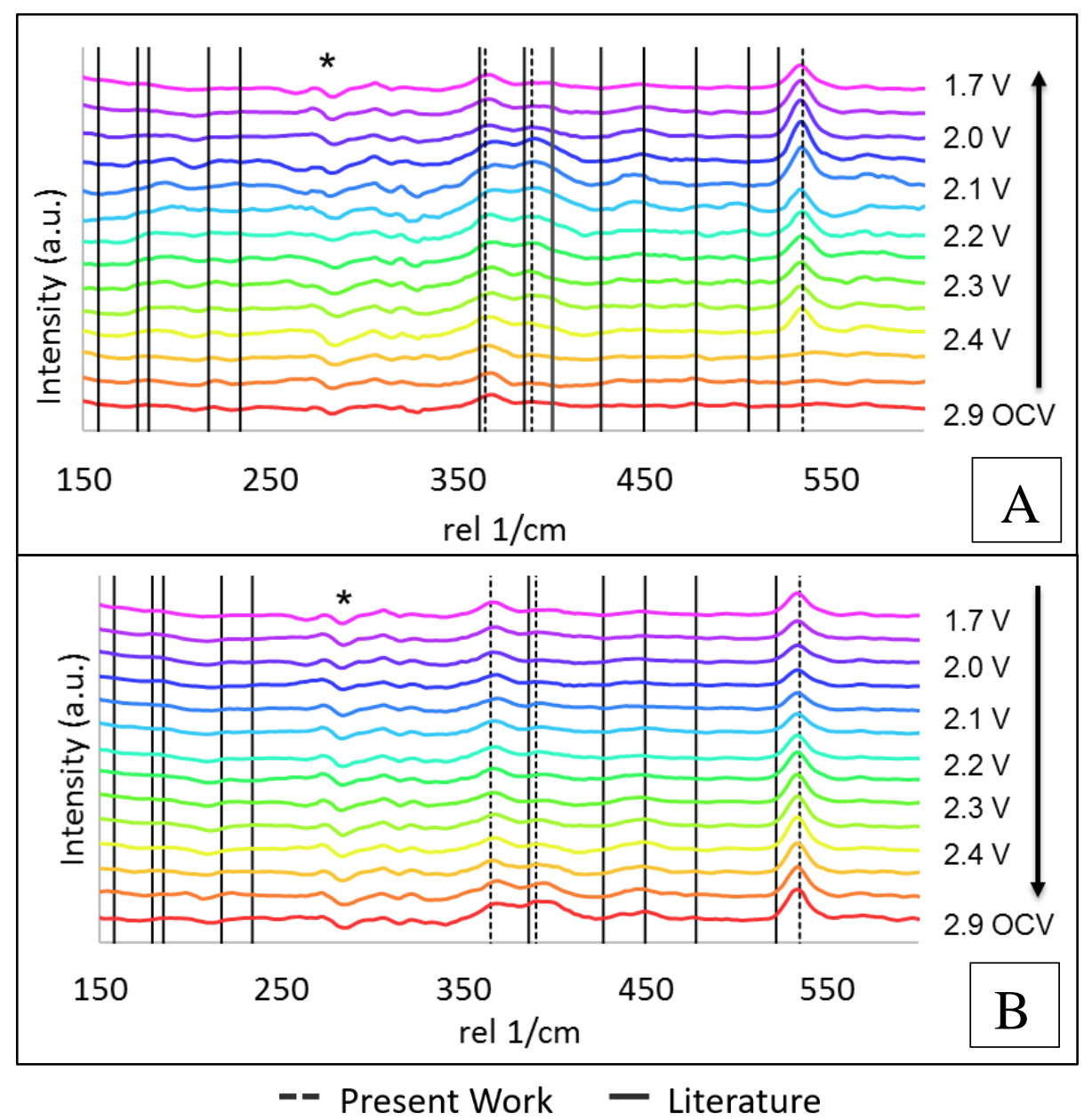

Figure 48: Raman spectra of replicate \#1 for in situ A.) discharge and B.) charge at each voltage step. Solid black lines are polysulfide peaks from Hagen et al. ${ }^{39}$ and dashed lines are peaks in the current work. * indicates where electrolyte peak subtraction has occurred. All spectra have an integration time of 30 seconds and 10 accumulations at a power of $8 \mathrm{~mW}$.

Furthermore, even if all sulfur initially in the cathode dissolved into the electrolyte, which is almost certainly not the case, the concentration of sulfur would only be about $2 \mathrm{mM}$ as 
compared to $50 \mathrm{mM}$ in the $\mathrm{Li}_{2} \mathrm{~S}_{8}$ standard.

The spectra obtained for the voltage steps during discharge and charge are shown in Figure 48. The processed, in situ spectra are much noisier than the standards despite having undergone the same data processing procedure. There are several likely, contributing factors to the observed, low signal to noise ratio, including a low sulfur concentration, the presence of lithium and an electrochemical gradient, and the use of the Witec Raman microscope. The Witec Raman microscope tends to have more noise because it uses a multimode fiber.

To make fitting the peaks easier and more accurate, the in situ data underwent further processing to smooth the spectra using the MATLAB ${ }^{\circ}$ function, smooth, with a span of 3 . This function uses a moving average filter and takes the point above and below the point of interest (span of 3), and averages them. Care must be taken when smoothing spectra to ensure that data is not altered or lost. Thus, full analysis was carried out before and after smoothing and no large changes in peak intensities or trends were observed. For further detail on spectral processing, see Appendix B.

Three peaks stand out strongly despite the noise, including broad peaks at approximately 365 and $390 \mathrm{~cm}^{-1}$ as well as a sharper peak at $533 \mathrm{~cm}^{-1}$. There are also smaller peaks at approximately 450, 265, and $570 \mathrm{~cm}^{-1}$. Peaks were fit throughout discharge and charge using a Lorentzian function as with the standards. In cases where fitting a peak was not relevant (e.g. a peak had too low of an intensity), the intensity of the spectrum rather than the intensity of the fit was recorded. 
Once again, peak assignment is difficult and the broad peaks are likely a combination of several peaks.

The $365 \mathrm{~cm}^{-1}$ peak is most likely predominately $\mathrm{S}_{8}{ }^{2-}$ since it corresponds nicely to

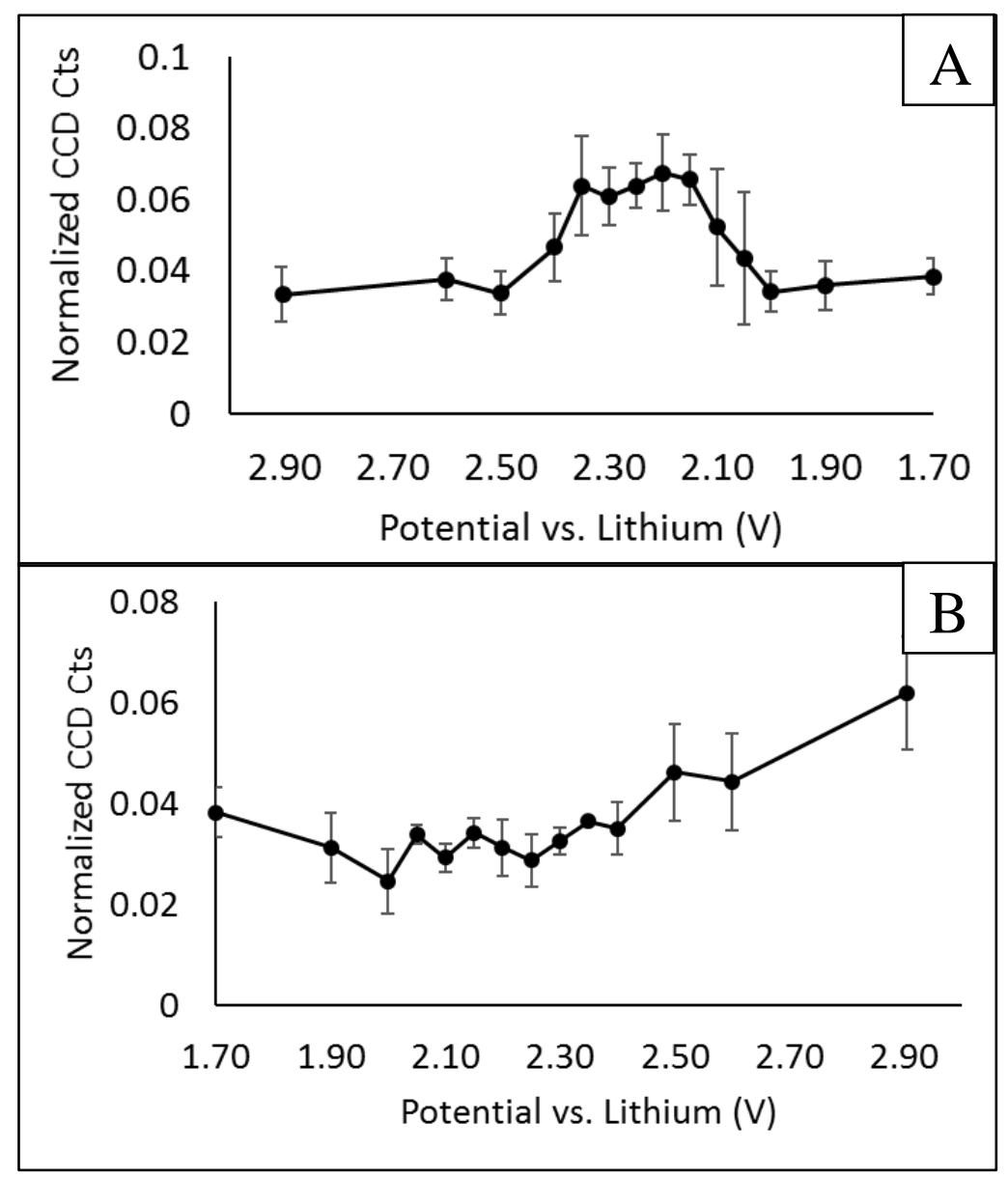

Figure 49: $365 \mathrm{~cm}^{-1}$ peak intensities during the A.) discharge and B.) charge of the in situ Li-S T-cell. Error bars are from three replicates.

the value calculated by Hagen et al. at $362 \mathrm{~cm}^{-1}$ (Table 6) and since it is present at the beginning of discharge (Figure 49 A). The presence of this peak before the start of the experiment is likely due to self-discharge. While the batteries sat overnight, their open circuit potential decreased from $\sim 3$ to $\sim 2.9 \mathrm{~V}$ vs. lithium when the experiment was started. It is possible, that as $\mathrm{Li}_{2} \mathrm{~S}_{8}$ is generated (the lithium source is most likely from the LiTFSI 
salt), a mixed potential at the cathode is created, decreasing the observed voltage. $\mathrm{Li}_{2} \mathrm{~S}_{8}$ dissolves into the electrolyte because it is soluble.

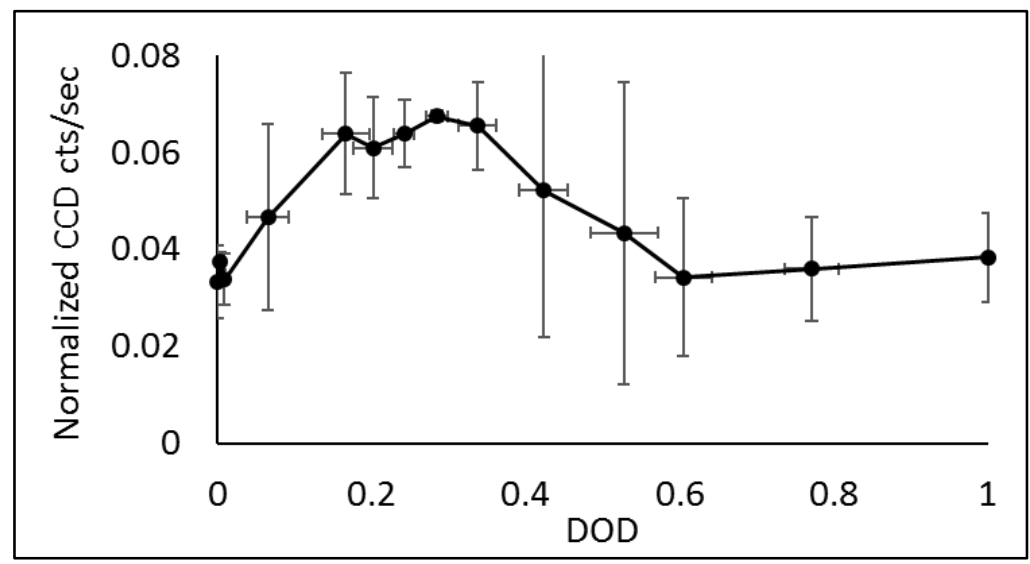

Figure 50: $365 \mathrm{~cm}^{-1}$ peak intensities as a function of depth of discharge. Error bars are from three replicates. Vertical error bars are error in peak intensity while horizontal error bars show error in the depth of discharge between three replicates.

The intensity of $365 \mathrm{~cm}^{-1}$ peak is also plotted as a function of depth of discharge to show the variation in state of charge at which each spectrum was acquired. It can be seen during the discharge cycle, that the peak intensities have the largest standard deviation between three replicates at voltages where a discharge plateau occurs, such as near $2.1 \mathrm{~V}$. Variations in when a spectrum was manually taken at these voltages amplified the error.

The $390 \mathrm{~cm}^{-1}$ peak either had a low intensity or no peak at all at the beginning of discharge in the three replicates. Its closest peak assignment is $\mathrm{S}_{7}{ }^{-}$and $\mathrm{S}_{7}{ }^{2-} \cdot{ }^{39}$ At $2.4 \mathrm{~V}$, the $390 \mathrm{~cm}^{-1}$ peak begins to increase with respect to the $365 \mathrm{~cm}^{-1}$ peak until they shift closer together and become near equal in intensity at $2.15 \mathrm{~V}$. The ratio then decreases between $2.15 \mathrm{~V}$ and $1.7 \mathrm{~V}$ as the battery finishes discharging. The 365 and $390 \mathrm{~cm}^{-1}$ peaks are separated during early discharge, but both broaden and combine to span from 350 to 420 $\mathrm{cm}^{-1}$ as the battery continues to discharge as shown in Figure 51 with representative fits for cell replicate one. 


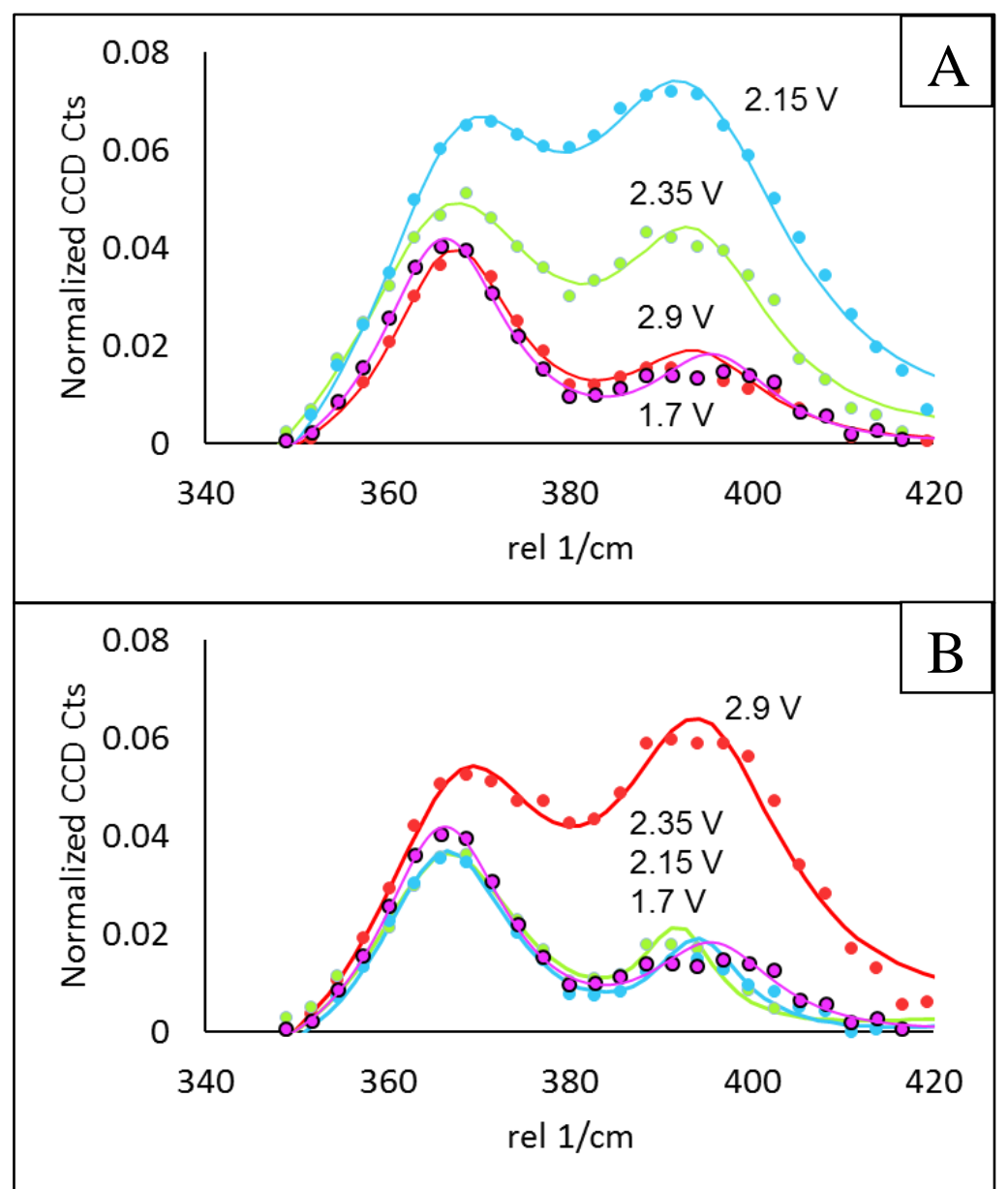

Figure 51: Representative raw data and fits of the peaks located at approximately 365 and $390 \mathrm{~cm}^{-1}$ during A.) discharge and B.) charge. This shows how the peaks shift and broaden during discharge. Colors are consistent with previous in situ spectra for each voltage.

Since the spectra were smoothed, only qualitative trends in peak position, rather than exact values, can be observed with confidence. The change in the ratio of these peaks during charge and discharge is plotted in Figure 52.

Upon charging, the expected reversal of this process is not observed. The ratio is highly variable across the replicates but the general trend of a steady increase in the ratio until reaching a value of approximately 1 when the battery is fully charged is shown in Figure 52. 
The peak at $533 \mathrm{~cm}^{-1}$, corresponding to $\mathrm{S}_{3}{ }^{-39,67,82,85,86}$ appears at $2.4 \mathrm{~V}$ and increases in intensity until $2.2 \mathrm{~V}$ before starting to decrease as shown in Figure 53. The peak remains located at $533 \pm 2 \mathrm{~cm}^{-1}$ throughout discharge. The $\mathrm{S}_{3}{ }^{-}$radical appears with

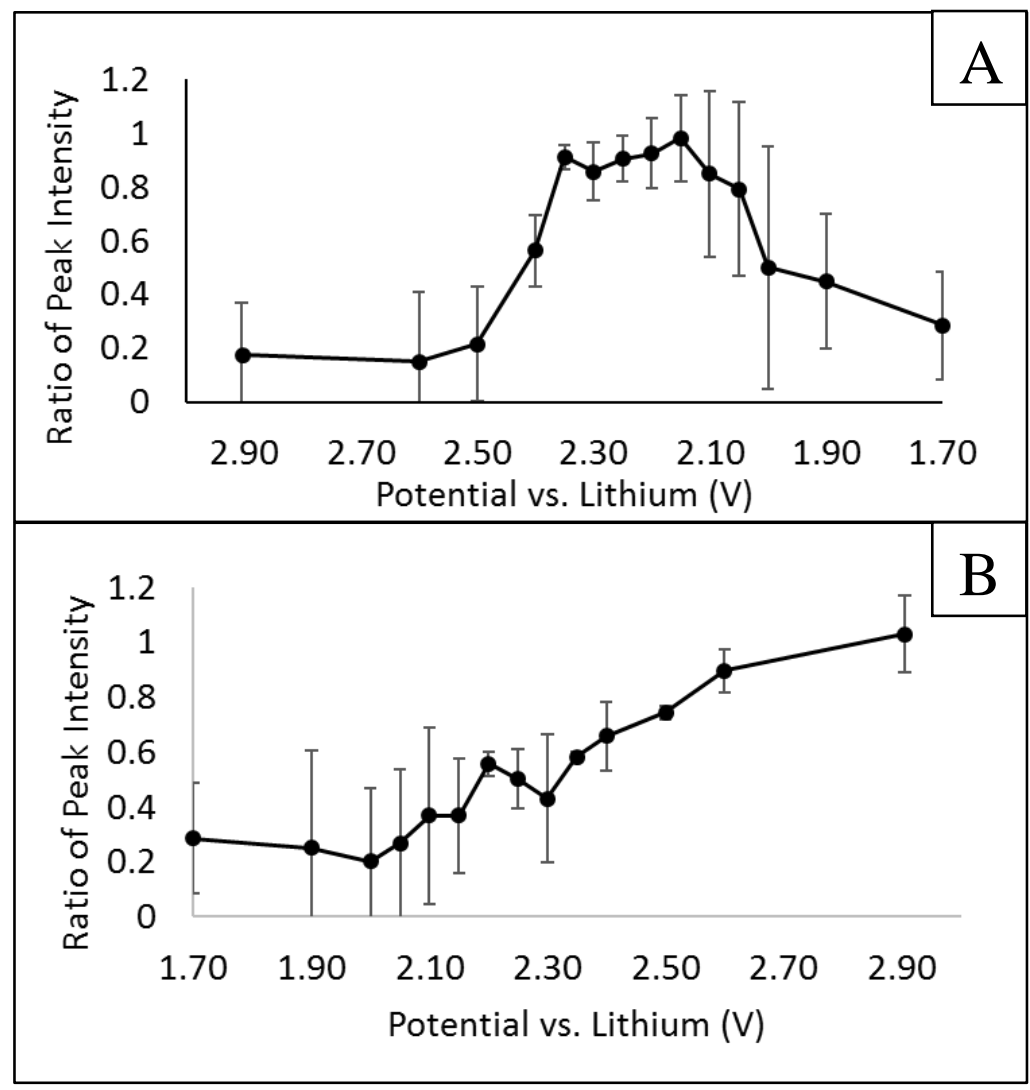

Figure 52: Ratio of 390 to $365 \mathrm{~cm}^{-1}$ peak intensities during the A.) discharge and B.) charge of the in situ Li-S T-cell. Error bars are from three replicates.

the generation of long-chain polysulfides, indicating a rapid equilibrium of the dissociation reactions. The $\mathrm{S}_{3}^{-}$radical is believed to form through the dissociation of $\mathrm{S}_{6}{ }^{2-}$ ( $\mathrm{n}=6$ in Equation 6). The weak presence of $\mathrm{S}_{6}{ }^{2-}\left(544 \text { and } 434 \mathrm{~cm}^{-1}\right)^{39}$ suggests that the $\mathrm{S}_{3}{ }^{-}$radical is favored at equilibrium. 


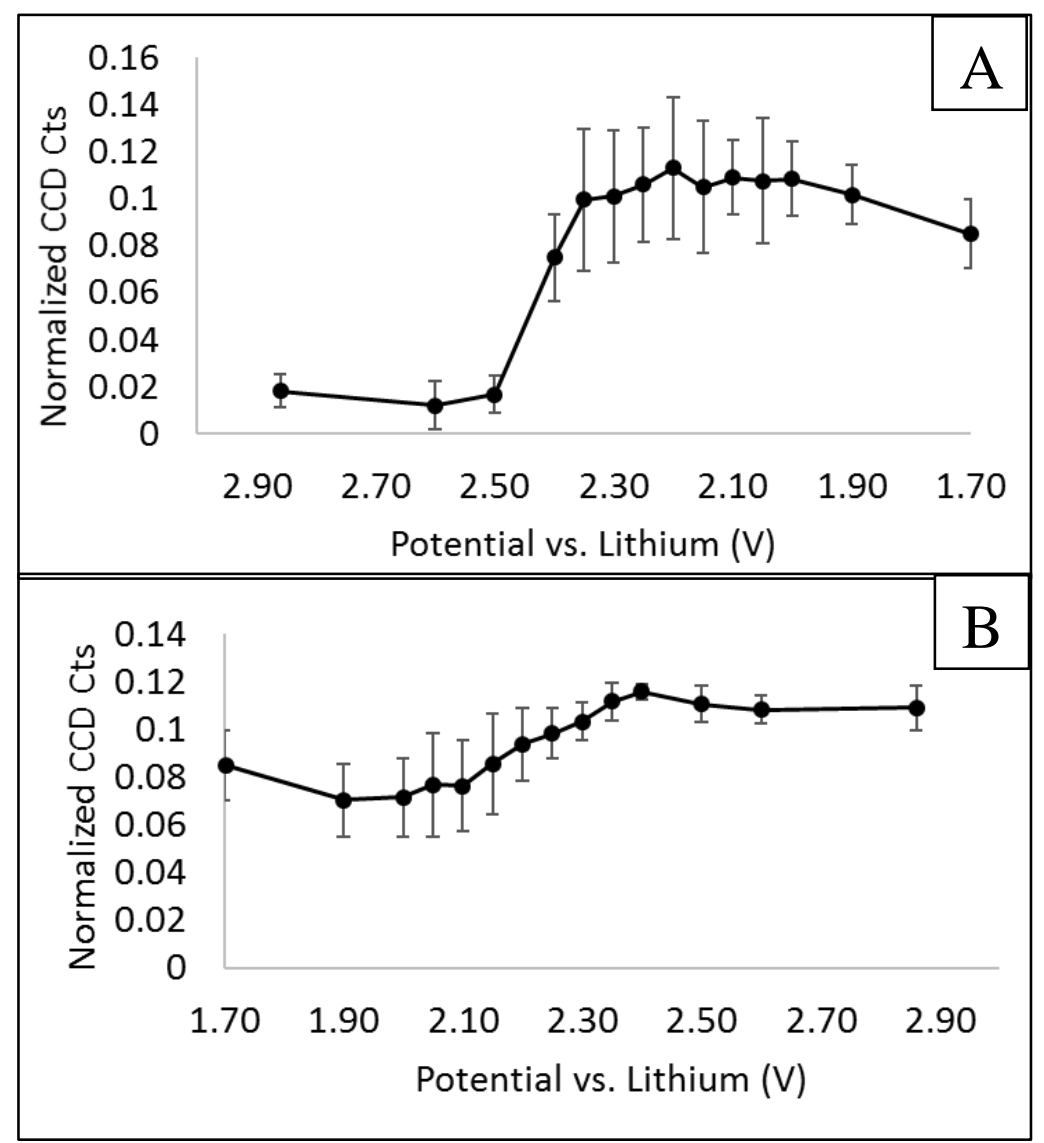

Figure 53: $533 \mathrm{~cm}^{-1}$ peak intensities during the A.) discharge and B.) charge of the in situ Li-S T-cell. Error bars are from three replicates.

The peaks near 265,450 , and $570 \mathrm{~cm}^{-1}$ were much less consistent between replicates than the more intense peaks discussed thus far. The peaks of 265 and $570 \mathrm{~cm}^{-1}$ in particular become insignificant when averaged between the replicates. These peaks may become more evident if the polysulfide concentration were greater. The $450 \mathrm{~cm}^{-1}$ peak intensity as a function of voltage is depicted in Figure 54. Its peak position varied between 440 and $450 \mathrm{~cm}^{-1}$ because it was so broad. Despite a large amount of error, there is a similar trend as with the other polysulfide peaks. This peak was broad and most likely corresponds to shorter chain polysulfides such as $\mathrm{S}_{3}{ }^{2-}, \mathrm{S}_{4}{ }^{2-}$, and $\mathrm{S}_{4}^{-}$in addition to some long chain polysulfides. ${ }^{39}$ 


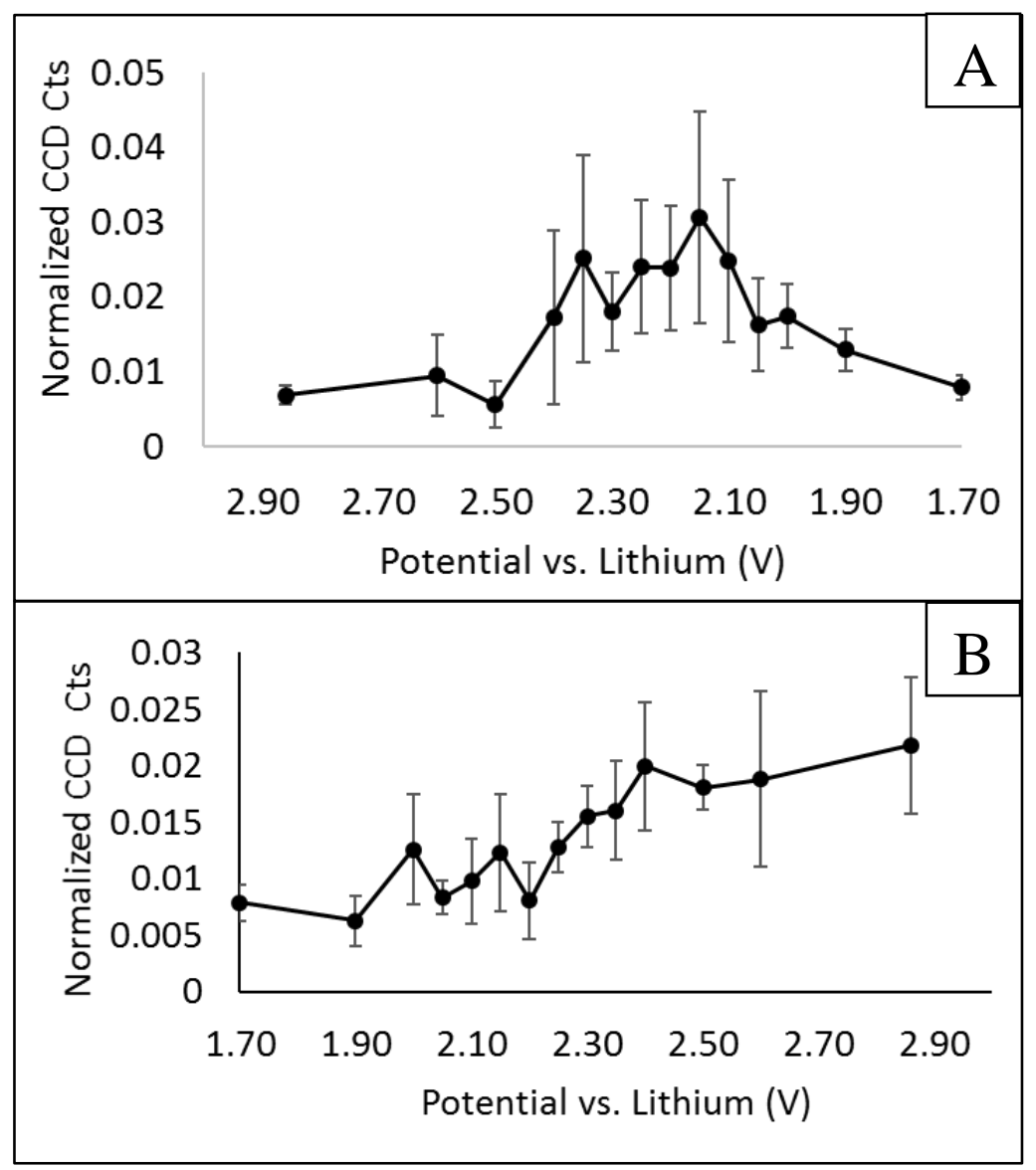

Figure 54: $450 \mathrm{~cm}^{-1}$ peak intensities during the A.) discharge and B.) charge of the in situ Li-S T-cell. Error bars are from three replicates.

Lastly, the $1066 \mathrm{~cm}^{-1}$ dithionite anion peak is also present, also with a large error (Figure 55). There is less certainty in the intensity of this peak because its position is outside the range in which polysulfides are Raman active, changing the absorptivity and background subtraction. Qualitative trends and changes can still be determined. The presence of this peak is most likely due to trace oxygen in the glovebox. If a large exposure of air had occurred, an increase in fluorescence would have been observed as discussed in the section on cell components. This was not observed, so the cell seal must have been sufficient.

In summary, polysulfide peaks at approximately 390,450 , and $533 \mathrm{~cm}^{-1}$ begin to increase in intensity at $2.4 \mathrm{~V}$. The peak at $365 \mathrm{~cm}^{-1}$ is most likely $\mathrm{S}_{8}{ }^{2-}$ and is present prior 


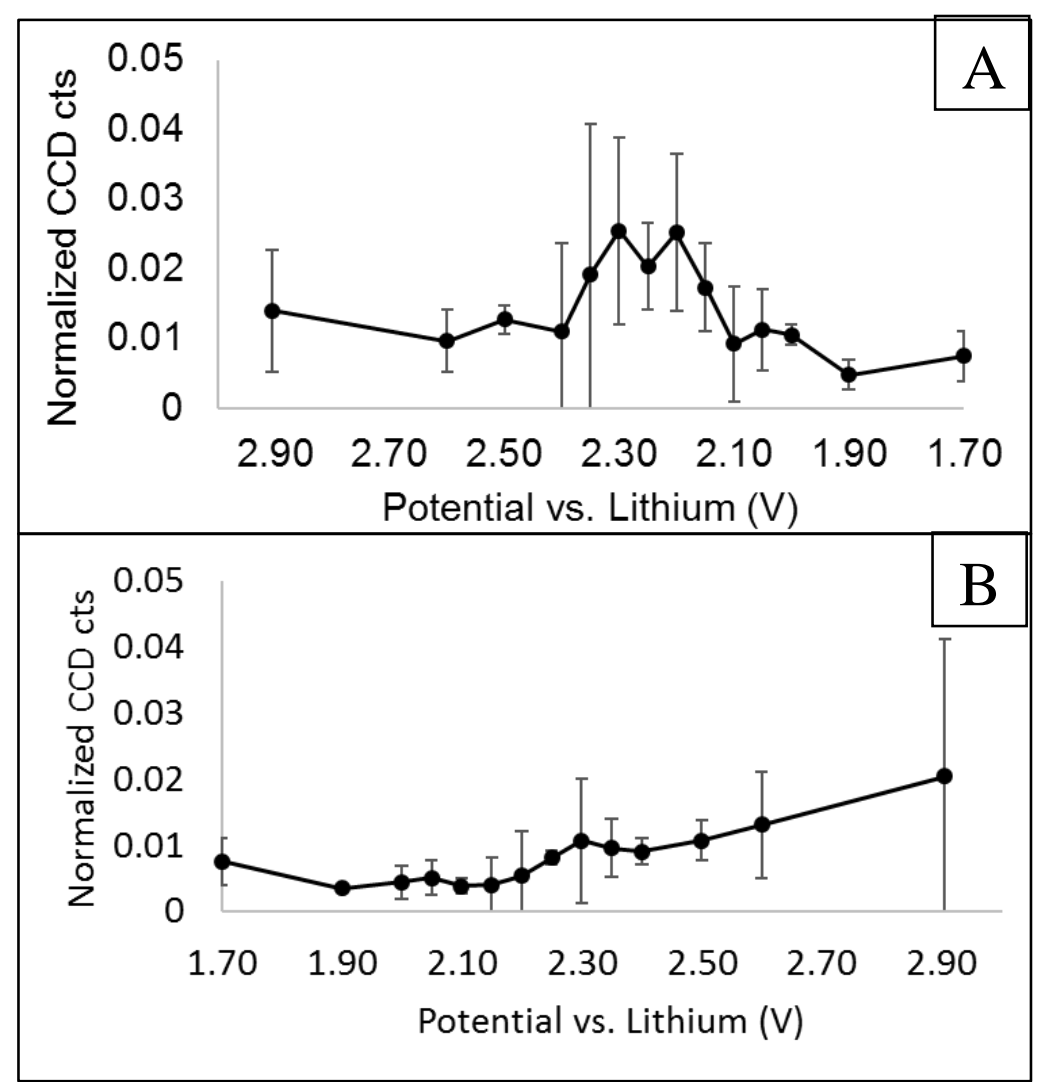

Figure 55: $1066 \mathrm{~cm}^{-1}$ peak intensities during the A.) discharge and B.) charge of the in situ Li-S T-cell. Error bars are from three replicates.

to cycling due to self-discharge. This species is present throughout discharge, but decreases around $2.15 \mathrm{~V}$ as it is converted to short chain polysulfides. The 390 peak, which is most likely $\mathrm{S}_{7}{ }^{-}$and $\mathrm{S}_{7}{ }^{2-}$, follows a similar trend. The $450 \mathrm{~cm}^{-1}$ peak, corresponding to short chain polysulfides, is also present throughout, but has its maximum at approximately $2.15 \mathrm{~V}$. The $533 \mathrm{~cm}^{-1}$ peak is indicative of the $\mathrm{S}_{3}^{-}$radical. This suggests that it is favored over $\mathrm{S}_{6}{ }^{2-}$ in the dissociation equilibrium reaction. All species do not see the reversal of these trends upon charging, instead they all increase in intensity. This is most likely due to the large E/S ratio and the polysulfide shuttle. It may also indicate a loss in useful sulfur inventory from the cathode to the electrolyte, however tracking of the speciation for additional cycles is needed to confirm this. 
The peaks observed in the in situ cell were not all observed in the standards and vice versa. The $\mathrm{S}_{3}^{-}$radical, $\mathrm{S}_{7}^{-}$, and $\mathrm{S}_{7}{ }^{2-}$ polysulfides were present in both. Thus the equilibria achieved in the two systems is different. System properties and conditions such as concentration, solvent, electrochemical gradients, etc. greatly affect the Raman peak positions and intensities. This explains the variation of the peaks in this study from many literature sources as these peaks are specific to the DME: DOL solvent system. 


\section{Conclusions}

Lithium polysulfide standards were successfully synthesized under argon and were shown to be stable for at least one week after synthesis if maintained under argon and stored in the dark. All three of the nominal standards, $\mathrm{Li}_{2} \mathrm{~S}_{8}, \mathrm{Li}_{2} \mathrm{~S}_{6}$, and $\mathrm{Li}_{2} \mathrm{~S}_{4}$ had the same polysulfide species present at equilibrium, namely approximate peaks at $119\left(\mathrm{~S}_{5}^{2-}\right), 200$ $\left(\mathrm{S}_{7}{ }^{-}\right.$and $\left.\mathrm{S}_{4}{ }^{-}\right), 390\left(\mathrm{~S}_{7}{ }^{-}\right.$and $\left.\mathrm{S}_{7^{-}}{ }^{2-}\right), 450\left(\mathrm{~S}_{4}^{-}, \mathrm{S}_{3}{ }^{2-}, \mathrm{S}_{4}{ }^{2-}, \mathrm{S}_{6}{ }^{-}\right.$, and $\left.\mathrm{S}_{8}{ }^{2-}\right), 510\left(\mathrm{~S}_{4}^{-}\right.$and $\left.\mathrm{S}_{7}{ }^{-}\right)$, and 533 $\mathrm{cm}^{-1}\left(\mathrm{~S}_{3}^{-}\right)$. Despite having the same species present, the three standards could be distinguished from each other based on differences in relative peak intensities. Not all of the peaks observed in the standards were seen in the in situ cell. This result, combined with multiple species present in the standards, makes it difficult to relate the standards to the in situ cell. However, the knowledge of the stability of these standards may prove useful for other characterization techniques.

Despite showing promise initially, the in situ coin cell proved to be infeasible for the timescale of this work, so a less realistic T-cell with the large E/S ratio of $1850 \mathrm{~mL} /$ gram sulfur was used for in situ Raman experiments. This approach was an improvement from the value in the $\mathrm{Wu}$ et al. paper, but not from that in the Hagen et al. paper.

Due to the absorptivity of the polysulfides, the speciation in the bulk of the electrolyte was tracked during one discharge and charge cycle. At the beginning of the experiment the $365 \mathrm{~cm}^{-1}\left(\mathrm{~S}_{8}{ }^{2-}\right)$ peak was already present from self-discharge. The peak then increased at $2.35 \mathrm{~V}$, keeping nearly the same intensity until it decreased at $2.15 \mathrm{~V}$. The 450 $\mathrm{cm}^{-1}$ peak, belonging to shorter chain polysulfides, reached a maximum at $2.15 \mathrm{~V}$. The $\mathrm{S}_{3}{ }^{-}$ peak at $533 \mathrm{~cm}^{-1}$ appeared at $2.4 \mathrm{~V}$ and increased until about $2.15 \mathrm{~V}$ and then started to decrease. All species were present during the majority of discharge. During the charge 
cycle, all the polysulfide peaks increased in intensity rather than reversing the trends seen during charge. This irreversibility showed that not all polysulfides were removed from solution, possibly from the large E/S ratio, large electrode separation, or the shuttle effect. 


\section{Future work}

Future work includes designing a better in situ cell that decreases the electrolyte to a more realistic E/S ratio perhaps by further investigation into the coin cell. Doing this would allow for different Raman focal points rather than just focusing in the bulk electrolyte. It would also increase the concentration of polysulfides in the electrolyte and may give cleaner spectra.

Multivariate analysis could also be applied to this work to try and better determine what polysulfide species are contributing to which peaks.

Additional cycles could be run to determine the loss of electrochemically accessible sulfur to the electrolyte, if any, with cycling.

Lastly, initial experiments have indicated photo-electrochemistry may be playing a role in the speciation of the polysulfide speciation as shown in Figure 56 for $2.35 \mathrm{~V}$ during discharge. When the laser is turned on, there is a response in the current decay (Figure 56 A). This response appears to have a voltage, and therefore a polysulfide speciation, dependence (Figure 56 B). Future work could try to quantify this phenomenon.

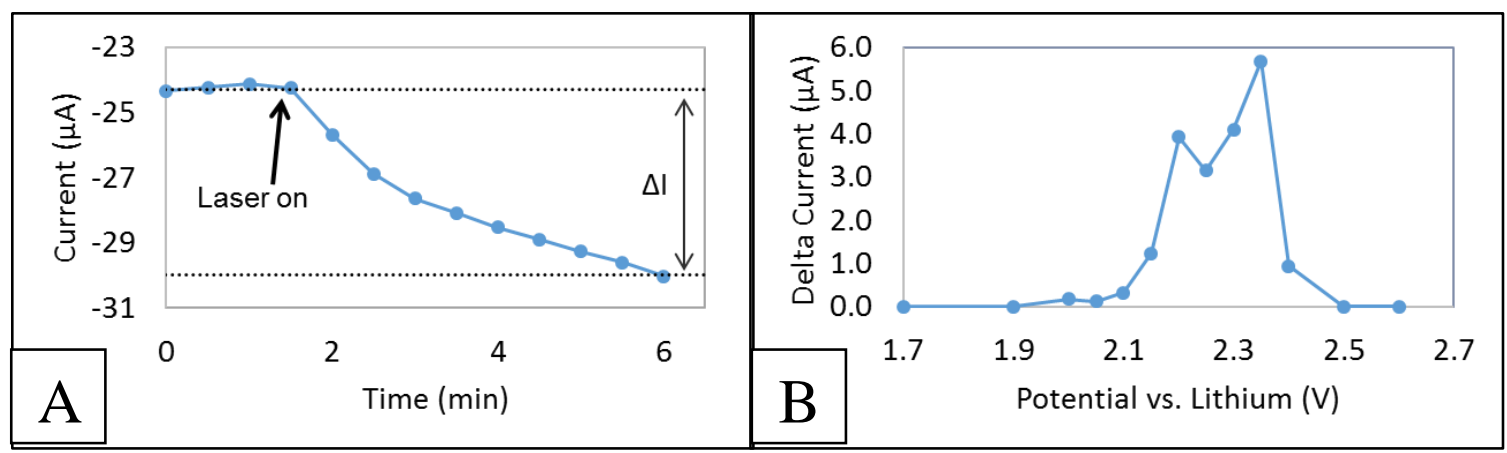

Figure 56: Initial experiment results on A.) the effect of the laser on the current decay and B.) dependence on voltage. Data from current decay at $2.35 \mathrm{~V}$ during the discharge of cell replicate number one. 


\section{Appendices}

\subsection{Appendix A: Mass Spectra for all Polysulfide Standards}

Mass spectra for samples A-H from Figure 15 are given in Figure 57.
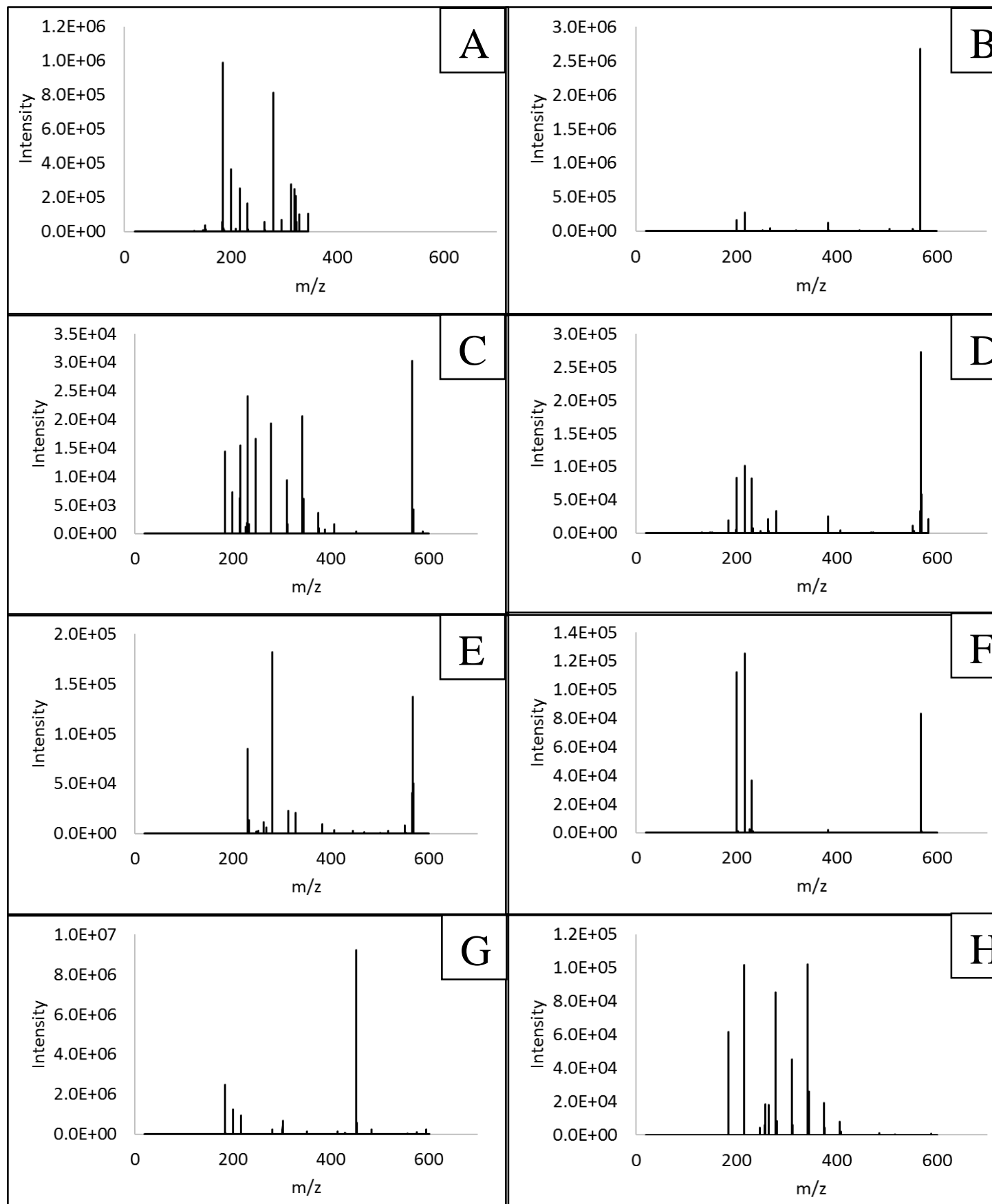

E
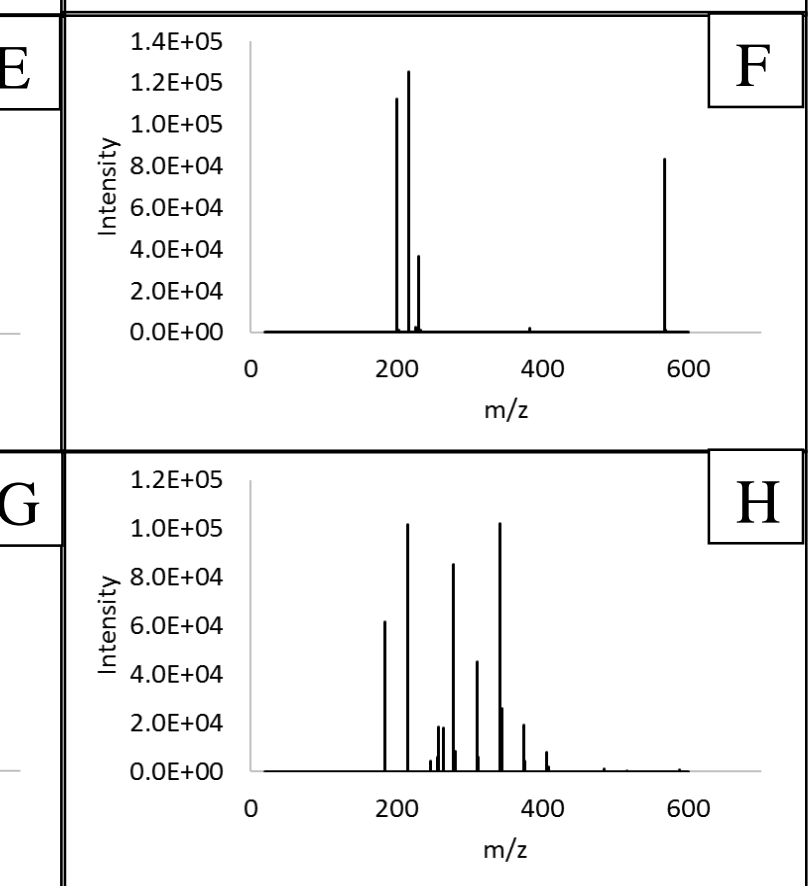

Figure 57: Mass spectra of sample standards A-H where A.) is $0.2 \mathrm{mmol} \mathrm{Li} 2 \mathrm{~S}, 0.075 \mathrm{mmol} \mathrm{S}_{8}$ in $5 \mathrm{~mL} \mathrm{DME}$, B.) is $0.2 \mathrm{mmol} \mathrm{Li} 2 \mathrm{~S}, 0.075 \mathrm{mmol} \mathrm{S} 8$ in $5 \mathrm{~mL} \mathrm{1:1} \mathrm{DME:} \mathrm{DOL,} \mathrm{C.)} \mathrm{is} 0.2 \mathrm{mmol} \mathrm{Li} 2 \mathrm{~S}, 0.075 \mathrm{mmol} \mathrm{S} 8$ in ACN, D.) is $50 \mathrm{mM}$ "Li2 $\mathrm{S}_{8}$ " in 1:1 DME: DOL, E.) is $50 \mathrm{mM}$ "Li2 $\mathrm{S}_{6}$ " in 1:1 DME: DOL, F.) is $50 \mathrm{mM}$ "Li2 $\mathrm{S}_{4}$ " in 1:1 DME: DOL, G.) is $0.2 \mathrm{mmol} \mathrm{Li}_{2} \mathrm{~S}, 0.075 \mathrm{mmol} \mathrm{S} 8$ in $5 \mathrm{~mL} \mathrm{DME}$, and $\mathrm{H}$.) is $0.2 \mathrm{mmol} \mathrm{Li}_{2} \mathrm{~S}, 0.075 \mathrm{mmol} \mathrm{S}_{8}$ in $5 \mathrm{~mL} \mathrm{ACN}$. 


\subsection{Appendix B: Spectral Processing}

The first step in spectral processing was to remove cosmic rays with a filter size and dynamic factor of 4 in WiTec Project. The filter size determines the total window over which each point is evaluated. The window size is $2 *($ filter size $)+1$. The dynamic factor determines the sensitivity of cosmic ray removal.

In most cases spectra were obtained as a long time series meaning that each accumulation was recorded separately. This was done to be able to track if peaks were changing during spectra acquisition. This also helps make the removal of cosmic rays easier. The downside to this is that this increases the read error of the spectra because the CCD counts have to be read to the computer multiple times rather than just once. However,

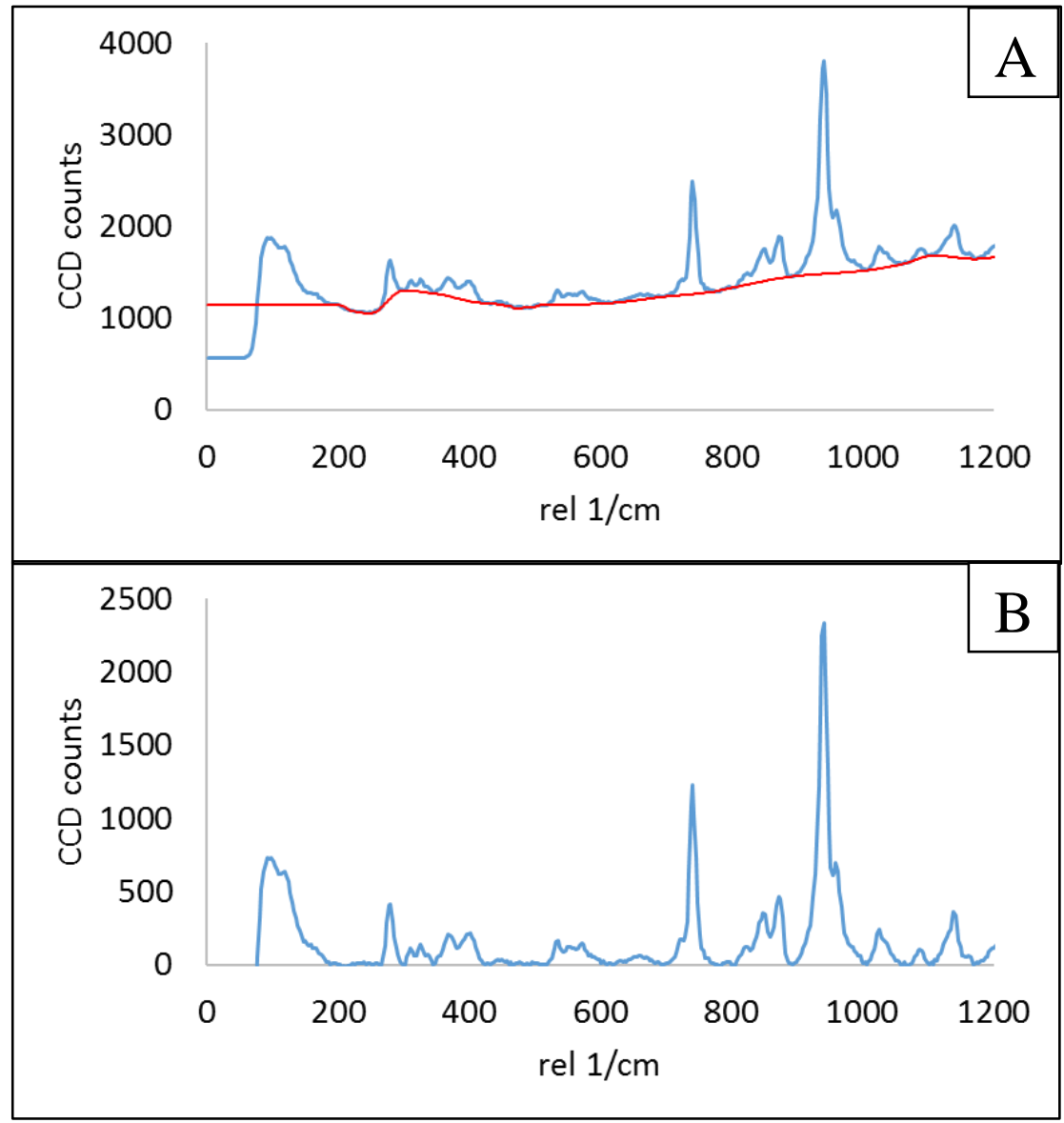

Figure 58: Example of background subtraction for a $\mathrm{Li}_{2} \mathrm{~S}_{8}$ standard A.) before and B.) after background subtraction. 
this error is small in contrast to the benefits of being able to see changes in peaks. The accumulations were averaged together into one spectrum.

The background of each spectrum was subtracted by using MATLAB® to fit a piecewise cubic hermite interpolating polynomial (PCHIP) to minima on the spectrum. The minima were determined by looking at 5 points below and above a hand-picked point and taking the minimum value. Doing this helped to minimize any loss of data. The use of PCHIP rather than a normal spline prevented any unintended waves between interpolation points. An example of a raw data set, in the region of interest, and its background subtraction is shown in Figure 58.

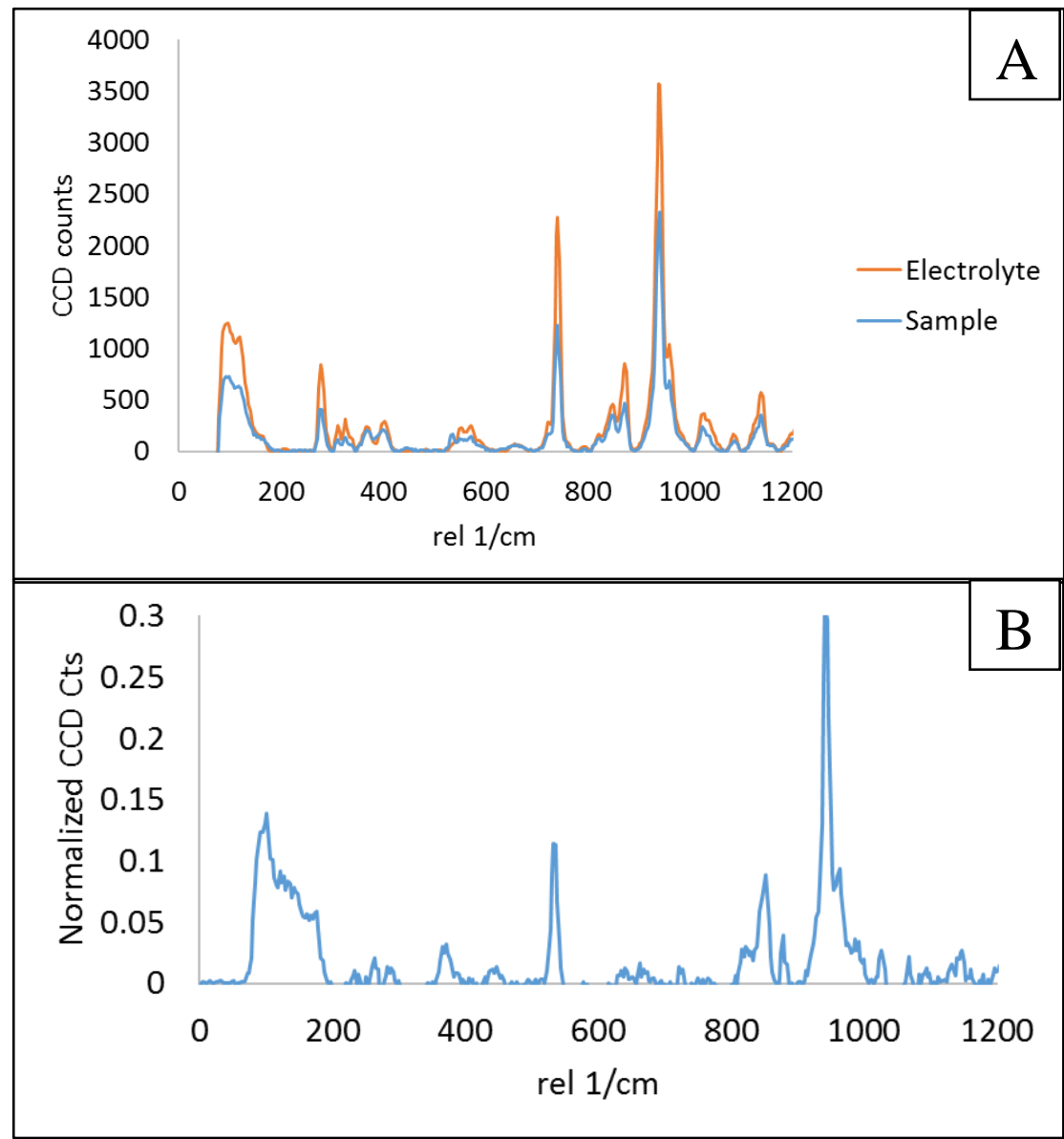

Figure 59: Example of normalization to the $740.7 \mathrm{~cm}^{-1}$ LiTFSI peak and subtraction of electrolyte peaks where A.) is a comparison of the electrolyte and a $\mathrm{Li}_{2} \mathrm{~S}_{8}$ standard prior to normalization and electrolyte subtraction and B.) is after normalization and electrolyte peak subtraction. 
All spectra were then put in terms of CCD counts per second and normalized to the maximum value that most closely corresponded to the $740.7 \mathrm{~cm}^{-1}$ LiTFSI peak. Therefore, all normalized peaks where LiTFSI was in the system are relative to this peak. LiTFSI should not change in intensity and thus is a good peak to compare to.

Once normalized, the spectra were scaled by multiplying by an average scale factor determined by the value needed to match the 280 and $740.7 \mathrm{~cm}^{-1}$ peaks in the sample to that of the electrolyte with its background removed. This only adjusted the spectra slightly since their peak at $740.7 \mathrm{~cm}^{-1}$ was already equal to 1 . The absorptivity of the polysulfides was wavelength dependent. Using an average scale-factor helped mitigate the changes in

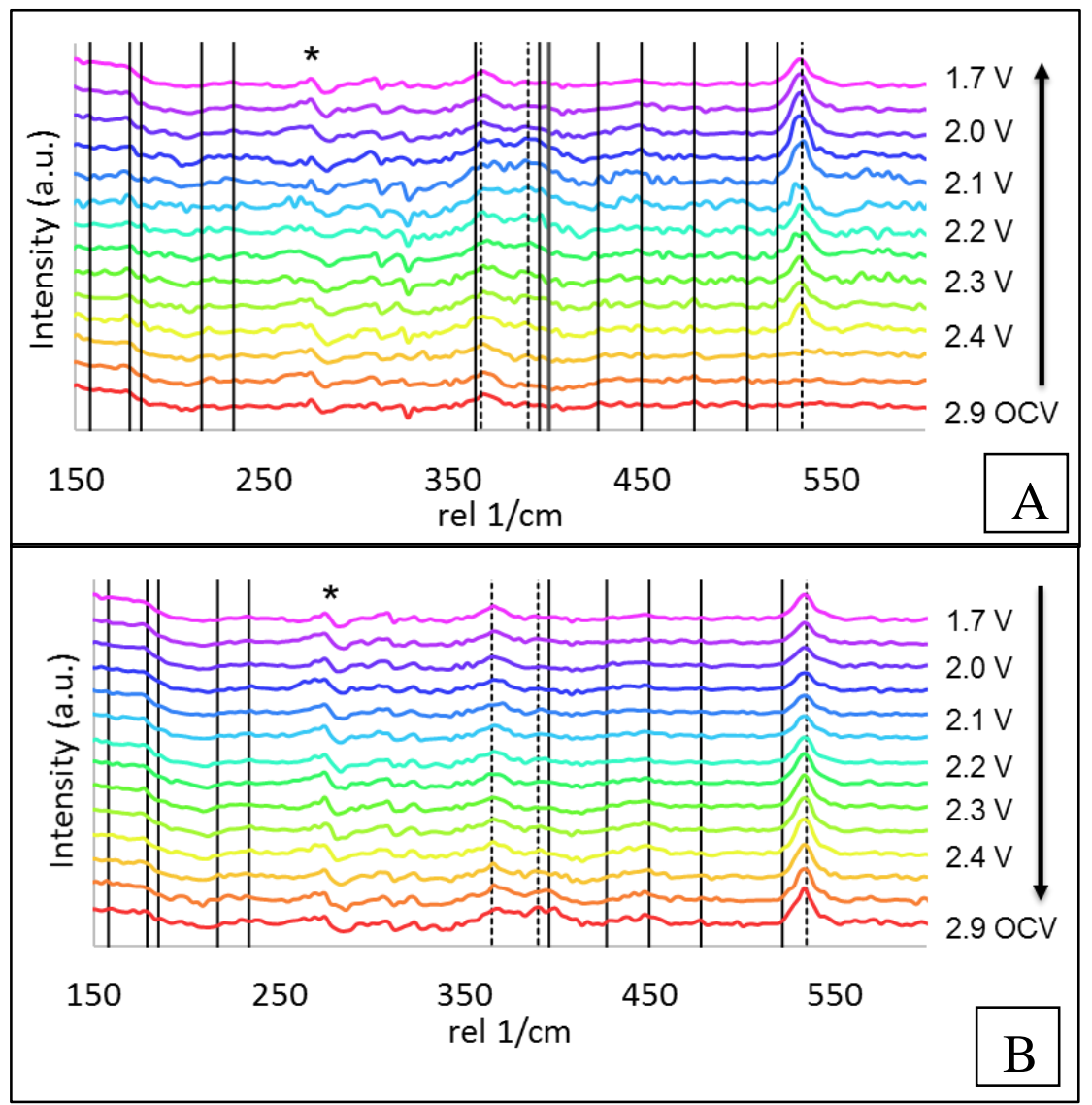

Figure 60: In situ spectra for replicate cell one prior to smoothing during A.) discharge and B.) charge. Solid black lines are polysulfide peaks from Hagen et al. and dashed lines are peaks in the current work. * indicates where electrolyte peak subtraction has occurred. All spectra have an integration time of 30 seconds and 10 accumulations at a power of $8 \mathrm{~mW}$. 
electrolyte peak intensity due to the absorptivity of polysulfides at different wavelengths above approximately $200 \mathrm{~cm}^{-1}$ and below $900 \mathrm{~cm}^{-1}$. An example of this method is shown in Figure 59. It can be seen from Figure 59 that above approximately $900 \mathrm{~cm}^{-1}$ there are still intense electrolyte peaks present. This lack of complete subtraction is due to the change in absorptivity outside the polysulfide Raman-active range. Since all polysulfide peaks, excluding the dithionite anion peak at $1066 \mathrm{~cm}^{-1}$, were below $600 \mathrm{~cm}^{-1}$, it was not necessary to fit an additional wavelength-dependent scaling factor to subtract electrolyte peaks above $900 \mathrm{~cm}^{-1}$.

In cases where LiTFSI was not present, as in the component analysis section of this report, values were normalized by the conventional means of normalized value $=$ (raw value - minimum) / (maximum - minimum).

The in situ T-cell spectra were smoothed to allow easier analysis. No large differences in values or trends were observed after smoothing. For comparison, the spectra prior to smoothing are shown in Figure 60.

\subsection{Appendix C: Voltage Steps and Current Decay, T-Cell Replicates}

The normal, constant discharge curve at a rate of C/50 (20.8 $\mu \mathrm{A})$ is shown in Figure 61. It shows the correct shape for a Li-S cell with two plateaus. The plateaus are shifted to higher voltages $(2.4 \mathrm{~V}$ and $2.15 \mathrm{~V}$ rather than $2.35 \mathrm{~V}$ and $2.10 \mathrm{~V})$ than seen in the coin cell at $\mathrm{C} / 10$ because the lower rate allows for a smaller over potential. The slower rate of $\mathrm{C} / 50$ was used to allow for diffusion across the large gap between electrodes.

The voltage steps and current decays for replicates two and three are shown in Figure 62. Due to a computer error, a spectrum was not obtained for $1.9 \mathrm{~V}$ and $2.0 \mathrm{~V}$ on 
the charge cycle of replicate number 2 . These points in the discussion are the result of the average of two rather than three replicates.

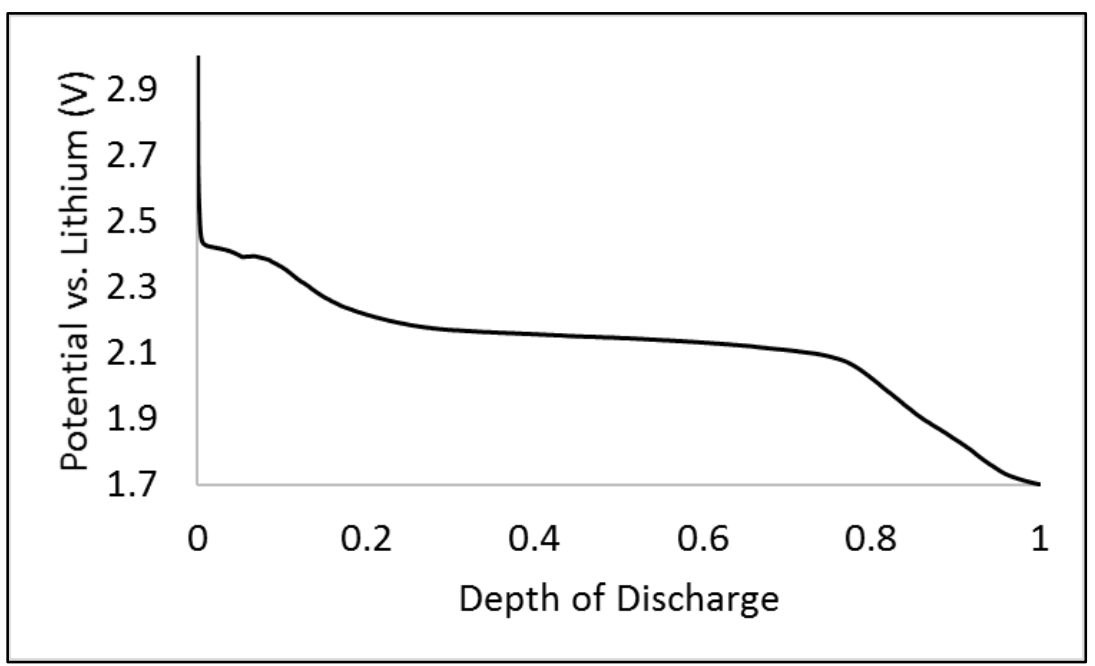

Figure 61: Normal, constant discharge of a T-cell at C/50.

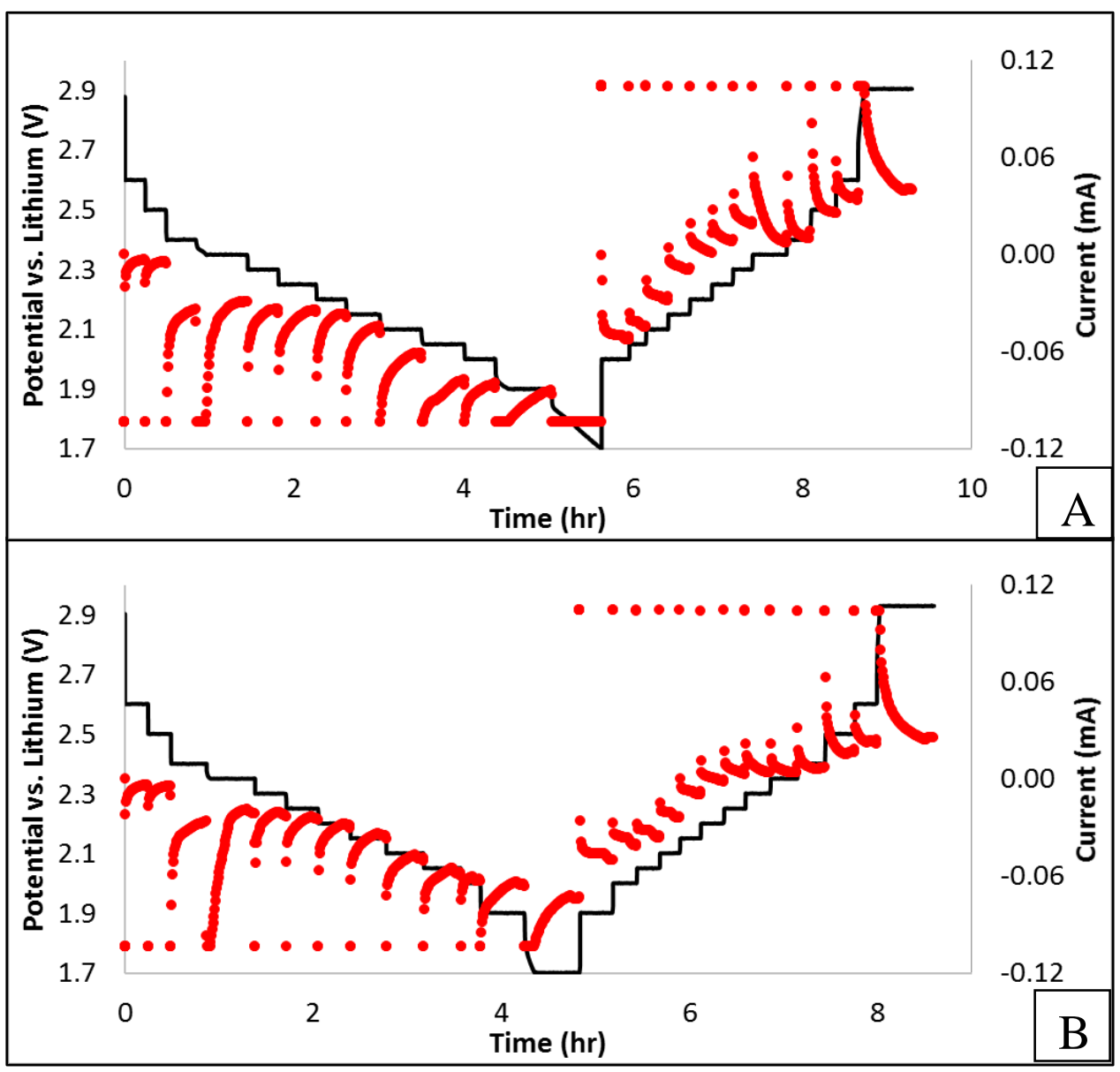

Figure 62: Voltage steps and current decays for A.) T-cell replicate two and B.) T-cell replicate three. Red is current on the right y-axis and black is voltage on the left y-axis. 


\section{References}

1. S. Cohen, The Transition to Renewable Energy is Difficult But Feasible, in, T. H. Post Editor, The Huffington Post (2014).

2. A. Manthiram, Y. Z. Fu, S. H. Chung, C. X. Zu and Y. S. Su, Chem Rev, 114, 11751 (2014).

3. A. Rosenman, E. Markevich, G. Salitra, D. Aurbach, A. Garsuch and F. F. Chesneau, Adv Energy Mater, 5 (2015).

4. B. X. Chen and N. Bilton, Building a Better Battery, in, T. N. Y. Times Editor (2014).

5. C. Harvey, This is how cities of the future will get their energy in, T. N. Y. Times Editor (2016).

6. H. L. Pan, X. L. Wei, W. A. Henderson, Y. Y. Shao, J. Z. Chen, P. Bhattacharya, J. Xiao and J. Liu, Adv Energy Mater, 5 (2015).

7. J. Hannauer, J. Scheers, J. Fullenwarth, B. Fraisse, L. Stievano and P. Johansson, Chemphyschem, 16, 2755 (2015).

8. T. B. Reddy, Linden's Handbook of Batteries, The McGraw-Hill Companies (2011).

9. M. Barghamadi, A. Kapoor and C. Wen, J Electrochem Soc, 160, A1256 (2013).

10. P. G. Bruce, S. A. Freunberger, L. J. Hardwick and J. M. Tarascon, Nat Mater, 11, 19 (2012).

11. X. L. Ji and L. F. Nazar, J Mater Chem, 20, 9821 (2010).

12. H. Kim, G. Jeong, Y. U. Kim, J. H. Kim, C. M. Park and H. J. Sohn, Chem Soc Rev, 42, 9011 (2013).

13. Fittipal.F and L. Pauciulo, J Appl Phys, 37, 4292 (1966).

14. D. Eroglu, K. R. Zavadil and K. G. Gallagher, J Electrochem Soc, 162, A982 (2015).

15. R. Xu, J. Lu and K. Amine, Adv Energy Mater, 5 (2015).

16. X. Ji and L. F. Nazar, J Mater Chem, 20, 9821 (2010).

17. Y.-X. Yin, S. Xin, Y.-G. Guo and L.-J. Wan, Angew Chem Int Edit, 52, 13186 (2013).

18. Z. Li, Y. M. Huang, L. X. Yuan, Z. X. Hao and Y. H. Huang, Carbon, 92, 41 (2015).

19. Q. L. Zou and Y. C. Lu, J Phys Chem Lett, 7, 1518 (2016).

20. M. Cuisinier, C. Hart, M. Balasubramanian, A. Garsuch and L. F. Nazar, Adv Energy Mater, 5 (2015).

21. C. Barchasz, F. Molton, C. Duboc, J. C. Lepretre, S. Patoux and F. Alloin, Anal Chem, 84, 3973 (2012).

22. V. Knap, D. I. Stroe, M. Swierczynski, R. Teodorescu and E. Schaltz, J Electrochem Soc, 163, A911 (2016).

23. L. F. Nazar, M. Cuisinier and Q. Pang, Mrs Bull, 39, 436 (2014).

24. M. N. Liu, F. M. Ye, W. F. Li, H. F. Li and Y. G. Zhang, Nano Res, 9, 94 (2016).

25. R. D. Rauh, K. M. Abraham, G. F. Pearson, J. K. Surprenant and S. B. Brummer, J Electrochem Soc, 126, 523 (1979).

26. J. C. Guo, Y. H. Xu and C. S. Wang, Nano Lett, 11, 4288 (2011).

27. X. L. Ji, K. T. Lee and L. F. Nazar, Nat Mater, 8, 500 (2009).

28. M. K. Song, E. J. Cairns and Y. G. Zhang, Nanoscale, 5, 2186 (2013).

29. M. K. Song, Y. G. Zhang and E. J. Cairns, Nano Lett, 13, 5891 (2013).

30. J. L. Wang, L. Liu, Z. J. Ling, J. Yang, C. R. Wan and C. Y. Jiang, Electrochim Acta, 48, 1861 (2003).

31. J. L. Wang, J. Yang, J. Y. Xie, N. X. Xu and Y. Li, Electrochem Commun, 4, 499 (2002).

32. B. Zhang, X. Qin, G. R. Li and X. P. Gao, Energ Environ Sci, 3, 1531 (2010).

33. S. C. Han, M. S. Song, H. Lee, H. S. Kim, H. J. Ahn and J. Y. Lee, J Electrochem Soc, 150, A889 (2003).

34. L. W. Ji, M. M. Rao, H. M. Zheng, L. Zhang, Y. C. Li, W. H. Duan, J. H. Guo, E. J. Cairns and Y. G. Zhang, J Am Chem Soc, 133, 18522 (2011). 
35. Y. C. Qiu, W. F. Li, W. Zhao, G. Z. Li, Y. Hou, M. N. Liu, L. S. Zhou, F. M. Ye, H. F. Li, Z. H. Wei, S. H. Yang, W. H. Duan, Y. F. Ye, J. H. Guo and Y. G. Zhang, Nano Lett, 14, 4821 (2014).

36. D. Aurbach, E. Pollak, R. Elazari, G. Salitra, C. S. Kelley and J. Affinito, J Electrochem Soc, 156, A694 (2009).

37. Y. Yang, M. T. McDowell, A. Jackson, J. J. Cha, S. S. Hong and Y. Cui, Nano Lett, 10, 1486 (2010).

38. N. A. Liu, L. B. Hu, M. T. McDowell, A. Jackson and Y. Cui, Acs Nano, 5, 6487 (2011).

39. M. Hagen, P. Schiffels, M. Hammer, S. Dorfler, J. Tubke, M. J. Hoffmann, H. Althues and S. Kaskel, J Electrochem Soc, 160, A1205 (2013).

40. B. D. McCloskey, J Phys Chem Lett, 6, 4581 (2015).

41. V. Moss and D. Nole, Battery employing lithium - sulphur electrodes with non-aqueous electrolyte, in, United States (1968).

42. Donor Number, in (2016).

43. A. Manthiram, Y. Fu, S. H. Chung, C. Zu and Y. S. Su, Chem Rev, 114, 11751 (2014).

44. N. Angulakshmi and A. M. Stephan, Frontiers in Energy Research, 3 (2015).

45. E. Peled, Y. Sternberg, A. Gorenshtein and Y. Lavi, J Electrochem Soc, 136, 1621 (1989).

46. J. Gao, M. Lowe, Y. Kiya and H. Abruna, The Journal of Physical Chemistry, 25132 (2011).

47. C. Barchasz, J. C. Lepretre, S. Patoux and F. Alloin, Electrochim Acta, 89, 737 (2013).

48. J. Scheers, S. Fantini and P. Johansson, J Power Sources, 255, 204 (2014).

49. L. M. Suo, Y. S. Hu, H. Li, M. Armand and L. Q. Chen, Nat. Commun., 4, 9 (2013).

50. X. Liang, Z. Y. Wen, Y. Liu, M. F. Wu, J. Jin, H. Zhang and X. W. Wu, J Power Sources, 196, 9839 (2011).

51. L. X. Yuan, J. K. Feng, X. P. Ai, Y. L. Cao, S. L. Chen and H. X. Yang, Electrochem Commun, 8, 610 (2006).

52. J. W. Park, K. Ueno, N. Tachikawa, K. Dokko and M. Watanabe, J Phys Chem C, 117, 20531 (2013).

53. H. S. Ryu, H. J. Ahn, K. W. Kim, J. H. Ahn and J. Y. Lee, J Power Sources, 153, 360 (2006).

54. B. Scrosati, F. Croce and S. Panero, J Power Sources, 100, 93 (2001).

55. J. Hassoun and B. Scrosati, Adv. Mater., 22, 5198 (2010).

56. M. Nagao, A. Hayashi and M. Tatsumisago, Electrochem Commun, 22, 177 (2012).

57. A. Jozwiuk, H. Sommer, J. Janek and T. Brezesinski, J Power Sources, 296, 454 (2015).

58. D. Zheng, D. Y. Qu, X. Q. Yang, X. Q. Yu, H. S. Lee and D. Y. Qu, Adv Energy Mater, 5 (2015).

59. M. Cuisinier, P. E. Cabelguen, S. Evers, G. He, M. Kolbeck, A. Garsuch, T. Bolin, M. Balasubramanian and L. F. Nazar, J Phys Chem Lett, 4, 3227 (2013).

60. Y. Gorlin, A. Siebel, M. Piana, T. Huthwelker, H. Jha, G. Monsch, F. Kraus, H. A. Gasteiger and M. Tromp, J Electrochem Soc, 162, A1146 (2015).

61. M. U. M. Patel, I. Arcon, G. Aquilanti, L. Stievano, G. Mali and R. Dominko, Chemphyschem, 15, 894 (2014).

62. K. H. Wujcik, D. R. Wang, A. Raghunathan, M. Drake, T. A. Pascal, D. Prendergast and N. P. Balsara, J Phys Chem C, 120, 18403 (2016).

63. H. Wang, N. Y. Sa, M. N. He, X. Liang, L. F. Nazar, M. Balasubramanian, K. G. Gallagher and B. Key, J Phys Chem C, 121, 6011 (2017).

64. J. Xiao, J. Z. Hu, H. H. Chen, M. Vijayakumar, J. M. Zheng, H. L. Pan, E. D. Walter, M. Hu, X. C. Deng, J. Feng, B. Y. Liaw, M. Gu, Z. D. Deng, D. P. Lu, S. C. Xu, C. M. Wang and J. Liu, Nano Lett, 15, 3309 (2015).

65. L. A. Nimon, V. D. Neff, R. E. Cantley and R. O. Buttlar, J Mol Spectrosc, 22, 105 (1967).

66. L. M. Suo, Z. Fang, Y. S. Hu and L. Q. Chen, Chinese Phys B, 25 (2016).

67. H. L. Wu, L. A. Huff and A. A. Gewirth, Acs Appl Mater Inter, 7, 1709 (2015).

68. N. A. Canas, S. Wolf, N. Wagner and K. A. Friedrich, J Power Sources, 226, 313 (2013). 
69. J. Nelson, S. Misra, Y. Yang, A. Jackson, Y. J. Liu, H. L. Wang, H. J. Dai, J. C. Andrews, Y. Cui and M. F. Toney, J Am Chem Soc, 134, 6337 (2012).

70. S. Walus, C. Barchasz, J. F. Colin, J. F. Martin, E. Elkaim, J. C. Lepretre and F. Alloin, Chem Commun, 49, 7899 (2013).

71. T. Yim, M. S. Park, J. S. Yu, K. J. Kim, K. Y. Im, J. H. Kim, G. Jeong, Y. N. Jo, S. G. Woo, K. S. Kang, I. Lee and Y. J. Kim, Electrochim Acta, 107, 454 (2013).

72. Y. S. Su, Y. Z. Fu, T. Cochell and A. Manthiram, Nat. Commun., 4 (2013).

73. R. D. Rauh, F. S. Shuker, J. M. Marston and S. B. Brummer, J Inorg Nucl Chem, 39, 1761 (1977).

74. Confocal Raman Microscopy, Springer (2010).

75. Raman Scattering, in, University of Cambridge (2015).

76. T. Dieing, O. Hollricher and J. Toporski, Confocal Raman Microscopy, p. 289, Springer-Verlag Berlin Heidelberg, Ulm, Germany (2010).

77. G. J. Janz, J. W. Coutts, J. R. Downey and E. Roduner, Inorg Chem, 15, 1755 (1976).

78. G. J. Janz, E. Roduner, J. W. Coutts and J. R. Downey, Inorg Chem, 15, 1751 (1976).

79. G. J. Janz, J. R. Downey, E. Roduner, G. J. Wasilczyk, J. W. Coutts and A. Eluard, Inorg Chem, 15, 1759 (1976).

80. O. El Jaroudi, E. Picquenard, A. Demortier, J. P. Lelieur and J. Corset, Inorg Chem, 39, 2593 (2000).

81. O. El Jaroudi, E. Picquenard, A. Demortier, J. P. Lelieur and J. Corset, Inorg Chem, 38, 2394 (1999).

82. F. P. Daly and C. W. Brown, J Phys Chem-Us, 77, 1859 (1973).

83. F. P. Daly and C. W. Brown, J Phys Chem-Us, 79, 350 (1975).

84. F. P. Daly and C. W. Brown, J Phys Chem-Us, 80, 480 (1976).

85. P. Dubois, J. P. Lelieur and G. Lepoutre, Inorg Chem, 27, 73 (1988).

86. J. T. Yeon, J. Y. Jang, J. G. Han, J. Cho, K. T. Lee and N. S. Choi, J Electrochem Soc, 159, A1308 (2012).

87. Split Test Cell with Quartz Window for Battery Electrode In-situ Analysis: Optional Insert Size \& Au Coating - EQ-STC-QW, in, MTI Corporation. 